\title{
Training Requirements for Railroad Dispatchers: Objectives, Syllabi and Test Designs
}

Office of Research

and Development

Washington, DC 20590

S. Reinach

J. Gertler

Foster-Miller, Inc.

350 Second Avenue

Waltham, MA 02451-1196

G. Kuehn

IIT Research Institute

10 West $35^{\text {th }}$ Street

Chicago, IL 60616-3799 


\section{NOTICE}

This document is disseminated under the sponsorship of the Department of Transportation in the interest of information exchange. The United States Government assumes no liability for its contents or use thereof.

\section{NOTICE}

The United States Government does not endorse products or manufacturers.

Trade or manufacturers' names appear herein solely because they are considered essential to the objective of this report. 
Technical Report Documentation Page

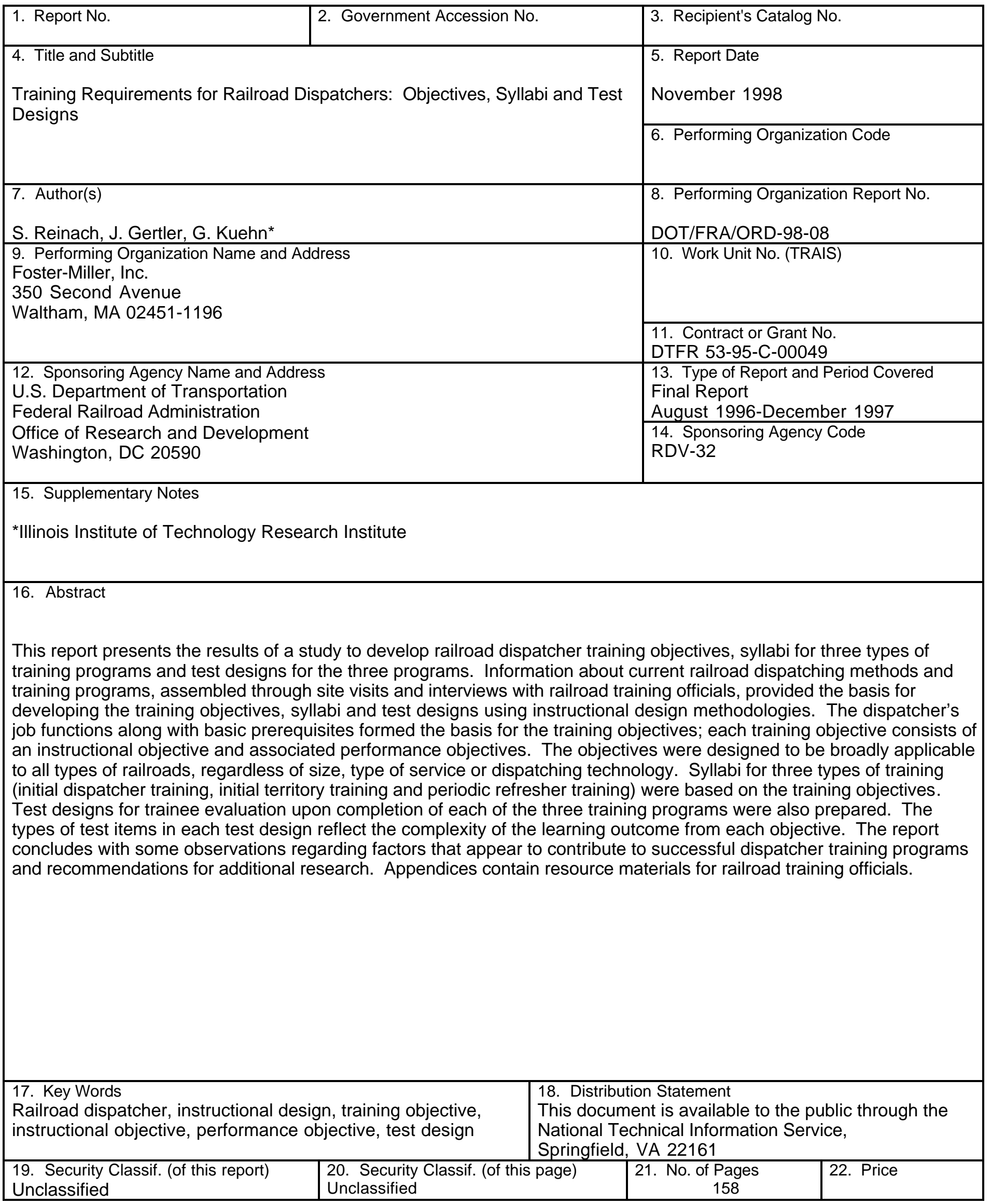

Form DOT F 1700.7 (8-72) Reproduction of completed page authorized 

This report presents the findings and results of a research study designed to develop recommendations regarding training for railroad dispatchers. The focus of the study was on developing training objectives, testing methods and training syllabi. The work was performed under Contract DTFR53-95-C-00049 with guidance from Thomas Raslear of the Office of Research and Development, Federal Railroad Administration. The authors also extend their appreciation to Thomas Keane of the Office of Safety, Federal Railroad Administration, for providing a background on the FRA's two railroad dispatcher audits and for answering numerous questions throughout the course of the project.

Thanks are also due to William Clifford, President, American Train Dispatchers Department (ATDD), and Les Parmelee, former President, ATDD, for their valuable feedback on the training objectives and model syllabi. The authors also wish to thank the six railroads that arranged site visits or interviews for the study team and the numerous railroad industry representatives who reviewed the draft training objectives and model syllabi and provided valuable feedback.

Susan Madigan, Transit Safety Management, provided expertise and assistance throughout the project, including significant contributions to the training objectives and model syllabi. Duncan Allen and Winn Frank, DeLeuw, Cather, provided assistance in selecting railroads for site visits and in structuring the training objectives. Frank Raposa provided assistance in the process of developing the training syllabi. 


\section{CONTENTS}

Section $\quad$ Page

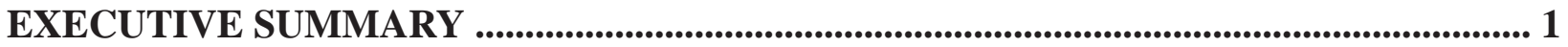

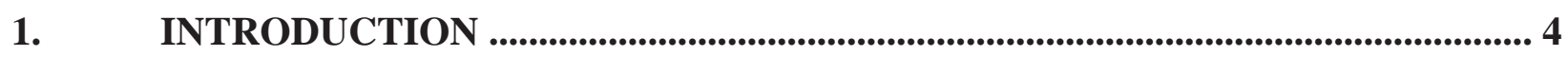

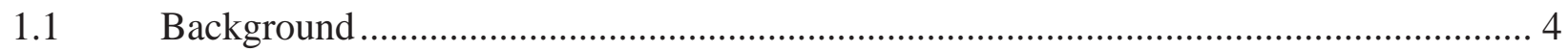

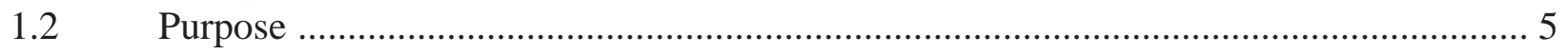

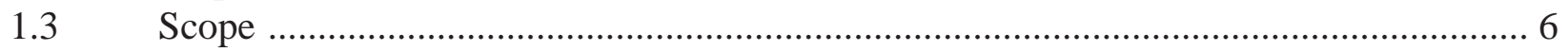

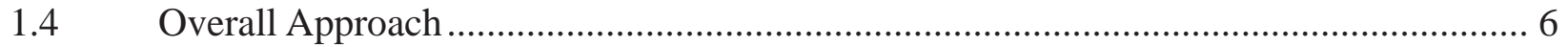

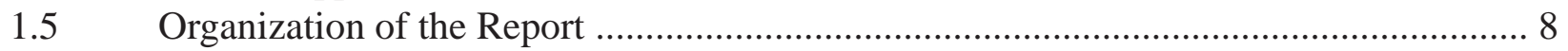

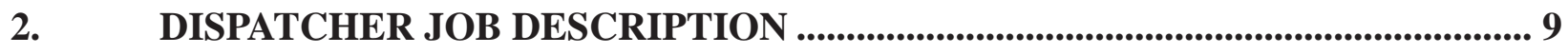

2.1 The 1974 Devoe Report .................................................................................. 9

2.2 Changes in the Dispatching Environment ............................................................. 10

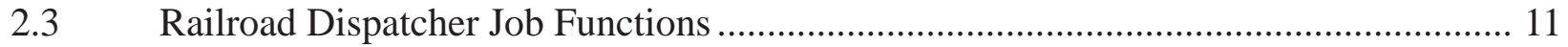

2.4 Dispatching and Train Control Technology ...................................................... 12

3. CURRENT TRAINING PROGRAMS ............................................................................... 14

3.1 Collection of Training Materials from Existing Industry Programs ......................... 14

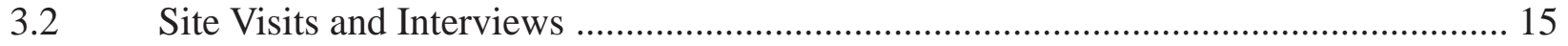

S.3 Summary of Site Visits and Training Materials .................................................. 16

4. DEVELOPMENT OF TRAINING OBJECTIVES ............................................... 18

Instructional Design Process ............................................................................ 20

4.2 General Framework: Bloom's Taxonomy ........................................................ 20

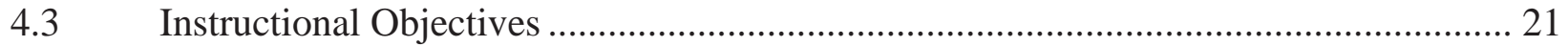

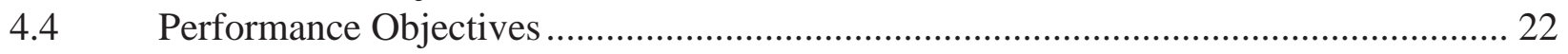

4.5 Initial Development of Training Objectives .................................................... 22

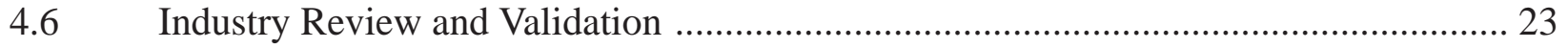

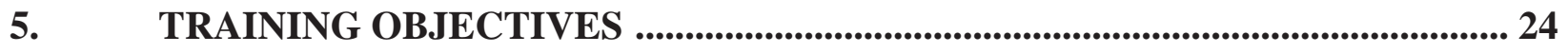

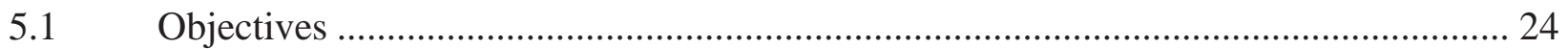

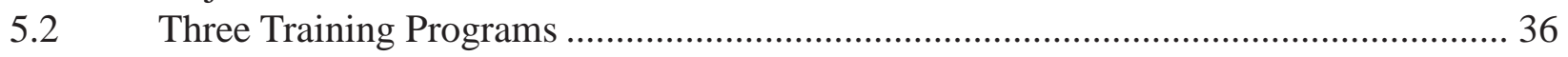


6. DEVELOPMENT OF MODEL SYLLABI .................................................... 39

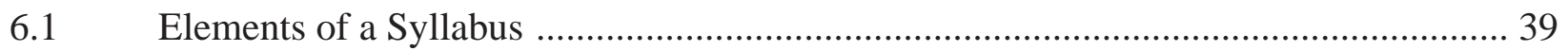

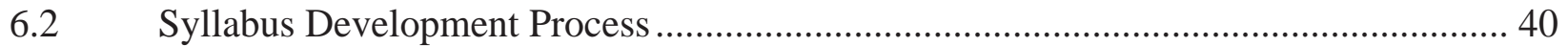

6.2.1 Initial Development of Model Syllabi ................................................................. 41

6.2.2 Industry Review and Validation ................................................................... 41

6.2.3 Issues Relevant to Developing and Using Syllabi ............................................... 44

6.3 Syllabus Implementation Tool ..................................................................... 44

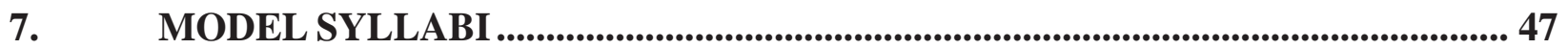

7.1 A Model Syllabus for Initial Dispatcher Training ................................................ 47

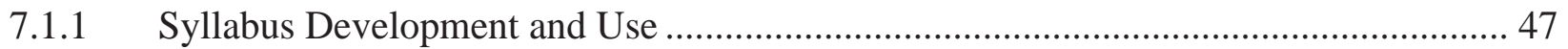

7.1.2 Issues Relevant to Initial Dispatcher Training ......................................................... 49

7.2 A Model Syllabus for Initial Territory Training ................................................... 57

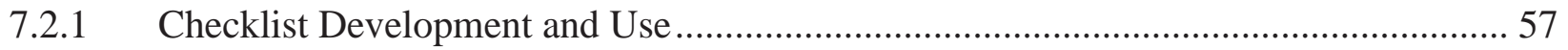

7.2.2 Issues Relevant to Initial Territory Training .......................................................... 58

7.3 A Model Syllabus for Periodic Refresher Training ................................................ 65

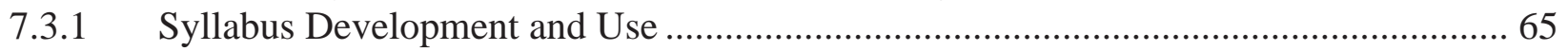

7.3.2 Issues Relevant to Periodic Refresher Training ...................................................... 66

8. DEVELOPMENT OF TEST DESIGNS ........................................................................ 69

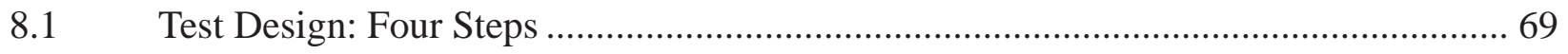

8.1.1 Step 1: Select Appropriate Objectives ............................................................ 70

8.1.2 Step 2: Create a Table of Specifications ................................................................. 70

8.1.3 Step 3: Adjust Table of Specifications to Reflect Relative Importance...................... 70

8.1.4 Step 4: Specify the Format and Number of Test Items ......................................... 71

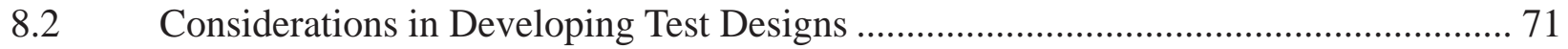

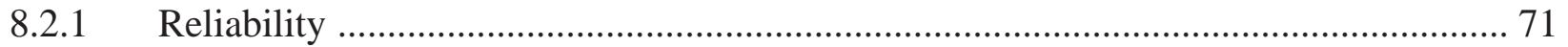

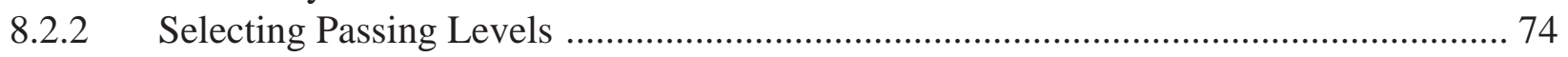

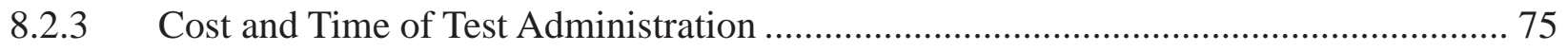

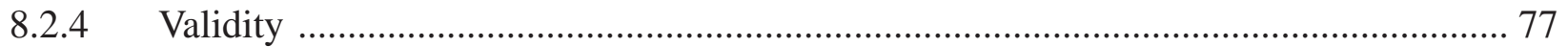

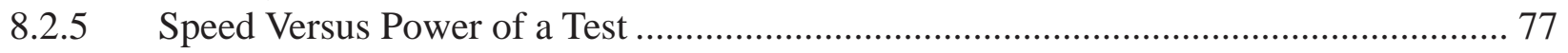

8.2.6 Criterion-Referenced versus Norm-Referenced Testing ......................................... 78

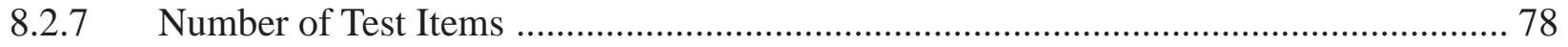

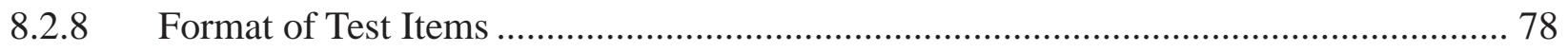

8.2.9 Time Permitted to Take the Test ......................................................................... 79

8.2.10 Formative versus Summative Tests ................................................................... 79

8.2.11 Use of Subject Matter Experts in Test Design ................................................... 80 
9. TEST DESIGNS ........................................................................................................... 810

9.1 A Test Design for the Evaluation of Initial Dispatcher Training ………..................... 81

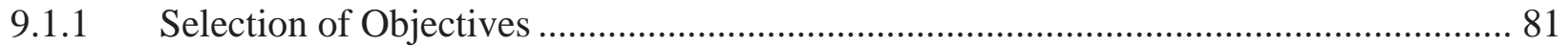

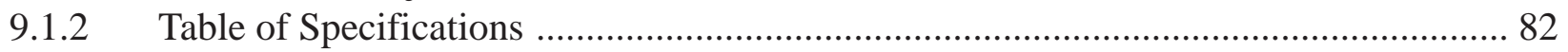

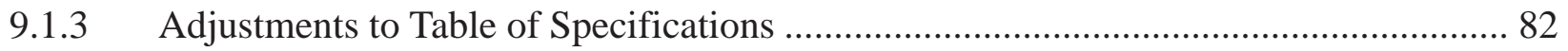

9.1.4 Number and Format of Test Items …………........................................................ 84

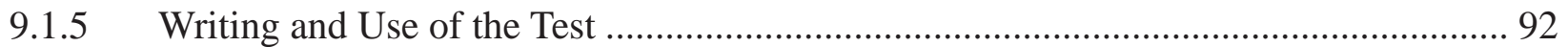

9.2 A Test Design for the Evaluation of Initial Territory Training ..................................... 94

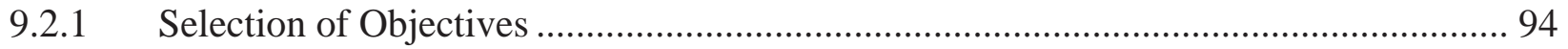

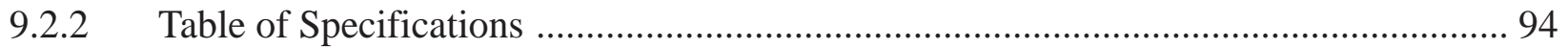

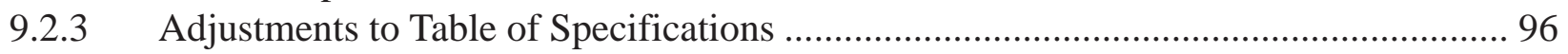

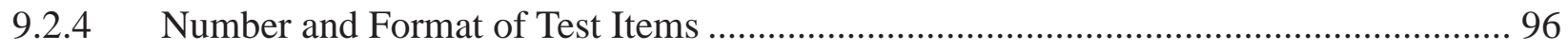

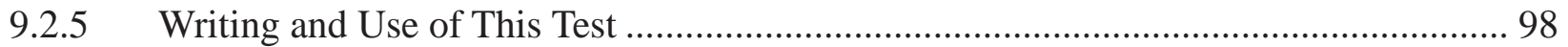

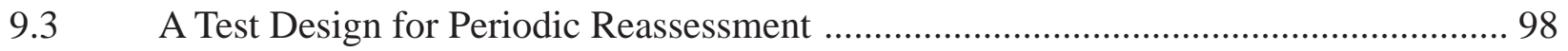

9.3.1 Selection of Objectives .......................................................................................... 100

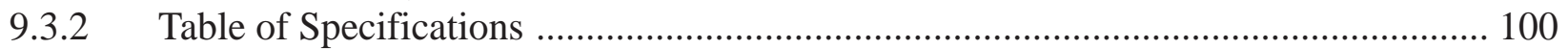

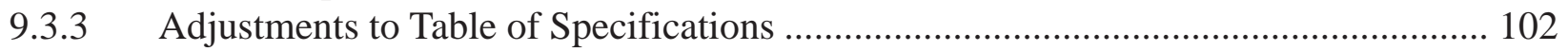

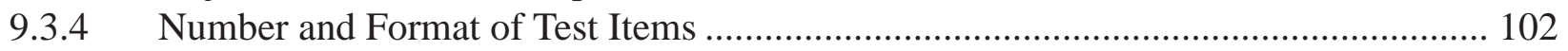

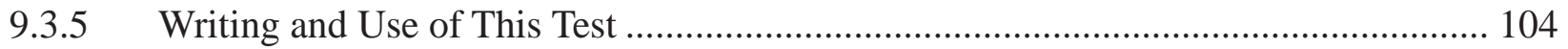

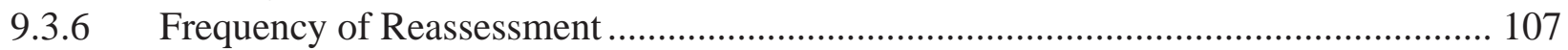

9.4 Alternative Approaches to Test Design ………....................................................... 110

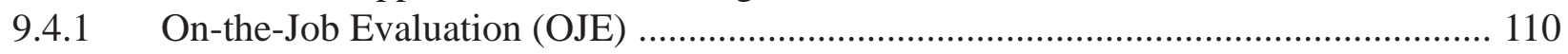

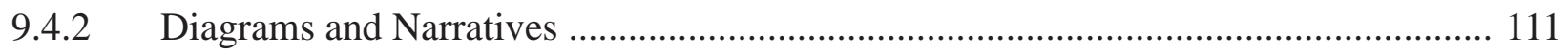

10. CONCLUSIONS AND RECOMMENDATIONS _................................................ 112

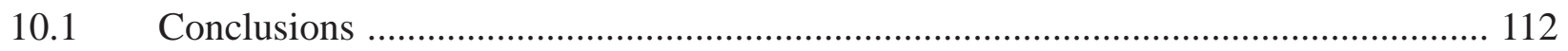

10.2 Factors Contributing to a Successful Program ......................................................... 112

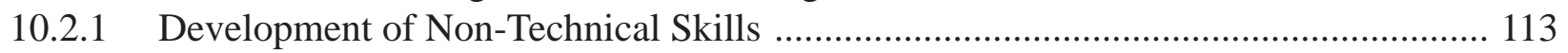

10.2.2 Integration of Initial Dispatcher (Mostly Classroom) Training and Initial Territory (Mostly OJT) Training .............................................................................. 113

10.2.3 Simulation and Computer-Based Instruction …….................................................... 114

10.2.4 Integration of Real-World Dispatcher Experience ...................................................... 115

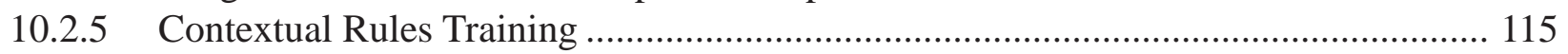

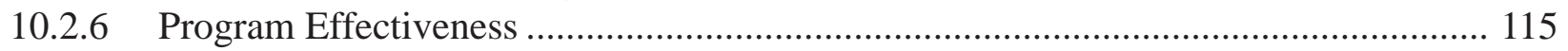

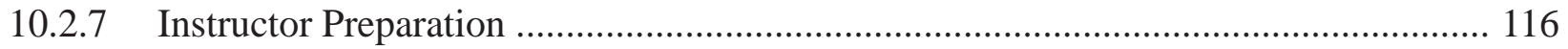

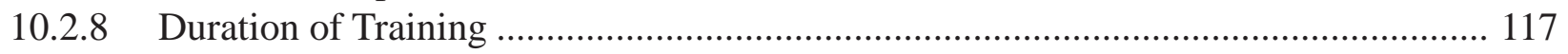

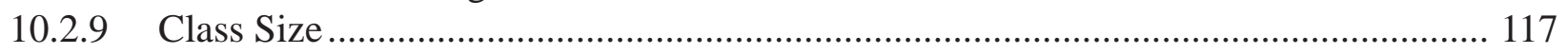

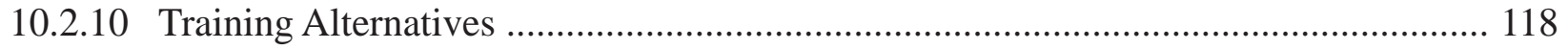

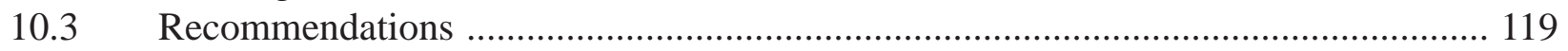

10.3.1 Develop Refresher Training Guidelines ………...................................................... 119

10.3.2 Determine the Need for Railroad Dispatcher Certification ……………...................... 119 
10.3.3 Review of Dispatcher-Instructor Compensation Practices ..................................... 119

10.3.4 Develop an Information Exchange Workshop ................................................... 120

10.3.5 Examine the Feasibility of Developing a State-of-the-Art Interactive Railroad

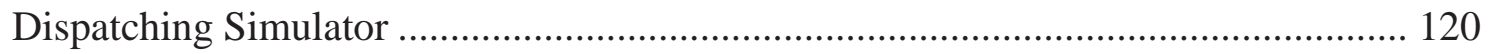

11. REFERENCES ................................................................................................................ 121

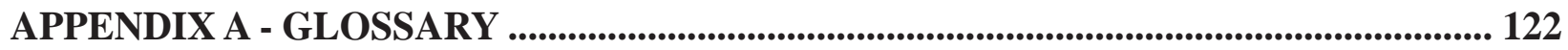

APPENDIX B - DISPATCHER TRAINING PROGRAM DESCRIPTIONS ..................... 128

APPENDIX C - PROGRAMS AT COMMUNITY COLLEGES ........................................ 133

APPENDIX D - INTERVIEW GUIDES FOR SITE VISITS .......................................... 135

APPENDIX E - EXAMPLE LIST OF ILLUSTRATIVE VERBS ...................................... 142

APPENDIX F - TRAINING RESOURCES .................................................................. 144 


\section{ILLUSTRATIONS}

Figure

Page

1. Overall research approach ................................................................................... 7

2. Railroad dispatcher's console with CADS .............................................................. 13

3. Development of dispatcher training objectives .................................................. 19

4. Schematic of the bottom-up approach used to develop the model syllabi .................... 42

5. Schematic of the approach used to develop the initial territory training checklist.......... 43

6. Copy of a blank Movement Permit Form (Form D) used by The Providence and Worcester Railroad Company ....................................................................................... 54 


\section{TABLES}

Table

Page

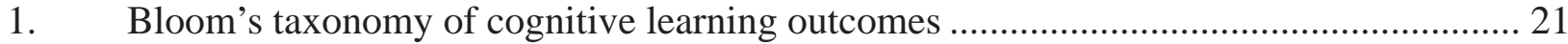

2. Instructional objectives for three training programs ............................................. 38

3. Two-tier classification of instructional objectives ................................................ 46

4. Syllabus outline for initial dispatcher training .............................................. 48

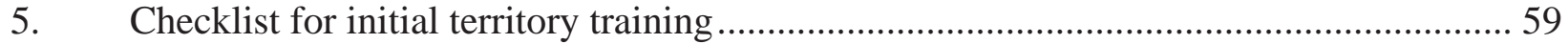

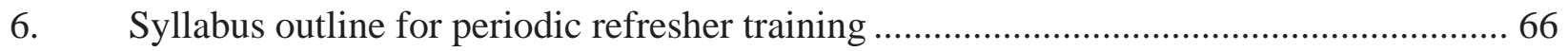

7. Table of specifications for a typical initial training program ................................... 83

8. Summary of a table of specifications for initial dispatcher training ............................ 84

9. Revised table of specifications for initial dispatcher training .................................. 85

10. Question matrix for initial dispatcher training test design ...................................... 87

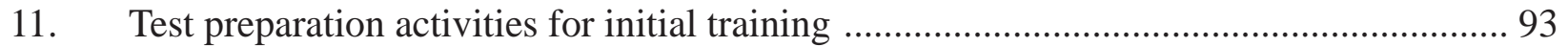

12. Test evaluation and posting activities for initial training ........................................ 93

13. Table of specifications for initial territory qualification ............................................ 95

14. Revised table of specifications for initial territory training ....................................... 97

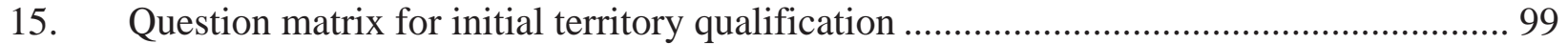

16. Test preparation activities for initial territory qualification ................................... 100

17. Test evaluation and posting activities for initial territory qualification ....................... 100

18. Table of specifications for periodic reassessment ................................................. 101

19. Summary of a table of specifications for periodic reassessment ................................ 102

20. Revised table of specifications for periodic reassessment ........................................ 103

21. Summary of a revised table of specifications for periodic reassessment .................... 104

22. Question matrix for periodic reassessment ....................................................... 105

23. Test preparation activities for periodic reassessment ............................................ 106

24. Test evaluation and posting activities for periodic reassessment ............................. 106

25. Recertification policies in other modes of transportation ........................................ 108 


\section{LIST OF ABBREVIATIONS}

ATDD American Train Dispatcher's Department of the Brotherhood of Locomotive Engineers Union.

BNSF The Burlington Northern Santa Fe Railroad.

CADS Computer-aided dispatching system.

CTC Centralized traffic control.

FRA Federal Railroad Administration.

GCOR General Code of Operating Rules.

HOS Hours of service.

MOW Maintenance of way.

NORAC Northeast Operating Rules Advisory Committee.

SME Subject matter expert.

T\&E crew Train and Engine crew. 


\section{EXECUTIVE SUMMARY}

Railroad dispatchers play a central and critical role in railroad operations. They are responsible for the safe and efficient movement of trains, as well as the protection of others who occupy the track. In a series of safety audits, the Federal Railroad Administration (FRA) found substantial variability among railroads in their initial dispatcher training, a lack of consistent standards for measuring a trainee's competence after completing dispatcher training, dependence on informal and ill-structured on-the-job training (OJT), and uneven practices regarding territorial familiarity and refresher training. The FRA believes that given the rapidly evolving changes in railroad dispatching technology and the lack of new dispatcher candidates with relevant railroad experience, in the coming years there is a potential for reduced safety due to insufficient dispatching training and testing standards.

The FRA initiated this research to address railroad dispatcher training requirements in order to increase the uniformity, quality and efficiency of training railroad dispatchers. The goals of this research were to 1) develop a set of railroad dispatcher training objectives, 2) develop syllabi for three training programs (initial dispatcher training, initial territory training, and periodic refresher training), and 3) develop a set of test designs for the three training programs.

The approach taken in the development of the training objectives, syllabi and test designs involved two main processes: gathering information about current railroad dispatching methods and training programs, and applying an instructional design methodology to the design of new training objectives, syllabi and test designs. Site visits and interviews with Class 1, commuter, shortline and regional railroads, and review of various railroads' training materials provided the background and basis for the development of the training objectives, syllabi and test designs. In addition, industry and union feedback was solicited to validate the accurateness and utility of the training objectives and syllabi. The instructional design methodology that was used involved classification of each objective into one of six learning outcomes based on a structured and established taxonomy. This approach provided a framework for the development of the training objectives, syllabi and test designs.

Training objectives were developed and organized around basic prerequisites and four railroad dispatcher job functions: planning, controlling track use, managing unplanned and emergency events, and record keeping and report writing. Training objectives that related exclusively to freight or electrified territories were listed separately. Each training objective consisted of an instructional objective and associated performance objectives. Instructional objectives are trainee-centered, general learning outcomes that are to be accomplished, while performance objectives are specifically defined, measurable outcomes that indicate completion 
of the instructional objective. The objectives were designed to be broadly applicable to all railroads, regardless of size, type of service (freight or passenger), or current technology.

Training objectives were then selected for three training programs: initial dispatcher training, where trainees learn the basic skills required to dispatch; initial territory training, where trainees have the opportunity to practice and apply the newly acquired skills; and periodic refresher training, which is designed to maintain dispatcher skills and knowledge and reinforce recent training on new equipment, procedures or rules. Objectives were selected for the three training programs based on two criteria: 1) the target audience for the initial dispatcher training and initial territory training are individuals who have no prior railroad experience or knowledge since many trainees are being hired off the street and this trend is expected to continue; and 2) to be applicable to the greatest number of railroads, the objectives for the training programs should target operation on a non-electrified, freight operation.

Forty-four objectives from the initial set of objectives were selected for initial dispatcher training; 24 objectives were selected for initial territory training; and 25 objectives were selected for periodic refresher training. Model syllabi were developed for each of the three training programs. The syllabi for the initial dispatcher training and the periodic refresher training took the form of outlines that were made up of major instructional units and subheadings. The syllabi for the initial dispatcher training and the periodic refresher training served to organize the objectives into a logical, meaningful grouping for the purposes of instruction and learning. A bottom-up approach was used to organize the objectives. In a series of iterations, the objectives were grouped according to their similarity or relatedness into subheadings; in turn, the subheadings were grouped into broader instructional units. The taxonomy used to classify each objective based on its learning outcome also helped to organize the objectives within each syllabus subheading.

The syllabus for the initial territory training took the form of a checklist. Initial territory training occurs on-the-job, where the presentation and ordering of different situations cannot be controlled. A checklist addressed each of the objectives selected for initial territory training, but it did not impose an order as to when they should be addressed.

Test designs were also developed for trainee evaluation upon completion of each of the three training programs. Test designs aid instructional designers by specifying the number and type of test items that should be written to address mastery of each objective selected for the evaluation. Development of the test designs was based on the learning outcomes expected by the objectives. Objectives with simpler learning outcomes were addressed with simpler types of test items, while objectives with more complex learning outcomes were addressed with test items appropriate to the level of complexity.

The report concludes with some observations regarding factors that appear to contribute to a successful training program. A sample of the factors includes:

- Development of non-technical skills such as leadership and time management. 
- Integration of initial dispatcher training (mostly classroom) and initial territory training (mostly OJT).

- Incorporation of real-world dispatcher experience into initial dispatcher training.

- Contextual rules training.

Lastly, additional research is recommended in four different areas:

- Examine refresher training/certification policies. More research needs to be conducted before specific recommendations can be made with regard to the need and frequency of periodic refresher training, as well as the potential need for dispatcher certification.

- Review current and future possible compensation practices for dispatchers who are involved in initial territory training (dispatcher-instructors). Interviews with dispatcherinstructors revealed that one of the problems in the current dispatcher-instructor role is that they are only minimally rewarded for their time and effort in training new dispatchers. Compensation practices should be explored to determine what is the best method of compensation to match dispatcher-instructors' increased involvement in training railroad dispatchers, and if the increased compensation will result in more effective training.

- Conduct an information exchange workshop in which those responsible for developing or maintaining railroad dispatcher training programs can share ideas, lessons learned, and experiences, and, in the long run, can potentially improve the uniformity, quality, and efficiency of railroad dispatcher training.

- Examine the feasibility of developing a state-of-the-art interactive railroad dispatching simulator. A high-fidelity, fully interactive operator-in-the-loop railroad dispatching simulator promises to increase training effectiveness by fully simulating a whole range of rail traffic conditions and desk and territory configurations. A fully interactive training simulator can be used for critical incident training as well as for advanced concept training (e.g., team training), and it can bridge the gap between initial dispatcher training and initial territory training.

The results of this research are intended to be used as a starting point and guide for railroads as they develop or revise their railroad dispatcher training programs. The emphasis throughout the report is on the process of developing the objectives, syllabi and test designs rather than on the finished product. The training objectives should be viewed as a starting point for railroads as they develop objectives suitable to their own needs. Using instructional design methods such as those presented in this report, and starting with this list of training objectives, railroads can develop their own training syllabi and test designs. The result will be that railroads will begin to share some degree of uniformity in their training programs. 


\section{INTRODUCTION}

\subsection{Background}

An assessment of railroad dispatcher training in 1990 (1) revealed substantial variability among railroads in their conduct of initial dispatcher training. There was a lack of consistent standards for measuring a trainee's competence after completing training. Dependence on informal and ill-structured on-the-job training (OJT) and uneven practices regarding territorial familiarity and refresher training were also problematic issues. The FRA's preference was that the railroad industry work cooperatively to resolve these problems and develop its own initiatives to approach dispatcher training in a uniform and consistent manner.

In 1992 Congress required that the FRA conduct a follow-up study to determine the extent to which the deficiencies identified in the earlier study had been remedied. The study, detailed in a 1995 Report to Congress ()ㅡ, found that dispatcher training remained problematic with regard to:

- Definition of on-the-job training (OJT) parameters.

- Inconsistent and variable standards/policies for periodic retraining of dispatchers and lack of a formal policy regarding periodic retraining.

- Variation in railroad policies concerning dispatcher familiarization road trips and lack of objectives and measurement tools for such training.

- Foregoing periodic retraining due to insufficient number of relief employees.

- Lack of opportunity for supervisory personnel to train themselves with changes in technology.

- Shift dispatchers not always afforded an opportunity to familiarize themselves with rule or technology changes before being put into a situation requiring "real time" application.

The FRA's investigation concluded that available accident data disclosed no statistically significant pattern of accidents resulting from inadequately trained dispatchers. Most dispatchercaused accidents resulted from other issues such as miscommunication or operating rule noncompliance. However, the FRA felt that given the rapidly evolving changes in railroad dispatching technology and the lack of new dispatcher candidates with relevant railroad experience, in the coming years there was a potential for reduced safety due to insufficient 
dispatching training and testing standards. Based on these findings, the FRA proposed two actions in its 1995 Report to Congress (ㅁ):

1. An FRA partnership with the Burlington Northern Santa Fe (BNSF) railroad, the National Railroad Passenger Corporation (Amtrak) and the American Train Dispatcher's Department of the Brotherhood of Locomotive Engineers (ATDD) to develop a model railroad dispatcher training program.

2. Development of (i) minimum training standards for railroad dispatchers, including initial, periodic, refresher and physical characteristics training and (ii) minimum operating rule and testing standards.

Following the 1995 Report to Congress (2) , the FRA initiated two activities to carry out the study's recommendations. An FRA working group representing the ATDD, BNSF, Amtrak and the FRA's Office of Safety was convened and met several times during 1996 to outline the elements of a railroad dispatcher training program. The working group reached a consensus on the topics that should be included in initial dispatcher training and periodic refresher training. Subsequently, the FRA's Office of Research and Development initiated work to support development of minimum training standards for railroad dispatchers. Specifically, the FRA seeks recommendations with respect to training objectives and methods, and duration and frequency of training for railroad dispatchers. This report documents the results of research toward these ends.

\subsection{Purpose}

The purpose of conducting the research documented in this report was to develop means to improve the uniformity, quality, and efficiency of training for railroad dispatchers. The project had the following three goals:

1. Develop a minimum set of recommended training objectives (including both instructional objectives and performance objectives) that are applicable and appropriate to all railroads, regardless of size, nature of operation (passenger or freight), or technology, and suitable for trainees with no prior railroad experience.

2. Develop performance measures for candidates completing the training.

3. Develop model syllabi that incorporate both the recommended training objectives and performance standards.

In addition to providing information to the FRA, this report is designed to serve as a resource for those instructional designers and trainers who have responsibility for training railroad dispatchers among the country's passenger and freight railroads. 


\subsection{Scope}

In keeping with the FRA's mandate to oversee railroad safety, this study concerns training needed to achieve and maintain safe and efficient movement of trains and protection of other track users. Dispatcher responsibilities that do not relate to the safe and efficient movement of trains or to the protection of other track users are beyond the scope of this study and therefore are not addressed in this report. However, railroads should develop training objectives to address non-safety job responsibilities and incorporate them into the training syllabi and test designs as needed.

Because of the changing profiles of railroad dispatcher candidates, the target audience for initial training is candidates with no prior relevant railroad experience. The earlier FRA railroad dispatcher assessment (1) found that industry-wide dispatchers are in the later stages of their careers. At the same time, the traditional career path from operator to dispatcher is rapidly disappearing. As a result, within the next decade many dispatchers will retire and the railroad industry will be facing the need to train a great many new dispatchers who do not have a railroad background. These individuals will most likely lack both knowledge of operating and safety practices, and a basic understanding of railroading.

\subsection{Overall Approach}

The overall study approach involved two main procedures: gathering information about railroad dispatching methods, and applying instructional design and testing theory to the development of the training objectives, test designs and model syllabi. Both procedures are discussed below.

To ensure that the functions of a railroad dispatcher were clearly and completely represented, enough information on the job of a railroad dispatcher had to be gathered. This study utilized two approaches to gathering sufficient information about current training programs and the job responsibilities of a railroad dispatcher. One approach was top-down, whereby the primary job functions of a railroad dispatcher were identified. The other approach was bottom-up, whereby existing railroad industry training program materials were reviewed and visits to several railroads were made to view first-hand the training programs and facilities and to interview trainers, trainees and working railroad dispatchers. The goal of the top-down approach was to develop a framework of a railroad dispatcher's job which formed the basis for structuring the training objectives. The goal of the bottom-up approach was to seek common, or essential, themes among all of the representative railroad dispatcher training programs in order to include these themes in the training objectives, test designs and model syllabi.

To provide structure to the development of the training objectives, test designs, and model syllabi, an instructional design process was used. According to (ㄱ) $)$ instructional design involves "a systematic process of translating principles of learning and instruction into plans for instructional materials and activities." Instruction involves the conveyance of information to learners to help them meet specific learning objectives. Design conveys intentional planning of a particular process or product. Thus, instructional design involves the purposeful planning of 
information conveyance. Instructional design is an iterative process. Often beginning points and ending points depend upon the goals and scope of a particular project. Furthermore, often instructional designers are called upon to address only one component of the entire process. The key factor is that there is congruence among all of the various instructional design components, from developing training objectives, to developing and carrying out the instruction, to measuring trainee performance.

There were three main tasks involved in this research: development of the training objectives; development of model syllabi; and development of test designs. The training objectives were developed first, followed by the development of three test designs for initial dispatcher training, initial territory training, and periodic refresher training. Lastly, model syllabi were developed for each of the three training programs. Figure 1 shows a schematic of the overall research approach. The model syllabi are presented before the test designs in the report, however, because the three syllabi provide "big pictures" of each of the training programs, while the test designs concentrate on the micro-aspects of each of the training programs.

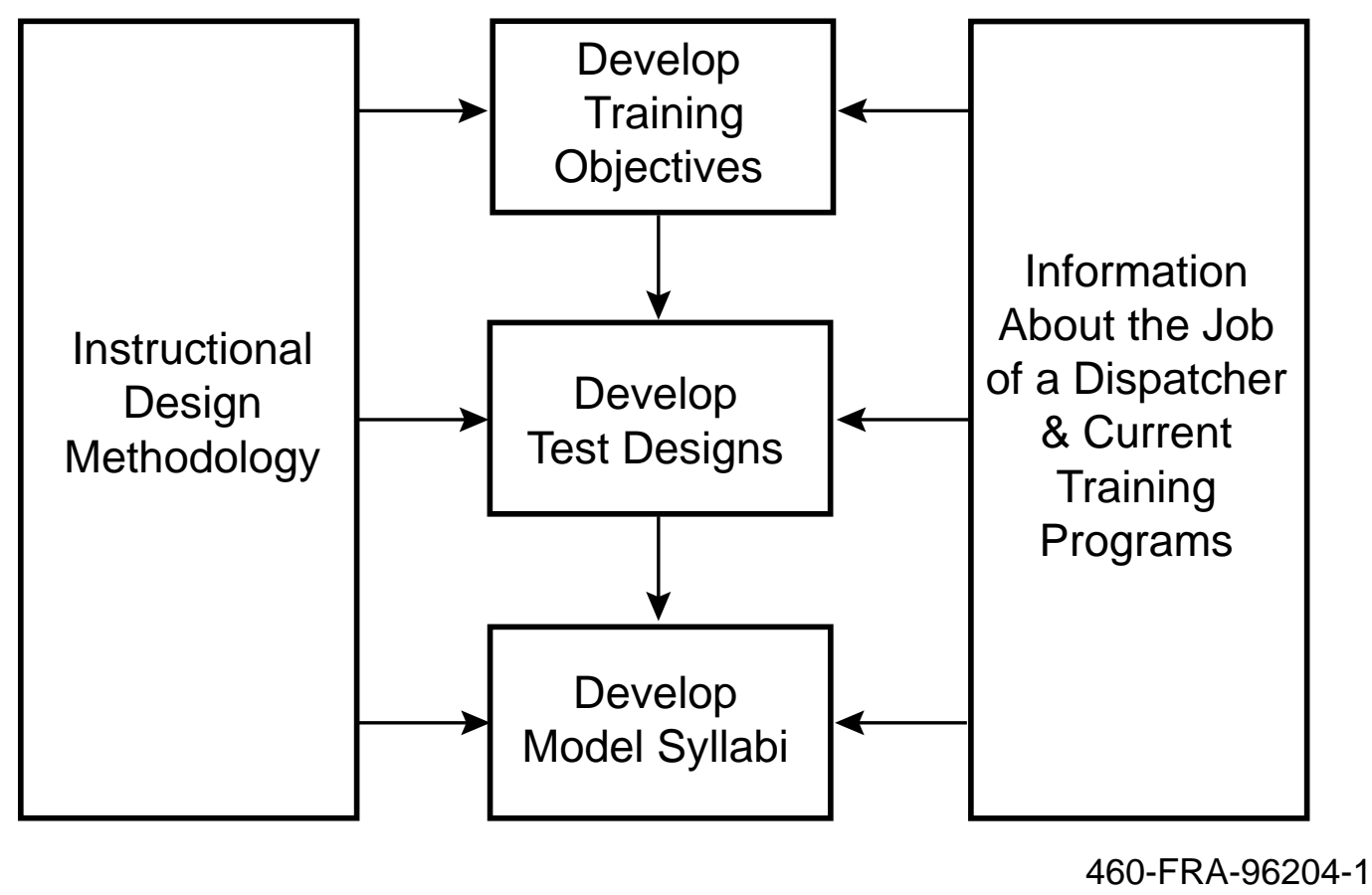

Figure 1. Overall research approach 


\subsection{Organization of the Report}

The report is divided into several sections. Section 2 presents a description of the job of a railroad dispatcher, including a review of earlier studies. Findings from railroad site visits and reviews of railroad training materials are presented in Section 3. Specific development of the training objectives is discussed in Section 4, while the training objectives are presented in Section 5. Section 6 discusses the development of the model syllabi, and Section 7 presents the three model syllabi. Section 8 discusses the development of the test designs, while Section 9 presents the three different test designs. Section 10 offers some conclusions to the research, and proposes some recommendations designed to enhance or improve railroad dispatcher training programs. Also included in Section 10 are some suggestions for the direction of future railroad dispatcher training research. Appendix A contains a glossary of railroad and instructional design terms used throughout this report. Appendix B contains brief summaries of nine different railroads' training programs. Appendix $\mathrm{C}$ presents a list of community colleges that offer an associate's degree in railroading. Appendix D presents the three interview guides (questionnaires) that were used to collect information during the site visits. Appendix E provides a list of illustrative verbs that instructional designers can use to help them write training objectives. Lastly, Appendix F provides some additional training resources that may be useful to instructional designers responsible for training railroad dispatchers. 


\section{DISPATCHER JOB DESCRIPTION}

The first step in developing the training objectives, test designs and model syllabi was to understand the job of a railroad dispatcher. Three reports provided substantial background on the duties and responsibilities of a railroad dispatcher. They were:

1. "An Analysis of the Job of Railroad Train Dispatcher" (4).

2. "National Train Dispatcher Safety Assessment Report to Congress" (1).

3. "Train Dispatcher's Follow-up Review Report to Congress" (르).

“An Analysis of the Job of Railroad Train Dispatcher," (ㄴ) a seminal report written by D.B. Devoe in 1974 for the FRA, provided a comprehensive description of the duties and functions of a railroad dispatcher, and provided a framework for developing the training objectives. The two other reports, both FRA audits, identified the problem areas in existing dispatcher training programs.

\subsection{The 1974 Devoe Report}

To ensure safe operations among the railroads, Congress passed the Federal Railroad Safety Act of 1970. The Federal Railroad Administration was called upon to enact rules, regulations, and standards, and to conduct research to ensure safe railroad operations. Since human performance was considered a critical component of safe railroad operations, a research project entitled, "Human Factors in Railroad Operations" was initiated. Before regulations and standards could be prescribed to a specific job area, however, the job itself had to be understood. Thus, as part of the project, jobs that directly affected the safety of train movements were assessed, one of which was the job of a railroad dispatcher.

Devoe's report described the job functions, job characteristics (e.g., workload, responsibilities, stress), and personal attributes of railroad dispatchers, and described the environment in which dispatchers worked. The report provided a functional analysis of the job of a railroad dispatcher, delineating the following six major functions of a railroad dispatcher:

1. Prepare documentation. The function included recording information pertaining to train operations, such as completing train order books, train sheets, transfer book details, and other relevant information.

2. Conduct preliminary planning. Preliminary planning was conducted prior to assuming dispatching responsibility, but was essential to efficient train operations. It included checking equipment status recorders, checking weather updates, reviewing relevant 
documentation, and reviewing current and planned train movements within the territory.

3. Monitor/coordinate train movements. This function, according to Devoe, involved primarily passive response to the current situation. Duties covered under this function included receiving and passing traffic information to the chief dispatcher as well as to other dispatchers, removal of some coordination or advisory actions, and deferral of some actions until later more opportune times. This function was primarily one of vigilance.

4. Initiate/stop train movements. This function comprised the biggest portion of a dispatcher's activities and workload. It included controlling signals and switches, communicating with train crews and other track users, and other self-initiated control tasks.

5. Respond to unplanned events. This function included all aspects that were affected by the occasion of an unplanned or unscheduled event. This included rescheduling trains and re-planning of actions, initiating corrective actions such as requesting assistance, interfacing with other affected parties, and dispatching services to fix a problem.

6. Respond to emergencies. This function was very similar to function 5 above, except for the increased danger posed as a result of the event, and the dire consequences that would occur if immediate corrective action was not taken. The dispatcher functions here were identical to those in function 5, except for an increased time urgency in executing them.

The Devoe report used a functional analysis rather than a task analysis of the job of a railroad dispatcher because of the greater generality of functions than tasks. Devoe wanted to ensure that an in-depth study of the job of railroad dispatcher at one railroad provided information that was representative of most, if not all, railroad dispatching jobs, regardless of the railroad. Devoe asserted that although each railroad may have its own way of performing the actual tasks, the overall functions that must be performed are similar across railroads. The Devoe report not only proved to be general across railroads at the time, it has proven to be applicable to the job of a railroad dispatcher more than 20 years after the report was published.

\subsection{Changes in the Dispatching Environment}

Each of the six basic functions laid out in the 1974 Devoe report are still relevant to today's dispatching environment and accurately describe the duties of a railroad dispatcher. While the basic functions of the dispatcher have not changed, the past 20 years have seen significant technological and operational changes in the dispatching environment. The introduction of computer assisted railroad dispatching and communications has made it possible for dispatchers to control larger territories. Changes in operating rules have allowed radio-transmitted directives to be used in place of traditional operator delivered train orders. 
Concurrent with the increased reliance on computers, large centralized dispatching centers have evolved due to railroad mergers and consolidations. Today, dispatchers for the larger Class 1 railroads work in shifts around the clock in large centralized operations along with as many as 45 other dispatchers, and may control territories that are located over 1000 miles away.

Changes in signal technology have led to a reduction in the use of tower operators and other field operations personnel, resulting in more direct dispatcher control over train movements, an increase in responsibilities, and an increase in the number of individual tasks involved in carrying out the same responsibilities. The reduction in field operations personnel has effectively eliminated the traditional career path from tower/block operator to dispatcher. As a result, the majority of recent dispatcher trainees did not have prior railroad operating experience upon entering a training program and this will most likely be the case in the future.

Consequently, railroad dispatcher training has become more in-depth and comprehensive to teach the basic railroad operational and safety procedures and skills, information that field personnel already knew before they were trained to become dispatchers.

\subsection{Railroad Dispatcher Job Functions}

In addition to the 1974 Devoe report (4), a variety of other information was examined, including two FRA reports $(\underline{1}, \underline{2})$, training materials from various railroads, and information gathered from discussions with subject matter experts. As a result of evaluating the different materials and information, the following set of four succinct dispatcher functions was developed, closely resembling Devoe's original six functions:

1. Planning. This function is identical to Devoe's second category, "Conduct preliminary planning."

2. Controlling track use. This function combines Devoe's third and fourth categories, "Monitor/coordinate train movements" and "Initiate/stop train movements." This function simply mixes passive and active train control into one broad category, whereas Devoe separated passive and active control into two distinct job functions. This category also includes dispatching MOW crews and equipment.

3. Managing unplanned and emergency events. Devoe classified unplanned and emergency events separately, though the only apparent difference was the severity of consequences and time urgency of responding to an emergency as compared to an unplanned event. Because these two functions were so similar, they were combined into one category.

4. Performing required record keeping. This function is identical to Devoe's first category, "Prepare documentation." Though most dispatches today rely heavily on computer-aided dispatching, there is still a lot of record keeping and report writing that they must do. 
The four functions presented above formed the basis for the development of the training objectives, which in turn formed the basis for the test designs and model syllabi. These four basic job functions are designed to be broad enough to be applicable to railroads that are technologically advanced as well as to railroads that operate with the same technology that was present in 1974, and they are intended to be applicable to all dispatchers, regardless of the dispatching technology, extent of territory, or nature of the railroad operation.

\subsection{Dispatching and Train Control Technology}

Current dispatching technology ranges from radio directives and paper forms, to almost "paperless" offices, where movement authorities and reports are completed using a computeraided dispatching system (CADS). Typically, the larger the railroad, the more technology the dispatchers have available.

In computer-aided dispatching systems, train movement authorities, voice communications, and other information about trains are entered into computers situated at each dispatcher's desk. Specific desk configurations vary by operation, but dispatchers likely have one or more computer screens and a keyboard at their desks, as well as a voice communications system. Typically, one or more computer screens presents a schematic of the interlockings and control points of a territory for which the dispatcher is responsible, and over which the dispatcher has control, and shows track occupancy or other conditions of sections of track. Other screens may be used for data entry or information retrieval. In many instances, schematics of all of a railroad's territories are displayed in front of the dispatching office so that dispatchers are able to view their own territory as well as adjacent territories. Using computers at their desks, railroad dispatchers can change signals and switches, and enter and retrieve information about trains (e.g., train location, train identification, locomotive power, train size and consist). Many computer-aided dispatching systems also record for future review and analysis every keystroke and entry that is made by the railroad dispatcher. Figure 2 depicts a state-of-the-art railroad dispatcher's console.

There is also a wide range of train control technologies that are currently being used, or are being explored for use in the future. At one extreme, there are dark territories that do not contain any signalized systems. Trains are moved using hand-written or verbal movement authorities issued by the train dispatcher. Before the advent of signalized systems and computer-aided dispatching, all dispatching was conducted in this manner, hence the term "paper railroad" to describe this manner of railroad dispatching. At the other end of the technology spectrum, there are currently several railroads that are working on a demonstration system of positive train control (PTC). Under PTC train speeds are automatically adjusted (the speed of the following train is either reduced or the train is completely stopped) to ensure safety, and at the same time the space between trains is reduced to increase throughput. PTC relies on a global positioning system (GPS), onboard computers, and other advanced technologies, and will likely change the way in which trains are dispatched. Among other changes, PTC will increase railroad dispatchers' reliance on computers to dispatch trains. 


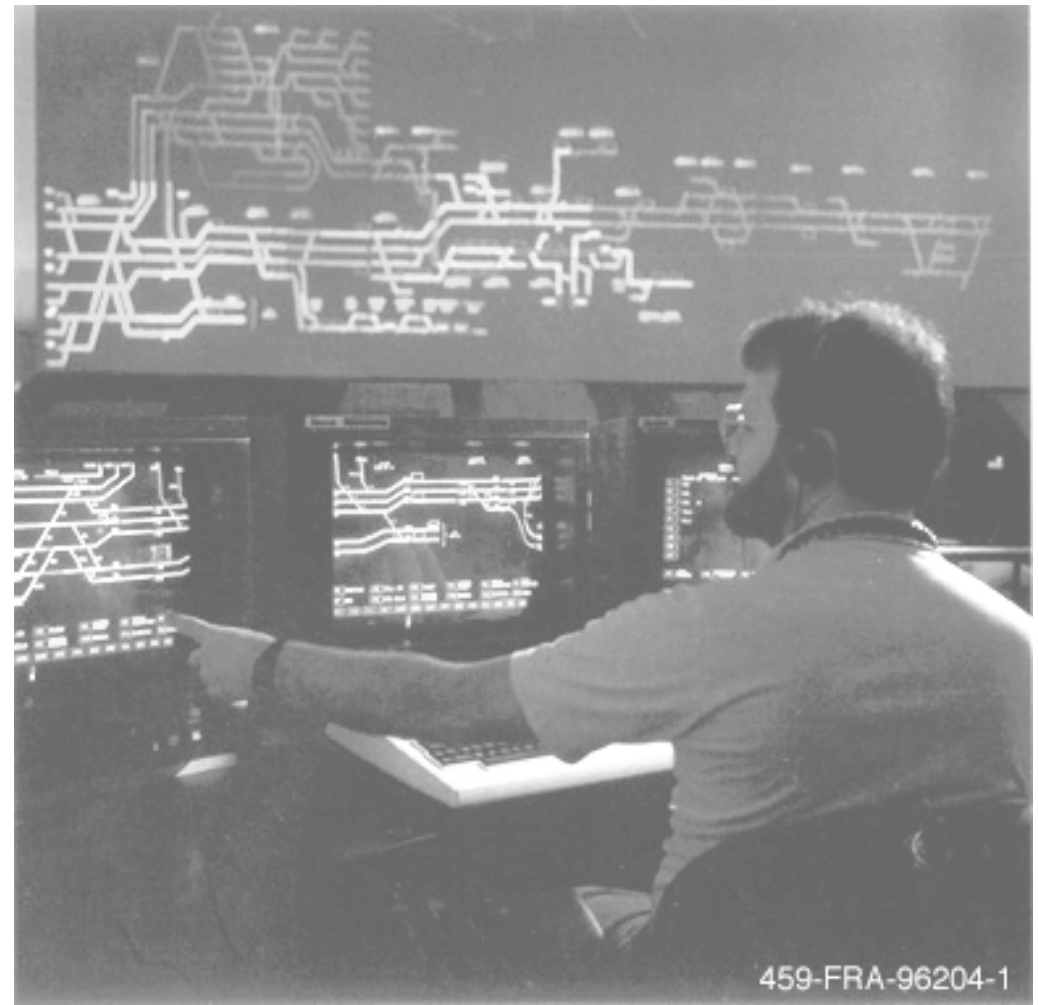

Figure 2. Railroad dispatcher's console with CADS 


\section{CURRENT TRAINING PROGRAMS}

Railroad dispatcher training materials and site visits provided the primary sources of information for this study. Five different Class 1, commuter, regional, and shortline railroads were visited, and a phone interview was conducted with a sixth railroad. Information collected during the visits came from training materials, interviews, and direct observation of the facilities, operations, and personnel. In addition to the site visits and phone interview, three other railroads provided a range of training materials that were used. The following two sections describe the types of training materials that were made available by railroads and the approach used for the site visits. Information gained from both the site visits and training materials is summarized in subsection 3.3.

\subsection{Collection of Training Materials from Existing Industry Programs}

A variety of training materials was provided by 15 railroads, representing Class 1, commuter, regional, and shortline railroads, and included representatives from both freight and passenger operations. Training materials ranged from a single annual rules exam to a complete training program. There was sufficient information for nine programs (five site visits, one phone interview, and three additional railroads' materials) to characterize them with respect to the following general topics:

- System size and dispatching technology.

- Duration of training.

- Training methods.

- Student profiles.

- Class sizes.

- Dispatcher proficiency testing and territory qualification.

- Target audiences.

- Candidate screening.

- Trainer experience.

- Refresher training.

Appendix B contains more specific information for each of the nine programs.

Course materials from community colleges that offer, or are developing, an Associate's Degree in Railroading, were also collected. These programs prepare individuals to work in the railroad industry by teaching both general education as well as more specific, railroad-related courses. Some programs are oriented more toward technical applications, while others are oriented more toward management applications. 
Johnson County Community College (JCCC) in Overland Park, Kansas, is currently the only program to offer technical training specific to railroad dispatchers. JCCC is a part of the National Academy of Railroad Sciences, a partnership between JCCC and Burlington Northern Santa Fe's Technical Training. JCCC's program includes both classroom work and field trips to on-site locations for training.

Community college programs as a whole were not a useful source of information to the project since many programs are still in their infancy, and only one program currently offers dispatcher-specific training. As these programs develop and evolve, however, they will likely provide a rich source of railroad dispatcher training information and will offer a training resource to railroads that do not have in-house training departments. Appendix $\mathrm{C}$ contains a list of these programs along with points of contact for each program.

\subsection{Site Visits and Interviews}

Five railroads were visited, representing Class 1, commuter, regional, and shortline operations, including both passenger and freight railroads. The five railroads that were visited were:

- CSX Transportation (Class 1).

- Norfolk Southern Railway Company (Class 1).

- Springfield Railway Terminal Company (regional).

- Providence and Worcester Railroad Company (shortline).

- New Jersey Transit (passenger).

Each site visit included discussions with individuals responsible for developing and/or implementing the dispatcher training program, interviews with railroad dispatchers who successfully completed the training program, and where possible, interviews with current trainees in the dispatcher training programs. A phone interview with a sixth railroad, the former Southern Pacific Railroad, was also arranged to discuss their dispatcher training program in more detail. Results from each of the site visits and the phone interview are provided in subsection 3.3.

The purposes of the site visits were:

- To gain an appreciation of the environment in which the railroad dispatcher works.

- To learn more about the specific dispatcher training programs and facilities.

- To learn about the experiences of those who are currently receiving, or recently completed, dispatcher training.

- To relate the training to the actual work environment. 
As part of each site visit, the study team was shown the dispatching center and training facilities used, including dispatcher simulators and computer-based training programs where available.

Three separate, but similar, interview guides (questionnaires) were developed to aid in collecting information from training instructors, dispatchers who recently completed the training program, and trainees currently in the program. Appendix D contains the three interview guides that were used during the site visits.

\subsection{Summary of Site Visits and Training Materials}

Information derived from the collected information, including some descriptive statistics, is summarized below. More complete information on each of the nine programs is included in Appendix B.

System size and dispatching technology: The range of operating sizes of the railroads that information was collected from varied from a single dispatcher working one shift per day, to more than 45 dispatchers working three shifts around the clock. The systems ranged from 30 to over 30,000 track miles. The technologies used by the different railroads ranged from a completely paper and voice communications operation to an essentially "paperless" computeraided dispatching system.

Duration of training: A majority of the training programs had two primary components: classroom and on-the-job-training (OJT). Classroom training generally included rules and systems learning, as well as some field trip activity. On-the-job training primarily involved application of learning in the dispatching environment, and qualification on a particular (initial) territory. In some programs, learning the physical characteristics of a territory occurred during the classroom portion of their training, while in other programs it was made a part of the OJT/ initial territory qualification. Classroom training times varied from as few as three weeks to as many as 22 weeks, while OJT times ranged from as little as two weeks to as many as 19 weeks. Several programs did not provide a specific time period for OJT, but rather offered OJT "until qualified."

Training methods: Training methods included classroom training (i.e., lectures, discussion, videotapes, slides, etc.), field trips, and OJT. Field trips ranged from day trips to local yards and maintenance shops, to week-long coverage of a territory via hi-rail car or train rides. Three of the programs incorporated simulators in their training. Furthermore, one program incorporated computer-based multi-media rules training, while a second program is currently developing one.

Student profiles: The backgrounds and experiences of current and recent trainees ranged from those with prior railroad experience to individuals coming "off-the-street" with no railroad experience. Furthermore, trainees coming "off-the-street" also had a wide variety of backgrounds, ranging from military and air traffic control (ATC) experience, to sales and cooking (one was a chef prior to becoming a railroad dispatcher). 
Class sizes: Where formal classroom instruction was employed, training class sizes ranged from as few as four to as many as 18 students. If a program used simulators in their training, the class size was typically limited by the number of simulators available. As a rule of thumb, at most two trainees would share one simulator. Thus, for example, if a program had six simulators, the class size was limited to a maximum of 12 trainees.

Dispatcher proficiency testing and territory qualification: Passing scores on exams covering rules, procedures, systems, and operations at many of the programs was 85 percent, and in some cases, it was 90 percent. In several programs, a failing grade resulted in immediate disqualification, while in other programs, there was some leniency in permitting the trainee to retake an exam after failing once. Qualification on a desk, often called "posting" or "cubbing," typically included subjective evaluations by a combination of any of the following individuals: the dispatcher responsible for the trainee, the Chief Dispatcher, Director of Operations, Director of Training, and Superintendent. The trainee's opinion of his or her own readiness was also usually solicited as part of the qualification evaluation process. One program is currently developing more explicit guidelines for qualification at a desk.

Target audiences: A majority of programs were geared toward individuals with no railroad background or experience, while a few were geared for individuals with at least some railroad experience (e.g., tower or block operators). Two programs that were designed for trainees without prior railroad experience did offer an abbreviated training program for individuals who entered the program with some prior railroad background or experience. Recently more and more training programs have changed to be designed for trainees with no prior railroad experience, and this trend is expected to continue as fewer and fewer trainees enter dispatcher training programs with prior railroad experience.

Candidate screening: Candidate screening included any combination of the following techniques: psychological and aptitude tests, physical tests (e.g., color blindness test, hearing test, general physical health, drug screening), and personal interviews. The degree of screening typically depended on the size of the operation, where larger operations engaged in more indepth and formal candidate screening.

Trainer experience: Most programs used subject matter experts as instructors. In fact, most instructors had at least some prior railroad dispatching experience. One program employed a train engineer who had over 20 years' experience as an instructor, but had not dispatched. In only two programs, however, were instructors provided with instruction on how to train others ("train the trainer").

Refresher training: All nine programs provided annual or biannual rules training and exams. Two programs are currently developing more comprehensive refresher training, to cover hazardous material handling, communications practices, and rule and operating procedure changes, while one program currently has in place a more comprehensive "Personal Development Plan." 


\section{DEVELOPMENT OF TRAINING OBJECTIVES}

A training objective, as referred to in this report, is a general category of objectives that consists of two other types of objectives: instructional and performance. One training objective consists of one instructional objective and several associated performance objectives. Instructional objectives are written from the learner's perspective, and focus on learning outcomes that should be accomplished at the conclusion of the instruction. They are general in form. In contrast, performance objectives are closely defined, measurable (i.e., observable) outcomes that a learner must accomplish, and which clearly indicate when instructional objectives have been achieved.

Figure 3 provides a schematic of the process for developing the railroad dispatcher training objectives. Reports, site visits, training materials, subject matter expert input, the FRA's working group's syllabus outline, and industry feedback all served as sources of information. An overall course objective for a dispatcher training program was first identified. Then, the job functions of a railroad dispatcher were delineated. Finally, training objectives consisting of instructional objectives and performance objectives were developed.

An instructional design (ID) approach was used to develop the training objectives. An ID approach provided a formal methodology in which to develop the objectives so that they would be general enough to be applied in any railroad setting, and useful since they are written from the student or trainee's perspective. First, a set of instructional objectives was developed with the help of information gathered from site visits and course materials. Then, a minimum of two performance objectives was developed for each instructional objective. The performance objectives represent only a small subset of all possible performance objectives that can be developed for each of the instructional objectives, and therefore, serve as examples only. The instructional and performance objectives that are presented in this report are intended to be used as a starting point and guide to help railroad training officials develop their own instructional and performance objectives tailored to their own training programs. It is up to each instructional designer to craft all of the necessary and applicable instructional and performance objectives for their own railroad dispatcher training program.

The development of the training objectives was also iterative. After a draft of the instructional objectives was developed, it was sent for review to over 20 industry personnel, including representatives from Class 1, regional, shortline, and passenger railroads; JCCC; union officials; and officials from the FRA. The goal of the industry review was to ensure that the instructional objectives were applicable to a variety of railroads. The feedback from industry representatives was also used to validate the utility and accurateness of the instructional objectives. Reviewer comments were incorporated when developing the final set of instructional 


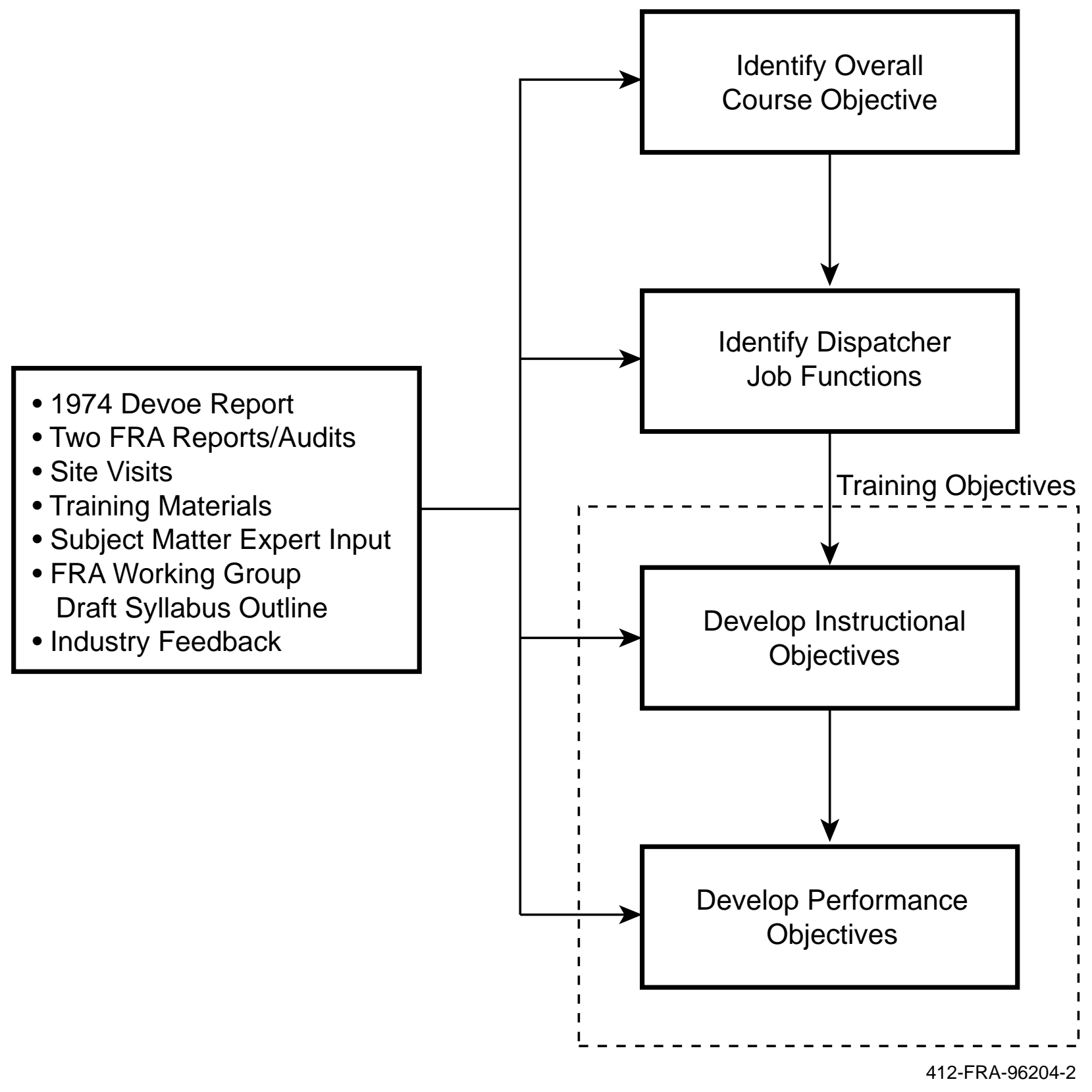

Figure 3. Development of dispatcher training objectives 
objectives. Since the performance objectives serve only as examples, they were not included in the industry review.

\subsection{Instructional Design Process}

The goal of developing the training objectives is to enable any railroad developing a railroad dispatcher training program to develop such a program with the confidence that by the end of the training, their dispatcher trainees will be able to safely and efficiently dispatch trains and control the use of tracks over the territory for which they will be dispatching. Railroads that are developing their own training program can use the training objectives as a starting point and guide to help them develop a set of training objectives (including both instructional and performance objectives) that will be specific to the needs and constraints of their own operation. Railroads that do not currently have a formal railroad dispatcher training program can use the training objectives to build a more formal railroad dispatcher training program, while railroads that have already developed formal dispatcher training programs can use the training objectives as a validation of their own programs.

Development of the training objectives will also aid the instructional designer in developing test designs to determine when the objectives have been met, and in developing a course syllabus, which will serve to organize the training objectives in a meaningful way. Training objectives should be considered the raw material for a railroad dispatcher training program. Once the training objectives are developed, a complete training program can be built around them. Training objectives serve to structure and guide a training program.

To aid the reader in understanding the instructional design process as it specifically relates to the development of the instructional and performance objectives, an example is provided of one instructional objective followed by two performance objectives that are directly relevant to the instructional objective. All three items together constitute one training objective. For example:

1.1 Understand the terminology used in relation to the job of train dispatching.

\subsubsection{Match <specific> jargon with their meanings.}

\subsubsection{Define <specific word>.}

Notice that the verbs used are oriented toward the learner's perspective. The instructional objective (1.1) is written in very general terms, while the verbs used to develop the specific performance objectives (1.1.1 and 1.1.2) are concrete, measurable behaviors that the trainee is expected to accomplish, and which indicate that, upon successful completion, the general instructional objective has also been accomplished.

\subsection{General Framework: Bloom's Taxonomy}

Bloom's taxonomy of educational objectives ( $\underline{5}$ ) was used as a guide to developing the training objectives. Bloom's taxonomy was chosen because it is familiar and accepted within the 
instructional design community, it is comprehensive, and it provides a proven structure and format for developing instructional and performance objectives.

Bloom's taxonomy aids instructional designers, specifically those who develop objectives, by identifying and categorizing three types, or domains, of educational outcomes: psycho-motor, affective, and cognitive. Each educational outcome (domain) is then further delineated in terms of its component categories. Railroad dispatching relies heavily on a cognitive set of tasks; therefore, the focus of this study is on the cognitive aspects of railroad dispatching. Bloom lists six categories of learning outcomes within the cognitive domain. Presented in Table 1, the learning outcomes increase in complexity from the simplest (1) to the most complex (6).

For each increasing level of complexity in a learning outcome, typically each previous level of complexity has already been achieved. In other words, less complex learning outcomes are subsumed by the more complex ones. Often, the simpler learning outcomes are building blocks for the more complex ones. Therefore, it is important to focus on the most complex (highestorder) learning outcome possible when writing objectives.

Each instructional objective has been labeled with the associated learning outcome category to help the reader understand and appreciate the level of learning expected by each instructional objective (and each of the performance objectives related to that instructional objective). It is not necessary to explicitly provide these learning outcome categories when developing instructional objectives for a training program; they should be used only to aid the instructional designer in creating the most appropriate objectives to fit the goals of the course and the abilities of the students.

When writing both instructional and performance objectives, it is helpful to have available a list of verbs that conveys the different categories of learning outcomes. In addition, some verbs are more appropriate for use in writing instructional objectives (e.g., knows, understands, solves, applies, judges), while other verbs are more appropriate for use in writing specific performance objectives (e.g., lists, names, identifies, prepares, devises, prioritizes). There are several sources of illustrative verbs available to aid instructional designers in writing instructional and performance objectives. Appendix E provides an example of one list found in (므). Since such a large portion of railroad dispatching is cognitive in nature, the list corresponds to Bloom's six cognitive learning outcomes. The list can be used by an instructional designer to develop a core set of railroad dispatcher instructional and performance objectives.

\subsection{Instructional Objectives}

Instructional objectives are intended to be generalizable and readily applicable to a training program since they focus on the trainee and what he or she will be able to do at the conclusion of training (the learning outcomes) rather than what a trainer should teach during the training (teaching content).
Table 1. Bloom's taxonomy of cognitive learning outcomes

\begin{tabular}{cl}
\hline Level & Category of Learning \\
\hline 1 & Knowledge \\
2 & Comprehension \\
3 & Application \\
4 & Analysis \\
5 & Synthesis \\
6 & Evaluation \\
\hline
\end{tabular}


The benefits of using instructional objectives are that instructional objectives provide direction for instruction, they provide guidelines for assessment, and they convey instructional intent to others (므). Furthermore, they are written in a manner that is condition-free and standard-free, allowing for more flexibility and generalization, enabling them to fit multiple situations without necessitating the rewriting of objectives for each situation. These instructional objectives are written to be equally applicable to railroads that depend heavily on technology and to those that use very little dispatching technology; they are written to be equally applicable to big and small railroads; and they are written to be equally applicable to both passenger and freight operations.

\subsection{Performance Objectives}

When designing an instructional unit (e.g., hazardous material rules, regulations, and procedures), both instructional and performance objectives should be developed. The instructional objectives provide top-level structure to the unit, while the performance objectives, also known as specific learning outcomes, call for the specific, measurable activities that a learner (i.e., the trainee) should be able to do at the conclusion of the instructional unit. A minimum of two performance objectives were developed for each instructional objective to serve as examples to aid railroad instructional designers and curriculum developers in tailoring a set of performance objectives to the needs of their specific railroad.

Performance objectives are typically comprised of three parts: (1) the condition in which the specified performance will be conducted, (2) the specified performance to be conducted and (3) the standard of successful performance. Conditions or standards of performance were not used in developing the performance objectives presented in subsection 5.1, however, since the conditions and standards of performance will vary from railroad to railroad. The action to be performed, however, will be applicable to all railroads. The following are two examples of performance objectives with all three parts: (1) condition, (2) performance, and (3) standard. In each of the two examples, all three parts of the performance objective are underlined and numbered according to which of the three parts they represent. The instructional objective is presented first to provide the context for the performance objectives. This example is related to the one found in subsection 4.1.

1.1 Understand the terminology used in relation to the job of train dispatching. Comprehension

\subsection{1 (1) Given the need to communicate with another dispatcher, (2) match (3) the following five terms with their meanings....}

1.1.2 (1) Given the need to communicate with a track crew in the field, (2) define (3) the following six words....

\subsection{Initial Development of Training Objectives}

An iterative approach was used to draft the training objectives, which consist of the instructional and performance objectives. Based on a modified set of railroad dispatcher job 
functions, a set of instructional objectives was developed, which, when achieved, indicated that a dispatcher trainee would be able to carry out the dispatcher functions at the completion of the training program. This process resulted in a list of approximately 50 instructional objectives. The instructional objectives were designed to be general enough to be equally applicable to Class 1, regional, and shortline railroads. Furthermore, the objectives were designed to be implemented regardless of the degree and amount to technology used by a railroad, from a totally manual all-paper operation to completely computer-aided dispatching.

After the initial instructional objectives were drafted, two or more performance objectives specific to each instructional objective were developed. These performance objectives are only a subset of all possible performance objectives that can be developed for each instructional

objective, however. It is up to each organization to design more specific, and directly applicable, performance objectives to meet their own goals.

\subsection{Industry Review and Validation}

After the initial development of the instructional objectives, feedback was solicited from 24 individuals, including railroad personnel, ATDD Union representatives, officials from the FRA, and community college officers. The 24 individuals represented a total of 17 different organizations. Reviewer feedback helped to hone the content and details of the instructional objectives, and ensured that the objectives were representative of all sizes and classes of railroad operations. Reviewers were asked to focus their attention on the following concerns:

- Are there any additional objectives that are applicable to all railroads?

- Are there any errors in the descriptions of what a railroad dispatcher trainee should be able to do upon completion of training?

- Are there any objectives which do not apply to your railroad?

- Do you have any general suggestions, comments or criticisms?

Fourteen individuals representing 12 organizations returned their comments. Class 1 , regional, and shortline railroads were represented, including both passenger and freight operations. Both the FRA and ATDD Union were also represented. All of the reviewer comments were incorporated into a final set of instructional objectives. They are presented in Section 5 along with a small sample of performance objectives. 


\section{TRAINING OBJECTIVES}

This section presents the training objectives that were developed as part of this research. Subsection 5.1 presents the initial set of training objectives that were developed. The list of objectives is comprehensive, but not exhaustive. Objectives that were not directly related to the safe and efficient movement and protection of trains and other track users were not included. Each individual railroad must decide what training objectives to add, remove, or modify based on their particular operations.

Instructional objectives developed in subsection 5.1 were then organized into three different training programs-initial dispatcher training, initial territory training, and periodic refresher training-based on their relevance to the particular training. If mastery of an instructional objective was important to, or necessary for, a training program, it was included in the set of instructional objectives for that particular training program. The subsets of instructional objectives selected for the three different training programs are discussed and presented in subsection 5.2.

\section{$5.1 \quad$ Objectives}

An overall course objective is presented first, followed by the instructional and performance objectives. The general prerequisites needed to dispatch trains safely are identified first. They are intended to serve as the building blocks for learning the other objectives. The remaining objectives are divided into the four general job functions identified in subsection 2.3. Briefly, the four job functions are:

- Planning.

- Controlling track use.

- Managing unplanned and emergency events.

- Performing required record keeping.

The objectives in these four categories are broadly applicable to all railroads, and are not listed in any particular order within each job function, except when an objective that focuses on knowledge of a method precedes an objective that focuses on the application of the same method. Following the four groups of objectives there are two additional categories, freight operations and electrified operations, that each contain several objectives. Railroads may choose to include either or both of these subsets of objectives if the objectives are applicable to their situation. For example, Norfolk Southern would incorporate those objectives listed under the freight operations category, while Metra would probably not use them. Furthermore, Northern Indiana Commuter Transportation District (NICTD) would incorporate the objectives under the 
electrified territories category, while Norfolk Southern would not use these objectives since Norfolk Southern does not operate any electrified territories.

Although the objectives discussed here make up a comprehensive list, it is not meant to be all inclusive. The unique operating characteristics of each railroad will determine whether the list must be contracted, expanded, or otherwise altered.

The railroad dispatcher job functions, instructional objectives, associated learning outcomes based on Bloom's taxonomy (ㅁ) (presented in italics), and performance objectives are presented below in the following format:

\section{Job function/prerequisite}

1.1 Instructional objective. Associated learning outcome

\subsubsection{Example of a performance objective.}

Overall course objective: Upon completion of the course, a trainee will demonstrate the ability to dispatch trains and other vehicles/equipment that travel on or along the rail safely and efficiently, and protect those individuals who work on or around the track.

\section{General prerequisites to train dispatching}

1.1 Understand the basic operational and administrative structure of the railroad. Comprehension

\subsubsection{List the major departments of your railroad.}

1.1.2 Explain the role of each department within your railroad.

1.2 Understand the general duties of a dispatcher and of other railroad operating personnel with whom contact may be necessary in the performance of such duties.

Comprehension

1.2.1 List the duties and responsibilities of a train dispatcher.

1.2.2 Name several other operating personnel with whom contact will be necessary while performing the duties of a train dispatcher.

1.3 Understand the terminology used in relation to the job of train dispatching. Comprehension

1.3.1 Match <specific > jargon with their meanings.

1.3.2 Define <specific word>. 
1.4 Understand the railroad's operating and safety rules, including federal regulations, as they apply to both a dispatcher's duties and to the railroad's operations in general. Comprehension

1.4.1 Explain the hours of service (HOS) regulation as it applies to a dispatcher.

1.4.2 Explain the hours of service (HOS) regulation as it applies to members of train and engine crews.

1.5 Demonstrate clear and coherent communications skills and procedures with train and engine crews, other dispatchers and other railroad operating personnel. Application

1.5.1 Explain the proper radio/phone procedure for communicating with train crews, maintenance of way, etc.

1.5.2 Demonstrate a proper communications protocol between the dispatcher and a train crew (or other personnel).

\subsubsection{List two reasons why <example of improper communications between a dispatcher and MOW foreman> is an example of poor communications.}

1.6 Demonstrate the ability to communicate with difficult (e.g., stubborn, irate, irrational) people, including train and engine crews, other dispatchers and other railroad operating personnel. Application

1.6.1 List four reasons why an individual may be uncooperative to work with.

1.6.2 Explain the procedure to follow when encountering a difficult or uncooperative individual.

1.6.3 Given a <specific situation>, demonstrate the ability to achieve a successful resolution.

1.7 Demonstrate the ability to resolve conflicting requests for track time ${ }^{1}$. Application

1.7.1 Give an example of a conflicting request for track time.

1.7.2 Describe how to resolve the conflicting request.

1.7.3 Demonstrate the ability to resolve a situation in which conflicting requests are made.

1.8 Demonstrate the ability to apply lifestyle training, including information about shiftwork, to prepare for, and maintain, a career as a train dispatcher. Application

${ }^{1}$ Objective 1.7 emphasizes the ability to manage people, not the ability to optimally plan track use. 
1.8.1 Describe how working third shift will impact the lifestyle of a train dispatcher.

1.8.2 Identify several potential work-related problems of continually working third shift or being on-call with no regular schedule and no regular days off.

1.8.3 Explain the relationship between shiftwork and fatigue.

1.8.4 List two countermeasures that can be employed to combat fatigue during a shift.

1.9 Demonstrate stress management techniques. Application

\subsubsection{Define stress.}

1.9.2 Describe the ill-effects of stress on-the-job.

1.9.3 Describe two techniques for managing stress on-the-job.

1.10 Know how to manage documents such as rule books, bulletins, General Orders, Special Instructions, etc. Knowledge

1.10.1 Explain the significance of an updated rule book.

1.10.2 Given a <specific > canceled rule, demonstrate updating your rule book.

\section{$2 \quad$ Planning}

2.1 Demonstrate the ability to assume or relinquish dispatcher duties in accordance with applicable requirements and procedures. Application

2.1.1 Name documents and other sources of information that must be checked prior to assuming responsibility for a desk.

2.1.2 Explain the general procedure for assuming responsibility for a desk.

2.1.3 Demonstrate the procedure for relinquishing duties to another dispatcher.

2.2 Demonstrate the ability to use information from passenger train schedules, freight service schedules, and track usage schedules and/or requests when planning and managing track use. Synthesis

2.2.1 Explain how to read a passenger train schedule.

2.2.2 Explain how to read a track usage schedule. 
2.3 Judge train and track user priorities. Evaluation

2.3.1 List factors that affect track user priorities.

2.3.2 Given a <specific > scenario, prioritize a list of competing track users (e.g., trains, MOW crews, inspectors, contractors).

2.4 Demonstrate the ability to understand and use all manual and computer-based dispatcher planning aids employed by the railroad. Application

2.4.1 List available manual and computer-based planning aids.

2.4.2 Explain how a <specific > planning aid is used.

2.4.3 Demonstrate use of a <specific > manual planning aid to predict the meeting of two trains.

2.5 Demonstrate the ability to prioritize a dispatcher's own tasks, i.e., manage time effectively, when planning and carrying out the day's activities (e.g., train movement planning, radio use, record keeping). Evaluation

2.5.1 Prioritize the following <specific〉 dispatcher tasks.

2.5.2 Given a <specific> situation, select the task that takes precedence and explain why that task takes precedence.

2.6 Demonstrate the ability to manage train and engine crew logistics. Synthesis

2.6.1 List the HOS requirements for T\&E crews.

2.6.2 Name individuals or departments who are involved in scheduling/replacing T\&E crews.

2.6.3 Explain the procedure for relieving a T\&E crew.

\section{Controlling track use}

3.1 Know where to retrieve, and how to use (i.e., understand) information about the physical characteristics of the territory/ies for which the dispatcher will be responsible. Comprehension

3.1.1 List two sources that contain information on the physical characteristics of a territory. 
3.1.2 Given a <specific territory, or part of a territory>, identify the nearest grade crossing.

3.2 Know the operating characteristics of the rolling stock used on the railroad as they pertain to dispatching. Knowledge

3.2.1 Define the power rating of each locomotive type used on your railroad.

3.2.2 List the types of cars that your railroad uses in transporting goods.

3.2.3 List the operating characteristics (e.g., capacity, usage, tonnage, etc.) of a $<$ specific type of > railroad car.

3.3 Know where to retrieve information about the important physical and operating characteristics of all the equipment operated on rail, as they relate to train dispatching and train operations. Knowledge

3.3.1 Name a source of information that contains physical and operating characteristics of the locomotives used on your railroad.

3.3.2 Identify a source of information that contains maintenance-of-way (MOW) equipment specifications.

3.4 Understand all forms of movement and protective authority used within the limits of the territory being dispatched. Comprehension

3.4.1 List the available forms of train movement and protective authority.

3.4.2 Explain each form of train movement and protective authority.

3.4.3 Describe the scope and limitations of each form of train movement and protective authority.

3.5 Demonstrate the ability to correctly issue all forms of train movement and protective authority used within the limits of the territory being dispatched. Application

3.5.1 Explain centralized traffic control.

3.5.2 Explain an Automatic Block System (ABS).

3.5.3 Explain the procedure for issuing authority in non-signaled territory.

3.6 Understand the general principles of railway signaling. Comprehension

3.6.1 Explain how signal systems (in general) work. 


\subsubsection{Define a signal aspect.}

\subsubsection{Define a signal indication.}

\subsubsection{Match signal aspects with their respective indications.}

3.7 Demonstrate full awareness of how to plan beyond the limits of a territory and to keep adjoining dispatchers apprised of information needed on approaching trains. Application

3.7.1 Explain why it is important to keep adjoining dispatchers apprised of information needed on approaching trains.

3.7.2 List three pieces of information about a train or its crew that an adjoining dispatcher should know as a train moves into his or her territory.

3.8 Demonstrate the ability to correctly apply and remove blocking devices. Application

3.8.1 Explain the purpose of a blocking device.

3.8.2 Give three examples of when blocking devices are required.

3.8.3 Explain the procedure for applying a blocking device.

3.8.4 Name two circumstances in which a blocking device can be removed.

3.9 Demonstrate the ability to correctly issue and remove speed restrictions. Application

3.9.1 Explain the purpose of a speed restriction.

3.9.2 Explain the procedure for issuing a speed restriction.

3.9.3 Define a temporary speed restriction.

3.9.4 Given a <specific situation〉, demonstrate issuing a speed restriction.

3.10 Understand track bulletins, train dispatcher bulletins, special instructions, and other operational updates. Comprehension

3.10.1 Define a track bulletin.

3.10.2 Give two examples of a special instruction.

3.11 Demonstrate the ability to safely authorize, dispatch, and monitor the use of tracks by non-shunting equipment and work crews. Application 
3.11.1 Define non-shunting equipment.

3.11.2 Give three examples of non-shunting equipment.

3.11.3 Explain the procedure(s) for dispatching non-shunting equipment.

3.11.4 List the precautions a dispatcher must take to monitor non-shunting equipment.

3.11.5 Describe the provisions of Roadway Worker Protection.

3.11.6 Explain the precautions a dispatcher must take to monitor work crews.

3.12 Know where to find operating and safety rules (including who to apply to for rules and procedures interpretation), federal regulations, phone numbers, emergency procedures, and other relevant information when needed. Knowledge

3.12.1 Identify the closest location (relative to a dispatching desk) where emergency procedures can be found.

3.12.2 Identify who to go to with a rules interpretation question.

3.13 Demonstrate the ability to reasonably estimate travel times between two locations for a variety of train make-ups over a variety of road, track, and operating conditions. Synthesis

3.13.1 Describe the factors that determine a train's travel time between two points.

3.13.2 Given a <specific > makeup and operating conditions of a train, estimate its travel time from <specific > point A to <specific > point B.

3.14 Demonstrate the ability to plan for, and arrange, train meets in the most expeditious manner possible. Synthesis

3.14.1 Given <specific> conditions, explain step by step the procedure for arranging a train meet between two trains.

3.14.2 Given <specific > conditions, plan a train meet between two trains.

\section{$4 \quad$ Manage unplanned and emergency events}

4.1 Where applicable to the job of a train dispatcher, demonstrate the ability to respond to wayside defect detectors. Application

4.1.1 Explain the function of wayside defect detectors. 
4.1.2 Name three different types of wayside defect detectors.

4.1.3 Explain the procedure for responding to a <specific > wayside defect detector.

4.2 Understand the procedure(s) to implement for an unplanned event or emergency. Comprehension

\subsubsection{Explain an unplanned event.}

4.2.2 Give three examples of an unplanned event.

4.2.3 Explain the procedure to implement for a <specific > unplanned event.

\subsubsection{Define an emergency.}

4.2.5 Give three examples of an emergency situation.

4.2.6 Explain the procedure to implement for a 〈specific > emergency situation.

4.3 Demonstrate the ability to implement a procedure in response to an unplanned event or emergency. Application

4.3.1 Demonstrate the ability to establish contact with required persons rapidly, effectively, and in appropriate order.

4.3.2 Demonstrate the ability to clearly and accurately inform, instruct, or direct train crews, emergency services, and railroad employees and officials as may be appropriate.

4.3.3 Demonstrate the ability to correctly apply all appropriate, available methods of protection for trains, employees, and property when an unplanned event or emergency occurs.

4.4 Formulate a plan of action when encountering an event for which no procedure has been established. Evaluation

4.4.1 Determine if a procedure exists for the event.

4.4.2 Devise a plan of action to take when encountering an event for which there is not an established procedure.

4.4.3 Given the need to contact another individual to formulate a procedure, identify who to contact. 
4.5 Demonstrate the ability to compensate for lost capabilities when a computer or system outage occurs within the dispatching center. Application

4.5.1 Explain the safety implications of a CADS system outage.

4.5.2 Explain the procedure to follow when a computer outage occurs within the dispatching center.

4.5.3 Demonstrate use of a backup system or procedure(s) to follow if a computer or system outage occurs within the dispatching center.

\section{$5 \quad$ Record keeping and report writing}

5.1 Know all records a dispatcher is required to initiate, maintain, and complete. Knowledge

5.1.1 Name all records a dispatcher must maintain.

5.1.2 Select from among a series of records those a dispatcher must maintain [as opposed to those a Chief or other operating personnel must maintain].

5.2 Demonstrate the ability to complete all required records using the means normally provided to do so. Application

5.2.1 List the customary means for completing records.

5.2.2 Explain the procedure to complete a <specific $>$ record.

5.2.3 Explain all definitions, categories, fields, ranges, and terms used in completing a <specific $>$ record.

5.2.4 Demonstrate completing a $<$ specific $>$ record.

5.3 Where records are completed with the aid of mechanical or electronic devices, demonstrate the ability to complete these records manually in the event of failure of the normal means. Application

5.3.1 State where to find the materials necessary to manually complete a 〈specific > record.

5.3.2 Explain the procedure for manually completing a $<$ specific $>$ record.

5.3.3 Demonstrate manually completing a <specific $>$ record for which an electronic record is ordinarily completed. 
5.4 Know what reports a dispatcher is required to initiate/complete. Knowledge

5.4.1 Name all reports a dispatcher is required to initiate/complete.

5.4.2 Describe the circumstances under which a dispatcher must initiate/complete a report.

5.5 Demonstrate the ability to initiate/complete required reports using the means normally provided to do so. Application

5.5.1 List the customary means for initiating/completing a <specific $>$ report.

5.5.2 Explain the procedure for initiating/completing a <specific $>$ report.

5.5.3 Explain definitions, categories, fields, ranges, and terms used when initiating/ completing a <specific > report.

\subsubsection{Demonstrate the ability to initiate/complete a $\langle$ specific $\rangle$ report.}

5.6 Where reports are completed with the aid of mechanical or electronic devices, demonstrate the ability to initiate/complete reports manually in the event of failure of the normal means. Application

5.6.1 State where to find the materials necessary to manually initiate/complete a <specific> report.

5.6.2 Explain the procedure for manually initiating/completing a <specific > report.

5.6.3 Demonstrate manually initiating/completing a <specific > report for which mechanical or electronic devices are ordinarily used.

5.7 Where applicable, and where a computerized report-generating capability is provided, demonstrate the ability to properly specify and obtain reports based on all fields or parameters that can be employed to generate such reports. Application

5.7.1 Describe the report-generating capabilities that a dispatcher has available when initiating/completing a <specific > report.

5.7.2 Given <specific > fields of interest, explain the procedure for generating a $<$ specific > report.

5.7.3 Given <specific > fields of interest, demonstrate generating a <specific > report. 


\section{Freight Operations}

1.1 Know how to manage the transport of hazardous materials, including precautions, emergency procedures, and their placement within a train. Knowledge

1.1.1 State where to find consist/bill of lading information on a train carrying hazardous materials.

1.1.2 State precautions associated with transporting hazardous materials.

1.1.3 Outline an emergency procedure to follow in case of an emergency.

1.2 Demonstrate the ability to manage and dispatch helper services (e.g., an extra engine or qualified pilot). Application

1.2.1 Explain the role/function of helper services.

1.2.2 Name three examples of situations in which helper services would be needed.

1.2.3 Explain the procedure for dispatching helper services.

1.2.4 Demonstrate dispatching helper services.

\section{Electrified Territories}

1.1 Understand the grounding hazards associated with the electric traction power systems (e.g., third rail or catenary) used by the railroad. Comprehension

\subsubsection{Explain electric traction power.}

1.1.2 Define a grounding hazard.

1.1.3 Name the grounding hazards associated with the railroad's electric traction power system.

1.2 Understand the general relationship between physical track sections and elements of any form of electric traction power employed by the railroad, including the basic mechanics of breaker operation and the isolation of traction power sections.

Comprehension

1.2.1 Explain the relationship between physical track sections and electric traction power.

1.2.2 Explain isolation of traction power. 


\subsubsection{Explain the function of breakers in an electric traction power system.}

1.3 Demonstrate the ability to rapidly effect (or communicate the need to effect) deenergization of one or more specific traction power sections. Application

1.3.1 List a railroad dispatcher's responsibilities for de-energizing/energizing a segment of track.

1.3.2 Identify the individual(s) who must be contacted in order to effect deenergization/energization of a segment of track.

1.3.3 Explain the procedure for de-energizing one or more segments of electrified track.

1.3.4 Given a <specific situation>, demonstrate rapidly effecting de-energization of a $<$ specific $>$ segment of track.

\subsection{Three Training Programs}

The second and third goals of this project called for the development of model syllabi and test designs for railroad dispatcher training. Three specific types of training were identified:

1. Initial dispatcher training. Initial dispatcher training includes learning the fundamental skills and knowledge required to dispatch trains safely and efficiently.

2. Initial territory training. Initial territory training involves applying, for the first time, the skills and knowledge gained in initial dispatcher training to the actual work environment. The result of initial territory training is that the dispatcher becomes "qualified" to dispatch trains on a particular territory. In the railroad industry, qualifying on a desk, whether it is their initial territory or their sixth one, is often referred to as "posting" or "cubbing."

3. Periodic refresher training. Periodic refresher training addresses the need for railroad dispatchers to maintain their skills and knowledge of operating rules and procedures. Skills that are not used may be lost, and procedures that are used infrequently may be forgotten. Periodic refresher training is intended to facilitate the maintenance of safe and efficient standards of railroad dispatching, and reinforce recent training on any new equipment or procedures.

The objectives specified in subsection 5.1 provide the raw material for the formulation of the three training types described above. The following criteria were used in selecting the objectives for each of the three training types:

1. The target audiences for the initial dispatcher training and initial territory training should be individuals who have no prior railroad operating knowledge or experience, 
since many dispatcher trainees are being hired off the street, without any railroad operations experience, and this trend is expected to continue.

2. To be applicable to the broadest range of railroad organizations, selection of instructional objectives to be included in each of the three training programs should be based on the premise that trainees will be learning to dispatch on a non-electrified, freight operation, since a majority of railroads in the United States are currently nonelectrified, freight operations.

Table 2 presents a matrix depicting which instructional objectives (referenced by number and organized by job function) were selected for the three different training programs. As can be seen, often an objective is used for more than one training type. Instructional objectives were selected as the basis for both the model syllabi and the test designs because they are broad enough to sufficiently describe syllabus units without further elaboration, they are broad enough to apply to different railroads, and they provide a uniform framework for developing the test designs. It is up to each individual railroad to develop more specific performance objectives based on these instructional objectives as well as those developed by each railroad. 
Table 2. Instructional objectives for three training programs

\begin{tabular}{|c|c|c|c|c|}
\hline \multirow[b]{2}{*}{ Job Function } & \multirow[b]{2}{*}{$\begin{array}{c}\text { Objective } \\
\text { No. }\end{array}$} & \multicolumn{3}{|c|}{ Training Type } \\
\hline & & $\begin{array}{c}\text { Initial } \\
\text { Dispatcher } \\
\text { Training } \\
\end{array}$ & $\begin{array}{c}\text { Initial } \\
\text { Territory } \\
\text { Training } \\
\end{array}$ & $\begin{array}{c}\text { Periodic } \\
\text { Refresher } \\
\text { Training } \\
\end{array}$ \\
\hline General Prerequisites & $\begin{array}{l}1.1 \\
1.2 \\
1.3 \\
1.4 \\
1.5 \\
1.6 \\
1.7 \\
1.8 \\
1.9 \\
1.10\end{array}$ & $\begin{array}{l}\sqrt{ } \\
\sqrt{ } \\
\sqrt{ } \\
\sqrt{ } \\
\sqrt{ } \\
\sqrt{ } \\
\sqrt{ } \\
\sqrt{ } \\
\sqrt{ } \\
\sqrt{ }\end{array}$ & & $\begin{array}{l}\sqrt{ } \\
\sqrt{ } \\
\sqrt{ } \\
\sqrt{ } \\
\sqrt{ }\end{array}$ \\
\hline Planning & $\begin{array}{l}2.1 \\
2.2 \\
2.3 \\
2.4 \\
2.5 \\
2.6\end{array}$ & $\begin{array}{l}\sqrt{ } \\
\sqrt{ } \\
\sqrt{ } \\
\sqrt{ } \\
\sqrt{ } \\
\sqrt{ }\end{array}$ & $\begin{array}{l}\sqrt{ } \\
\sqrt{ } \\
\sqrt{ } \\
\sqrt{ } \\
\sqrt{ } \\
\sqrt{ }\end{array}$ & $\begin{array}{l}\sqrt{ } \\
\sqrt{ } \\
\sqrt{ } \\
\sqrt{ }\end{array}$ \\
\hline Manage Track Use & $\begin{array}{l}3.1 \\
3.2 \\
3.3 \\
3.4 \\
3.5 \\
3.6 \\
3.7 \\
3.8 \\
3.9 \\
3.10 \\
3.11 \\
3.12 \\
3.13 \\
3.14\end{array}$ & $\begin{array}{l}\sqrt{ } \\
\sqrt{ } \\
\sqrt{ } \\
\sqrt{ } \\
\sqrt{ } \\
\sqrt{ } \\
\sqrt{ } \\
\sqrt{ } \\
\sqrt{ } \\
\sqrt{ } \\
\sqrt{ } \\
\sqrt{ } \\
\sqrt{ } \\
\sqrt{ }\end{array}$ & $\begin{array}{l}\sqrt{ } \\
\sqrt{ } \\
\sqrt{ } \\
\sqrt{ } \\
\sqrt{ } \\
\sqrt{ } \\
\sqrt{ } \\
\sqrt{ } \\
\sqrt{ } \\
\sqrt{ }\end{array}$ & $\begin{array}{l} \\
\sqrt{ } \\
\sqrt{ } \\
\sqrt{ } \\
\sqrt{ } \\
\sqrt{ } \\
\\
\sqrt{ }\end{array}$ \\
\hline Manage Unplanned and Emergency Events & $\begin{array}{l}4.1 \\
4.2 \\
4.3 \\
4.4 \\
4.5\end{array}$ & $\begin{array}{l}\sqrt{ } \\
\sqrt{ } \\
\sqrt{ } \\
\sqrt{ } \\
\sqrt{ }\end{array}$ & $\begin{array}{l}\sqrt{ } \\
\sqrt{ }\end{array}$ & $\begin{array}{l}\sqrt{ } \\
\sqrt{ } \\
\sqrt{ } \\
\sqrt{ }\end{array}$ \\
\hline Record Keeping and Report Writing & $\begin{array}{l}5.1 \\
5.2 \\
5.3 \\
5.4 \\
5.5 \\
5.6 \\
5.7\end{array}$ & $\begin{array}{l}\sqrt{ } \\
\sqrt{ } \\
\sqrt{ } \\
\sqrt{ } \\
\sqrt{ } \\
\sqrt{ } \\
\sqrt{ }\end{array}$ & $\begin{array}{l}\sqrt{ } \\
\sqrt{ } \\
\sqrt{ } \\
\sqrt{ }\end{array}$ & $\begin{array}{l}\sqrt{ } \\
\sqrt{ } \\
\sqrt{ } \\
\sqrt{ } \\
\sqrt{ }\end{array}$ \\
\hline Freight Operations & $\begin{array}{l}F 1.1 \\
F 1.2\end{array}$ & $\begin{array}{l}\sqrt{ } \\
\sqrt{ }\end{array}$ & $\begin{array}{l}\sqrt{ } \\
\sqrt{ }\end{array}$ & $\sqrt{ }$ \\
\hline Electrified Territories & $\begin{array}{l}\text { E1.1 } \\
\text { E1.2 } \\
\text { E1.3 }\end{array}$ & & & \\
\hline Total & & 44 & 24 & 25 \\
\hline
\end{tabular}




\section{DEVELOPMENT OF MODEL SYLLABI}

Section 6 discusses the process used in developing the three model syllabi. It begins with a general discussion of syllabi, and proceeds to address specific issues surrounding syllabi development for railroad dispatcher training. The section concludes with the presentation of a syllabus implementation tool that can be used with the model syllabi.

\subsection{Elements of a Syllabus}

A syllabus serves several purposes. It provides information to the trainees about the goals of the course, the content of the course, and what is expected or required from the trainees. It also aids the instructional designer in clearly and concisely organizing the course. A well-organized syllabus should provide a schedule or calendar of events, or some other meaningful organization of the course lessons, instructional units, or segments to be taught and learned. An effective syllabus will serve as a road map to the trainee, providing general direction about where trainees are going and useful information about how to get there, and will help the trainer follow the intended schedule of activities once the course has begun.

The primary focus in developing the model syllabi was on collecting and organizing the content within each syllabus; that is, what information should be included in each syllabus, and in what order the information should be presented. Although beyond the scope of this project, a complete syllabus should also contain the following elements:

- General course description/goals/objectives. A general description of the course should be included along with the overall course goals or objectives. Explicitly providing course goals or objectives helps the trainees to understand what is expected of them and delineates what the trainees will be able to do at the end of the training. It provides "the big picture." A description of the instructional methods that will be used may be included here as well.

- Course meeting times and location(s).

- Instructor information, including name(s) and contact information. Titles of instructors, office hours (if any), relevant phone numbers, mailbox locations (for homework assignments), email addresses, and emergency contact information should all be included.

- Information on the means of assessment, including quizzes, exams, written and other assignments, and their due dates. As much as possible, specific due dates should be 
included, and should be clearly tied to the schedule or calendar of events. Grading re-examination policies should be included here as well.

- Class participation, attendance and other class policy information. This information provides guidance to the trainees as far as what is expected of them during training. For example, specifying that class participation is required will facilitate greater two-way interaction between the instructor and trainees. Furthermore, such policies help the trainee in making difficult decisions about whether or not to miss a class or delay an assignment due to an extenuating circumstance.

- Any other relevant information and useful resources. It is important that the trainees be made aware of all resources that are available to help them succeed in their training and become dispatchers. Some examples include the availability of self-paced computerbased training modules for remedial training or assistance, access to a video library of a railroad's territory, or location of useful reference materials.

\subsection{Syllabus Development Process}

Syllabus outlines were developed for the initial dispatcher training syllabus and the periodic refresher training syllabus. However, upon consideration of the training activities involved in initial territory training, it was determined that a syllabus checklist would be more practical than a syllabus outline. Whereas the content and timeliness of classroom-based training can be controlled by the trainer/instructor, the events, timing, and sequence of activities on-the-job cannot be controlled. Once a trainee accompanies a dispatcher to learn on-the-job, the day's activities on the territory dictate what skills will be developed. Furthermore, trainees learning on different territories will be exposed to different dispatching activities at different times during their OJT. Thus, while one trainee may experience a train with an engine out of service on their first day, it may be a week before a second trainee experiences a similar situation. A checklist specifies all of the activities that must be addressed, but does not impose an order on when those activities must be learned.

Every railroad will develop a different syllabus, based on their unique environment and circumstances, and their respective syllabi will naturally reflect these unique differences as well. Consequently, the emphasis in this task was on the process for developing the model syllabi rather than on the final product (remember, the syllabi are model syllabi); similarly, the emphasis in developing the test designs was on the process rather than the final product (the test designs).

Some objectives, and consequently some syllabus instructional units, may not be included in the three model syllabi since the scope of the project is limited to the safety aspects of

dispatching trains. Objectives not directly related to safety, but important to dispatching trains or working in the railroad environment, should be added to a railroad's dispatcher training syllabus as warranted. An example is a railroad's policy regarding sexual harassment, which is important, but not directly related to the safety aspects of railroad dispatching. 


\subsubsection{Initial Development of Model Syllabi}

A bottom-up approach was used to organize the instructional objectives into instructional units and outlines for the initial dispatcher and periodic refresher training. Figure 4 presents a schematic for this bottom-up approach. The instructional objectives organized in subsection 5.2 served as the starting point for the development of each syllabus outline.

The objectives were then clustered, or grouped together, according to their content and informational similarity. Content-based category names were then given for each group of objectives. For example, for the initial training syllabus, which Figure 4 represents, 44 original objectives (bottom of figure) were grouped into 24 content-based categories (middle of figure). This process was repeated until a satisfactory set of six broad-based categories had been developed. This final set of categories became the instructional units for the training syllabus outline, and the content-based categories then became subheadings for the instructional units. The syllabus outline, also shown in Figure 4, shows the interplay and organization among the instructional objectives, the content-based categories (subheadings) and the instructional units.

This iterative process of organizing instructional objectives into more general categories served to impose a logical (based on informational content) order onto the objectives for the initial dispatcher and periodic refresher training syllabi. The number of iterations that it took to organize and group objectives into instructional units for each syllabus differed, depending on the number of objectives and the informational content contained therein. For example, it took two iterations to organize the instructional objectives into a syllabus outline for the periodic refresher training since relatively few skills were being addressed, while it took multiple iterations to develop the syllabus outline for initial dispatcher training, since it addresses a wide array of training skills.

Development of the syllabus checklist for initial territory training began by grouping instructional objectives based on informational similarity. However, after the instructional objectives were grouped into these categories, no further ordering was imposed (i.e., no further iterations). The categories became the instructional units, and then checklist items were developed that addressed each of the instructional objectives. Figure 5 provides a schematic for the development of the checklist items for the initial territory training syllabus. As shown in the figure, the instructional objectives feed into the instructional units, and both the instructional objectives and the instructional units feed into the checklist items. There was at least one checklist item developed for each instructional objective. A subject matter expert reviewed the checklist items, and after making several additions to the list, concluded that they were appropriate for use on-the-job. The checklist is meant to be comprehensive, but not exhaustive. Individual railroads are encouraged to refine the checklist items, and develop additional checklist items that address their unique situations.

\subsubsection{Industry Review and Validation}

After the initial set of syllabus outlines and checklist was developed, feedback was again solicited from a set of industry and ATDD union representatives. Reviewer feedback helped to 


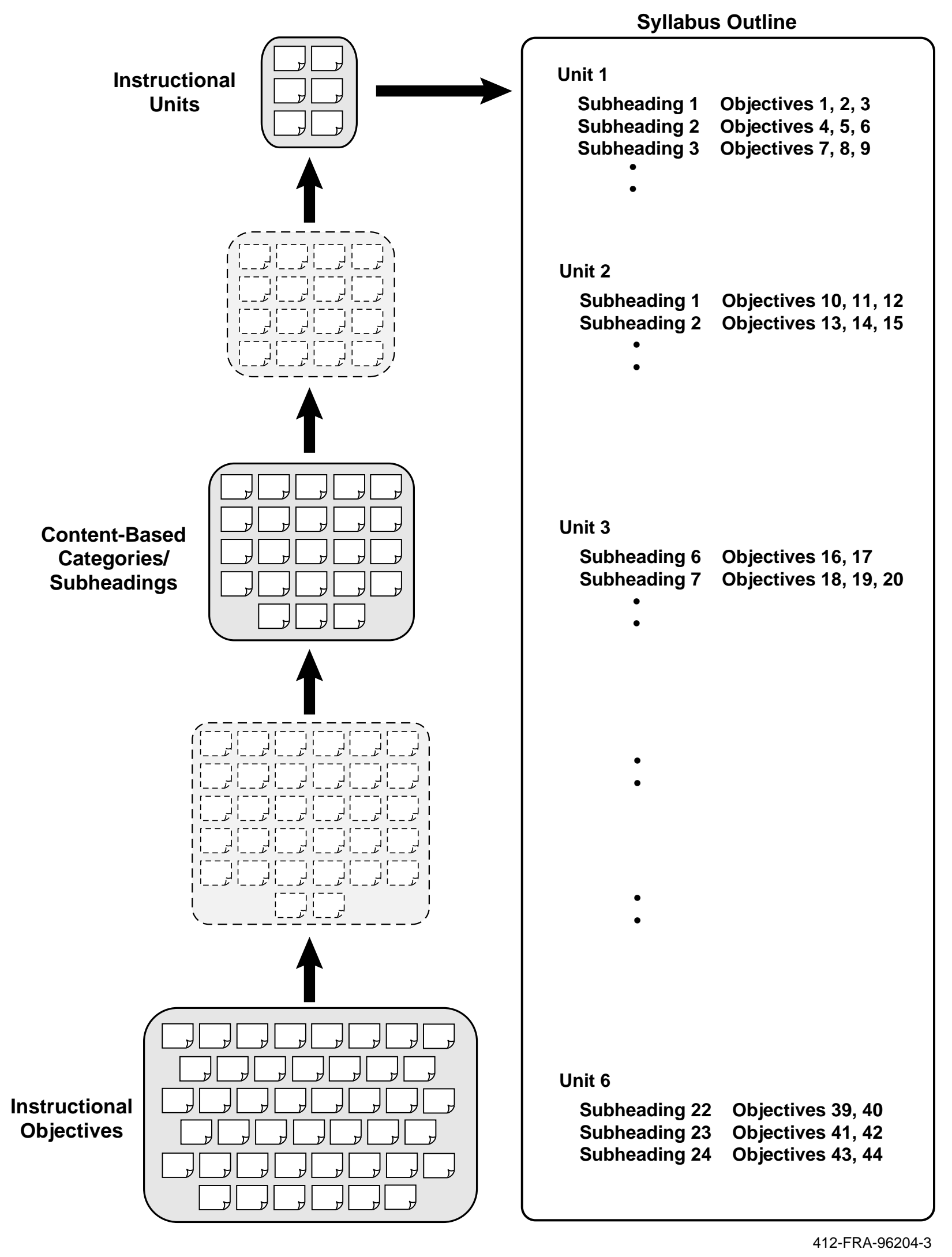

Figure 4. Schematic of the bottom-up approach used to develop the model syllabi 


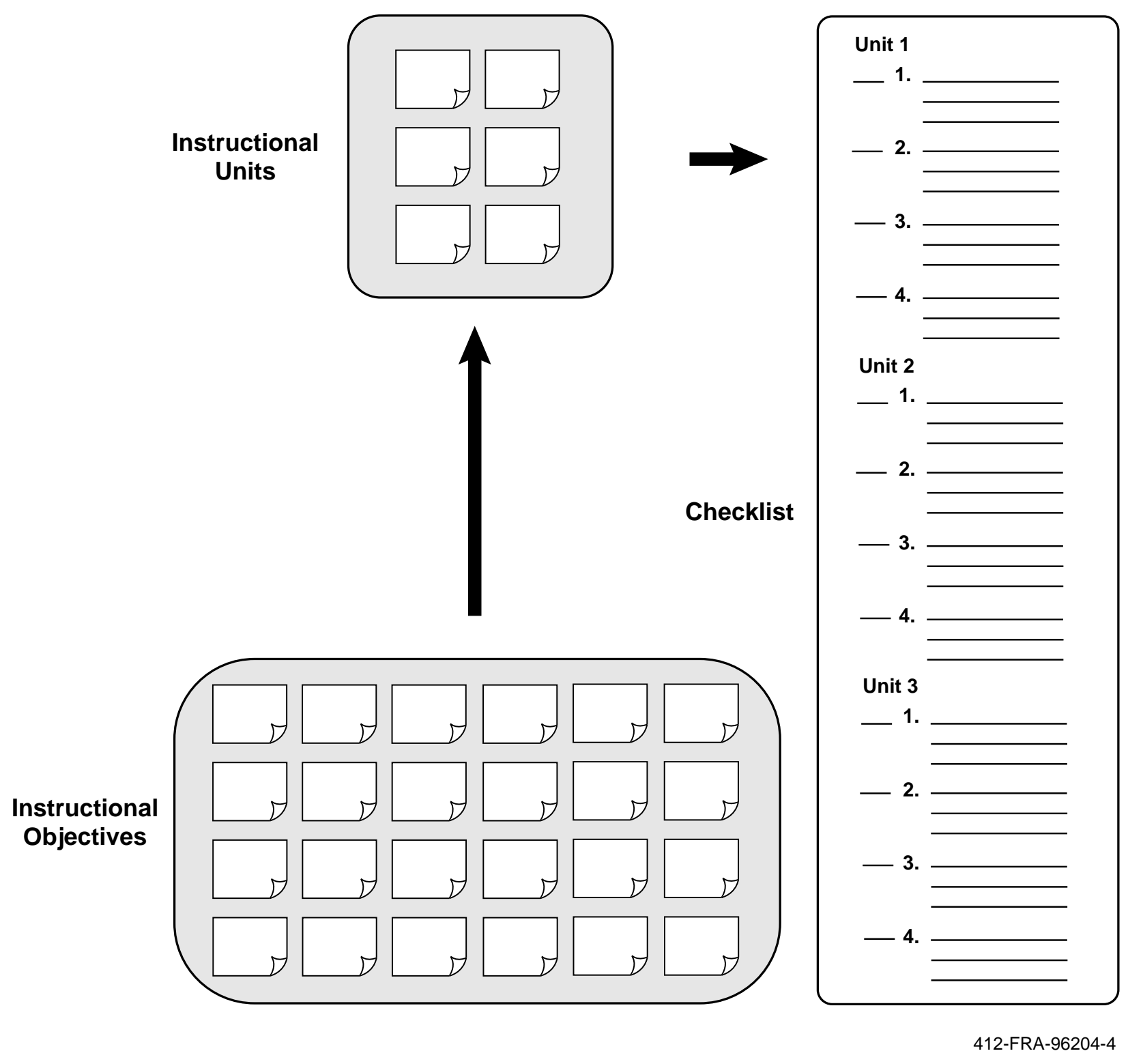

Figure 5. Schematic of the approach used to develop the initial territory training checklist 
hone the content, format and structure of the outlines and checklist. Reviewers were asked to focus their attention on the following concerns:

- Based on your experience and knowledge of railroad dispatching, is the organization of the outline logical and practical?

- Are there any omissions in instructional units and/or subheadings? Should we produce more subheadings for a particular instructional unit? Fewer?

- Do you have any general suggestions, comments or criticisms?

- Do you see value in using a syllabus checklist rather than following an outline when training dispatchers on their initial territory/ies?

\subsubsection{Issues Relevant to Developing and Using Syllabi}

In addition to developing the model syllabi, issues relevant to the development and implementation of each syllabus were examined. These issues included:

- Instructor preparation.

- Training delivery techniques.

- Training aids.

- Minimum training time to master the objectives.

- Prerequisite knowledge or experience.

- Optimal class size.

- Cost for delivering training.

- Cost for developing the training.

\subsection{Syllabus Implementation Tool}

To aid in determining which instructional objectives should be addressed first within a particular syllabus instructional unit, a tool was developed to classify instructional objectives into low or high complexity learning outcomes based on Bloom's taxonomy of educational objectives (ㅁ). The tool was implemented in the syllabus outlines for the initial dispatcher training and periodic refresher training syllabi. This tool is not applicable to the checklist for initial territory training, however, since ordering the instructional objectives is not an issue in its implementation.

Categorizing instructional objectives into low and high complexity learning outcomes enables a trainer or instructional designer to organize dispatcher training within a particular instructional unit based on the complexity of the learning outcomes of various instructional objectives. As a rule of thumb, skills based on less complex learning outcomes should be learned first, followed by skills that are based on more complex learning outcomes. An introduction to the syllabus tool is provided in this section, while its application is discussed more thoroughly in subsections 7.1 and 7.3. 
According to the level of learning outcome associated with each instructional objective (see subsection 4.2 for a discussion of Bloom's taxonomy) and the degree to which an objective required other objectives as prerequisites, relatively elementary or basic instructional objectives were placed in the bottom tier (low complexity). These objectives were essentially building blocks for other, more complex, instructional objectives within a specific job function. For example, it is important to understand track bulletins, railroad dispatcher bulletins, special instructions and other updates (objective 3.10) before learning how to authorize, dispatch and monitor track use by work crews (objective 3.11), since the updates will affect how work crews are dispatched and protected. It is important to note that the instructional objectives within each job function are not presented in any particular order, except where objectives related to the knowledge of a dispatching method or procedure naturally precedes objectives that relate to the application of that method or procedure. Objectives that were not directly considered building blocks to other objectives within a job function, and did not require other objectives to be learned first, were also placed in the bottom tier. For example, learning how to manage your own rule book with various addenda, corrections, and changes (objective 1.10) was categorized as a low complexity objective because it is not a direct building block to another objective, and it does not require other objectives to be learned first.

Complex instructional objectives that required other objectives to be learned first within a job function were placed in the top tier (high complexity). In general, objectives in the lower tier have simpler learning outcomes than those on the upper tier. Table 3 presents the results of classifying all of the instructional objectives into either a low or high complexity level based on their learning outcomes. Instructional objectives are separated by general job function and listed by number in Table 3 . 
Table 3. Two-tier classification of instructional objectives

\begin{tabular}{|c|c|c|c|c|}
\hline \multirow[b]{2}{*}{ Job Function } & \multirow[b]{2}{*}{ Objective No. } & \multirow[b]{2}{*}{ Learning Outcome } & \multicolumn{2}{|c|}{ Complexity } \\
\hline & & & Low & High \\
\hline General Prerequisites & $\begin{array}{l}1.1 \\
1.2 \\
1.3 \\
1.4 \\
1.5 \\
1.6 \\
1.7 \\
1.8 \\
1.9 \\
1.10\end{array}$ & $\begin{array}{l}\text { Comprehension } \\
\text { Comprehension } \\
\text { Comprehension } \\
\text { Comprehension } \\
\text { Application } \\
\text { Application } \\
\text { Application } \\
\text { Application } \\
\text { Application } \\
\text { Knowledge }\end{array}$ & $\begin{array}{l}\sqrt{ } \\
\sqrt{ } \\
\sqrt{ } \\
\sqrt{ }\end{array}$ & $\begin{array}{l}\sqrt{ } \\
\sqrt{ } \\
\sqrt{ } \\
\sqrt{ } \\
\sqrt{ }\end{array}$ \\
\hline Planning & $\begin{array}{l}2.1 \\
2.2 \\
2.3 \\
2.4 \\
2.5 \\
2.6\end{array}$ & $\begin{array}{l}\text { Application } \\
\text { Synthesis } \\
\text { Evaluation } \\
\text { Application } \\
\text { Evaluation } \\
\text { Synthesis }\end{array}$ & $\sqrt{ }$ & $\begin{array}{l}\sqrt{ } \\
\sqrt{ } \\
\sqrt{ } \\
\sqrt{ } \\
\sqrt{ }\end{array}$ \\
\hline Manage Track Use & $\begin{array}{l}3.1 \\
3.2 \\
3.3 \\
3.4 \\
3.5 \\
3.6 \\
3.7 \\
3.8 \\
3.9 \\
3.10 \\
3.11 \\
3.12 \\
3.13 \\
3.14\end{array}$ & $\begin{array}{l}\text { Comprehension } \\
\text { Knowledge } \\
\text { Knowledge } \\
\text { Comprehension } \\
\text { Application } \\
\text { Comprehension } \\
\text { Application } \\
\text { Application } \\
\text { Application } \\
\text { Comprehension } \\
\text { Application } \\
\text { Knowledge } \\
\text { Synthesis } \\
\text { Synthesis }\end{array}$ & $\begin{array}{l}\sqrt{ } \\
\sqrt{ } \\
\sqrt{ } \\
\sqrt{ } \\
\sqrt{ }\end{array}$ & $\begin{array}{l}\sqrt{ } \\
\sqrt{ } \\
\sqrt{ } \\
\sqrt{ } \\
\sqrt{ } \\
\sqrt{ } \\
\sqrt{ }\end{array}$ \\
\hline Manage Unplanned and Emergency Events & $\begin{array}{l}4.1 \\
4.2 \\
4.3 \\
4.4 \\
4.5\end{array}$ & $\begin{array}{l}\text { Application } \\
\text { Comprehension } \\
\text { Application } \\
\text { Evaluation } \\
\text { Application }\end{array}$ & $\begin{array}{l}\sqrt{ } \\
\sqrt{ }\end{array}$ & $\begin{array}{l}\sqrt{ } \\
\sqrt{ } \\
\sqrt{ }\end{array}$ \\
\hline Record Keeping and Report Writing & $\begin{array}{l}5.1 \\
5.2 \\
5.3 \\
5.4 \\
5.5 \\
5.6 \\
5.7\end{array}$ & $\begin{array}{l}\text { Knowledge } \\
\text { Application } \\
\text { Application } \\
\text { Knowledge } \\
\text { Application } \\
\text { Application } \\
\text { Application }\end{array}$ & $\sqrt{ }$ & $\begin{array}{l}\sqrt{ } \\
\sqrt{ } \\
\sqrt{ } \\
\sqrt{ } \\
\sqrt{ }\end{array}$ \\
\hline Freight Operations & $\begin{array}{l}\mathrm{F} 1.1 \\
\mathrm{~F} 1.2\end{array}$ & $\begin{array}{l}\text { Knowledge } \\
\text { Application }\end{array}$ & $\sqrt{ }$ & $\sqrt{ }$ \\
\hline Electrified Territories & $\begin{array}{l}\text { E1.1 } \\
\text { E1.2 } \\
\text { E1.3 }\end{array}$ & $\begin{array}{l}\text { Comprehension } \\
\text { Comprehension } \\
\text { Application }\end{array}$ & $\begin{array}{l}\sqrt{ } \\
\sqrt{ }\end{array}$ & $\sqrt{ }$ \\
\hline
\end{tabular}




\section{MODEL SYLLABI}

Model syllabi are presented for three different training programs: initial dispatcher training, initial territory training, and periodic refresher training. Each is discussed, in turn, below.

\subsection{A Model Syllabus for Initial Dispatcher Training}

A model syllabus for initial dispatcher training is presented in this section. First, the development of the syllabus is discussed, then the syllabus is presented, and finally, issues relevant to using the model syllabus are discussed.

\subsubsection{Syllabus Development and Use}

The model syllabus for initial dispatcher training was developed on the premise that trainees had no prior railroad experience and are being trained to dispatch on a large freight railroad. Forty-four instructional objectives were identified. The 44 objectives were grouped into 24 distinct content-based categories. The content-based categories were then reviewed for commonality by three raters. As a result of this review, several iterations of organizing the content-based categories occurred. Eventually, six instructional units were developed, accounting for all 24 content-based categories and all 44 instructional objectives.

The resulting syllabus outline is presented in Table 4. The outline consists of six instructional units and 24 subheadings that directly correspond to the content-based categories. The instructional units and subheadings are arranged in such a way as to generally progress from more fundamental dispatcher skills to more complex ones, with the exception of administrative functions, which have been placed last. In general, if the order of the syllabus outline is followed, new learning should build on previous learning.

All 44 instructional objectives are included in the second column of Table 4. Each instructional objective corresponds to a subheading (formerly a content-based category) in the syllabus outline. In several cases, instructional objectives are associated with more than one subheading. For example, since knowledge of operating and safety rules plays such an important part in railroad dispatching, the objective related to knowledge of rules, objective 1.4, is associated with almost every subheading. Of course, different rules will be learned depending on which part of the syllabus is being covered. As a second example, the following two objectives are associated with multiple subheadings because they are applicable in several parts of the syllabus outline: understand all forms of movement and protective authority used within the limits of the territory being dispatched (objective 3.4) and demonstrate the ability to correctly issue all forms of train movement and protective authority used within the limits of the territory being dispatched (objective 3.5). 
Table 4. Syllabus outline for initial dispatcher training

Instructional Units and Subheadings

Instructional Objectives

1. Introduction to dispatching

1.1 Introduction to the railroad: business practices and the $1.1,1.2,1.3$

operating environment

1.2 Introduction to the operating rules

1.3 Railroad safety rules and applicable FRA safety

1.4

regulations (e.g., HOS, drug and alcohol testing)

2. Personal, interpersonal, and management skills

2.1 Communications and interpersonal skills

2.2 Adapting to the lifestyle of a dispatcher

$1.5,1.6,1.7$

$1.8,1.9$

3. Operating characteristics

3.1 Operating characteristics of rail equipment (including

rolling stock, train handling, brakes, vehicle dynamics and control)

3.2 Hazardous materials (General)

$1.4,3.2,3.3$

$1.4, \mathrm{~F} 1.1$

4. The mechanics of dispatching: Controlling and protecting track occupancy

4.1 Blocks and signal systems

4.2 CTC

4.3 Track warrants/Form D's/Direct Train Control

$1.4,3.4,3.5,3.6$

$1.4,3.4,3.5,3.6$

$1.4,3.4,3.5$

4.4 Speed restrictions, bulletins and special instructions

4.5 Blocking devices

$1.4,3.4,3.5,3.6,3.9,3.10$

$1.4,3.4,3.5,3.6,3.8$

4.6 Non-shunting equipment and work crews (including the Roadway Worker Protection rules)

4.7 Communications systems and CADS

$1.4,3.11$

$1.4,3.4,3.5,3.6$

4.8 Physical characteristics of a territory: track mechanics, switches, crossings, derails.

5. The art of railroad dispatching

5.1 Managing track use

5.2 Arranging train meets

5.3 Planning beyond the limits of your territory

5.4 Managing train and engine crew logistics

5.5 Managing unplanned and emergency events

5.6 Hazardous material transport (Specific)

3.1

6. Administrative functions

6.1 Manage documents

$2.4,2.2,2.3,2.5, \mathrm{~F} 1.2$

$1.4,2.3,2.4,3.13,3.14, \mathrm{~F} 1.2$

$1.4,3.7$

2.6

$1.4,3.12,4.1,4.2,4.3,4.4,4.5$

$1.4, \mathrm{~F} 1.1$

1.10

$1.4,2.1$

of a shift

6.3 Record keeping and report writing

$1.4,5.1,5.4,5.2,5.3,5.5,5.6,5.7$ 
The ordering of the instructional objectives within each subheading of the syllabus outline is based on the results of the syllabus implementation tool described in subsection 6.3. It is recommended that objectives that fall in the "low" complexity category be addressed before objectives that are classified as "high" complexity for each of the syllabus units or content-based categories. For example, in subheading 5.5 in Table 4, entitled "Managing unplanned and emergency events," the following objectives should be addressed first, according to Table 3 , because they have less complex learning outcomes: understand the railroad's operating and safety rules (objective 1.4); know where to find operating and safety rules (objective 3.12) when needed; demonstrate the ability to respond to wayside defect detectors (objective 4.1); and understand the procedure to implement in response to an unplanned or emergency event (objective 4.2). These four objectives provide a foundation for learning the objectives with more complex learning outcomes: demonstrate the ability to implement a procedure in response to an unplanned event or emergency (objective 4.3), formulate a plan of action when encountering an event for which no procedure has been established (objective 4.4), and demonstrate the ability to compensate for lost capabilities when a computer or system outage occurs within the dispatching center (objective 4.5).

\subsubsection{Issues Relevant to Initial Dispatcher Training}

There are a number of issues or considerations related to implementing the syllabus outline for an initial dispatcher training program. Issues that directly or indirectly affect use of the syllabus in training dispatchers include:

1. Instructor preparation.

2. Training delivery techniques.

3. Training aids.

4. Minimum training time to master objectives.

5. Prerequisite knowledge or experience.

6. Optimal class size.

7. Costs for developing and delivering the training.

Each of these issues is addressed below, beginning with a general discussion of the issue, and followed by specific examples.

\subsubsection{Instructor Preparation}

There are two recommendations for instructor preparation. First, subject matter experts (SMEs) should be used whenever possible to impart information in their particular area of expertise. These individuals can provide a wealth of valuable experience, insight, and "lessons learned." In many of the railroad dispatcher training programs that were visited, the instructors were veteran railroad dispatchers. In addition, the use of guest SMEs (e.g., signal maintainer, railroad policeman, or train and engine crew member) to impart specific knowledge can enhance the learning experience because the instructor is able to offer personal real life experiences. 
The second recommendation is to ensure that instructors have had some background in delivering training, since training requires specific skills. Many trainers were dispatchers prior to becoming instructors, and may have never received formal training on how to deliver instruction. To make training most effective, it is recommended that all instructors complete a "train the trainer" program so that they are properly equipped with the appropriate instructional methods and techniques to railroad dispatchers.

\subsubsection{Training Delivery Techniques}

There are several training delivery techniques that may be used to convey information to trainees during the course of initial training. They include:

- Lectures.

- Discussion.

- Role-play.

- Field trips.

- Computer-based training (CBT).

- Simulation.

Each of these methods has its advantages and disadvantages. According to (ㄱ), the decision to use a particular delivery technique depends primarily on four factors:

1. Practical constraints such as availability of equipment, facilities, resources and funding.

2. The learning context and type of task that is to be learned (e.g., rules, procedures, or decision-making skills).

3. A technique's attributes (the ability of a technique to facilitate certain types of learning).

4. Trainee or learner characteristics.

In addition to conveying the necessary information that trainees need to develop dispatching skills, training must also allow the student to practice the skills that he or she will use on the job. While some training delivery techniques will be more appropriate for conveying new information to trainees, other techniques will be more appropriate for enabling trainees to practice newly developed skills.

Lectures are appropriate when introducing concepts, rules, and procedures. According to (즈), some positive attributes of people as a method of, or medium to, delivering training include the fact that people are extremely interactive, adaptable, and flexible, and people are capable of possessing empathy toward trainees in challenging or difficult training situations. However, people are extremely expensive compared to other delivery methods. Lectures may be used, for example, when introducing rules or exposing trainees to the operating characteristics of rail 
equipment for the first time. Lectures may also be ideal for introducing trainees to the various types of movement authorities used by the railroad.

Discussions are useful when trainees must learn difficult concepts or procedures, or when there are ambiguous rules involved with learning a skill. Discussions enable a trainee's specific concerns and questions to be addressed in detail due to the less structured nature of a discussion. Discussions can also be used by an instructor to implement generative learning strategies (ㅁ), where a trainee takes an active and constructive role in learning a particular skill, concept, or procedure by incorporating new information with prior information in order to generate new associations between them ( $\underline{3})$, rather than having the information and associations presented to them, as in a lecture. Generative learning through discussion may take longer than other types of learning; however, the "depth of learning" is deeper once the skill, procedure, or concept is learned. Discussions may be used after trainees have practiced a difficult or complicated skill, such as managing a minor emergency, which may require a series of dispatcher-initiated actions. Correct and incorrect trainee responses can be discussed among the class and instructor, and alternative approaches to a solution (there is usually more than one way to resolve the problem) can also be explored.

Role-playing may be useful when training interpersonal and communications skills, such as when a dispatcher must communicate to an irate, threatening individual who demands track time when there is none available. Role-playing may also be very effective in training dispatchers how to manage unplanned and emergency events. However, instructors are cautioned that roleplaying, when conducted in front of others, can cause some individuals to become distracted and anxious by feelings of embarrassment. If this is a problem, an alternative is to conduct roleplaying between a trainer and a trainee, or even between two trainers so that trainees learn vicariously through demonstration. It is also beneficial to have a backup technique that can be used in case trainees are uncomfortable with role-playing. Training aids can be used in conjunction with role-playing to produce a more realistic environment.

Field trips are appropriate when hands-on experience is warranted, or when a trainee would benefit most from fully experiencing a particular situation. For example, field trips may be used to introduce trainees to a dispatching office and to maintenance and other field departments (both to meet people and to see the physical components of a department). Field trips also provide a trainee the opportunity to experience first-hand the extreme noise levels in the cab.

One of the most recent developments in delivering training involves the use of computers. Computer-based training, or CBT, has several advantages over more traditional instructor-based training (adapted from ())):

- Computers can present information consistently and tirelessly, in different locations and at different times.

- Computers have multimedia capabilities, including sound, video, graphics, and text. 
- Computers can store and present an extremely large amount and variety of information; and computers can seamlessly record all of a trainee's responses.

- Computers have the ability to train on an individual or a group-based level.

- Immediate and individualized feedback and evaluation of trainee performance.

CBT has several potential uses in dispatcher training:

- Rules, concepts, and procedures training.

- Problem-solving (e.g., resolve conflicting track use requirement demands).

- Remedial training.

- Skills practice (e.g., properly complete a train order such as a Form D).

When using CBT, however, it is important to maintain some degree of instructor interaction to provide guidance, help, and support, and to answer any questions that the trainee may have about the CBT, or that the CBT cannot answer. CBT does not completely substitute for the instructor; rather, it supports an instructor's effort in training individuals to become railroad dispatchers. As such, it should be viewed as an instructor's tool.

In order to facilitate the transfer of learning from the training environment to the dispatching environment, it is important to make the training environment as similar to the actual dispatching situation as possible. Interactive simulators offer the closest experience to the actual dispatching environment, and thus, they are extremely useful in training dispatchers. Simulators are ideal for trainee practice of newly acquired skills, particularly high-level skills, such as executing train movement authorities and scheduling meets and passes.

It is important to note that these delivery techniques are not mutually exclusive, and in fact, all of these techniques can be employed over the course of a dispatcher training program. For example, lectures may be used to introduce basic materials and information; field trips may be used to provide hands-on experience; and discussions may be used to articulate or clarify a difficult concept or procedure. Finally, simulation may be employed so that trainees get the opportunity to practice the skills they will use on the job.

For further discussion of different training delivery techniques and their attributes, and for guidance in selecting a particular technique, see ().

\subsubsection{Training Aids}

Training aids facilitate an instructor's lesson plans, and trainees' learning, by providing additional media in which to convey information to trainees. Training aids also facilitate trainee practice of newly developed skills. Aids and delivery techniques are both training media, and there is no clean division between the two. For example, CBT is both a training delivery technique and a training aid. What is important is that both facilitate instruction and learning. 
Instructors have a variety of training aids available to them for use when training new dispatchers. They include:

- Tools of the trade (e.g,. a train sheet, train order forms, rule book).

- Printed text.

- Slides.

- Pictures and drawings.

- Videotapes.

- Computers/CBT.

- Mockups.

- Games.

- Paper and pencil simulation.

- Interactive simulation.

Original materials should be used whenever possible to give trainees experience with the actual materials that they will use when they dispatch. Experience with the actual materials facilitates transfer of training from the classroom to the dispatching office. A copy of a Movement Permit Form (Form D) is presented in Figure 6. Actual Movement Permit Forms should be used when trainees are learning how to properly complete and issue them.

Printed text, which is inexpensive to produce and duplicate, offers a portable, permanent, and easily accessible reference and record. Printed text is helpful when learning verbal information such as rules and procedures. Information that is referred to over and over, or that is infrequently accessed, but critical, should be printed and provided to trainees for their reference.

Video, slides, pictures and other graphics are particularly suitable when it is necessary or advantageous to convey visual attributes or spatial relationships. Still graphics such as slides, photographs, and drawings may be used, for example, if learning signal aspects and indications, or when learning designs of different highway-rail crossing warning devices. Slides, photographs, and drawings can provide close-up views that show enlarged details ( $\underline{3})$. Videos are ideal when conveying information that requires movement to understand, such as when learning railroad car coupling, or the physical aspects of track switching. Videos should also be used when it is advantageous to zoom in and out for close-up and telephoto views, or if it is beneficial to show elapsed or compressed time periods ( $\underline{3})$, such as when demonstrating the frequency with which cars illegally cross a busy grade-crossing. Use of visual aids, both still and motion, also reinforces verbal knowledge learning.

Computers and CBT, as training aids rather than as standalone delivery techniques, can be used to provide multimedia capabilities to a lecture. A discussion of CBT is provided in subsection 7.1.2.2. For further discussion of the attributes of different training aids, see (ㄱ).

\subsubsection{Minimum Training Time to Master Objectives}

Current industry practice regarding adequate training time provides guidance as to the minimum time required to master training objectives. The range of initial dispatcher training 


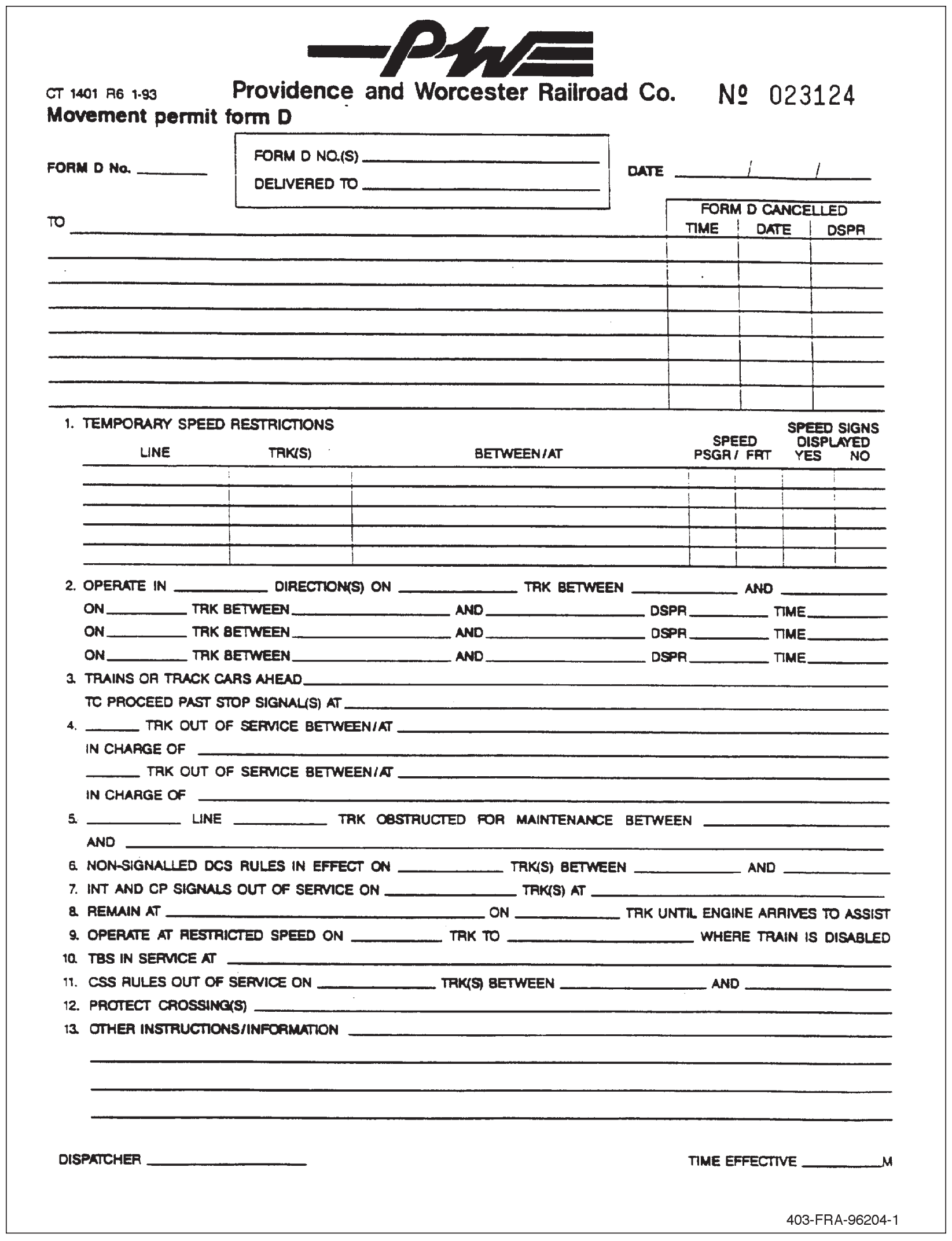

Figure 6. Copy of a blank Movement Permit Form (Form D) used by The Providence and Worcester Railroad Company 
times for the programs that were examined in conjunction with this project was between three and 22 weeks. Initial dispatcher training programs lasted an average of 11 weeks. All of the Class 1 railroads that were examined devoted at least 10 weeks, and had an average of 15 weeks, while the shortline and regional railroads devoted anywhere from three to six weeks to their initial training. Based on current practice, it is recommended that railroads devote at least 10 weeks to initial dispatcher training, corresponding to both the minimum time spent by the Class 1 railroads that were visited, and the average number of weeks that all of the railroads visited spent on initial dispatcher training. It is most important that the skills be acquired, regardless of the time it takes.

\subsubsection{Prerequisite Knowledge or Experience}

It was found that until recently most dispatchers came from the ranks of clerks and tower operators. However, this career path no longer exists in most railroads because centralized, computer-aided dispatching systems have enabled railroad dispatchers to do the jobs that clerks and tower operators once did, and thus, railroads have eliminated many of these jobs. As a result, railroads are now hiring individuals "off the street" with no railroad-specific experience to fill their need for railroad dispatchers. Consequently, training programs must start with very basic information about railroading, including an introduction to the various units or departments that make up a railroad, and lessons on railroad terminology. Previously the clerks and tower operators had this knowledge and used it as a foundation when they began their training to become railroad dispatchers. Training programs can no longer count on this foundation.

The syllabus for initial dispatcher training assumes that the trainees have no prior railroad experience, and therefore the prerequisites necessary to learn how to dispatch trains are included in the syllabus. If a class of trainees has prior railroad experience, some of the prerequisite objectives specified in the syllabus may be omitted. All trainees should have a basic foundation or framework which they can use when learning how to dispatch, whether through formal training at the beginning of the dispatcher course, or based on previous railroad experience. Even if an entire class of trainees has prior railroad experience, however, the "Personal and interpersonal skills" instructional unit, including objectives on communications skills and adapting to the lifestyle of a dispatcher, should not be omitted from their training. Furthermore, no rules training should ever be omitted, regardless of prior railroad experience.

\subsubsection{Optimal Class Size}

The optimal class size depends primarily on the resources available (e.g., access to a simulator, or classroom size). The maximum number of trainees in the eight programs that were examined was 18. Johnson County Community College (JCCC), which offers a dispatcher's training program in conjunction with Burlington Northern Santa Fe, limits their class size to 15. Availability of interactive simulators is probably the greatest constraint. Based on information from site visits, it is recommended that when interactive simulators are available, no more than two students should share a simulator so that each can obtain sufficient exposure and hands-on experience with the simulated system. Thus, for example, if a railroad owns five training simulators, the class size would be limited to 10 trainees. 


\subsubsection{Costs for Developing and Delivering Training}

Information about the costs for developing and delivering initial dispatcher training was gathered from several different sources, including a few of the programs that were visited and some non-railroad organizations that provide at least some dispatcher training or CBT development.

Development costs of initial dispatcher training primarily involve the time and salaries of those involved in the development process, typically subject matter experts (dispatchers, chief dispatchers, MOW department supervisors, etc.), instructors, and operations managers. Some of the railroads that were visited used an outside consultant, at least part-time, to help them organize and structure their training program. One rule of thumb for calculating training development costs, provided by a trainer in the Federal Aviation Administration (FAA), is to estimate $30 \mathrm{hr}$ of development time for every hour of finished training. Administrative costs should also be factored into the overall development costs.

Development of CBT involves the conversion of expert-based skill sets into computer-based instructional units or modules. The primary costs of CBT development are, thus, associated with the salaries of subject matter experts, who must help convey the technical aspects (skill sets) of railroad dispatching, and the salary(ies) of one or more computer programmers, who can convert the information into computer-based instruction. Many companies specialize in customdesigned CBT, and can help a railroad develop their own CBT program. Hardware and software expenses must also be considered, though these costs have steadily dropped over the last few years.

As an example in the lower range of CBT development costs (and scope), a joint effort by a freight and a passenger railroad to develop a single CBT module for instruction on dispatching over automatic block signal territory cost about $\$ 20,000$. As an example of CBT development costs in the upper range, one railroad that was visited was in the process of developing a comprehensive CBT program that will cost, in the end, approximately $\$ 400,000$ in salaries and consultant fees. The program will cover multiple topics, including safety and operating rules, lessons on dispatcher operating practices, and introductions to the different railroad operations departments and various types of movement authorities used by that railroad.

Implementation costs for $\mathrm{CBT}$ are minimal once the $\mathrm{CBT}$ has been developed and the hardware has been acquired. Costs include hardware maintenance, software upgrades, and troubleshooting support.

Smaller railroads may choose to use non-railroad resources for training. Two organizations offering training are JCCC and the Railway Education Bureau. A railroad may elect to send newly hired dispatcher trainees to JCCC for their training. JCCC's dispatcher training program costs just under $\$ 4000$ per trainee, and includes both initial training and OJT (14 and 10 weeks, respectively). The Railway Education Bureau offers a variety of self-paced lessons and workshop-style courses for railroad skills training. Though the Bureau does not provide dispatcher-specific training, it does offer rules training on both NORAC and GCOR rules. A 
railroad may choose to contract out this portion of their dispatcher training. Each rules training workshop costs about $\$ 4000$ and covers up to 15 attendees.

\subsection{A Model Syllabus for Initial Territory Training}

Initial territory training concentrates on applying those skills that have been acquired during initial dispatcher training. Initial territory training consists of two components: learning the physical characteristics of a territory for which a dispatcher will be responsible, and learning how to dispatch that particular territory. Since so much of learning the specific physical characteristics of a territory depends upon the unique environment and circumstances in which the territory is situated, it was found to be more useful to focus the discussion in this section on that portion of initial territory training that covers learning how to dispatch a particular territory.

While initial dispatcher training occurs in a controlled environment with lessons that can be well-organized and planned in advance, most of initial territory training (the portion concentrating on how to dispatch on a particular territory) takes place at a dispatcher's desk, "onthe-job," where it is subject to the events and circumstances of a particular territory, on a particular day, during a particular period of time. Dispatchers training at different desks will most likely experience different situations at different stages of their training. Since the events that transpire during a shift cannot be controlled by an instructor, and because every territory is different in its characteristics and its instructor (i.e., the current dispatcher), an approach other than a syllabus outline must be used to organize initial territory training. A checklist that mirrors a syllabus in basic content, but that does not prescribe an order or sequence of accomplishment, was therefore developed. A checklist provides guidance and standardization across different training situations, but it also allows for flexibility in the order/sequence in which the training occurs. The checklist developed in this section addresses both learning the physical characteristics of a territory as well as learning how to dispatch on that territory; however, the discussion focuses primarily on the portion of initial territory training that covers learning how to dispatch on a particular territory. Issues related to learning the physical characteristics of a territory are briefly discussed where relevant.

\subsubsection{Checklist Development and Use}

The process of developing the initial territory checklist began with the set of instructional objectives identified in subsection 5.2 for initial territory training. A bottom-up approach similar to that used in the development of the initial dispatcher training syllabus was taken to organize the 24 objectives into six broad-based categories that became instructional units. Checklist items were then developed for each of the instructional units based on the instructional objectives. Figure 5 provides a graphic representation of the process used to develop the syllabus checklist for initial territory training.

The checklist items specified in this section should be used as a model for railroads to develop their own checklist. Depending on the unique characteristics of a particular railroad, checklist items will be added or modified. For example, additional items which cover specific details about physical characteristics of a territory should be added to the checklist. Such items 
can be used by an instructor to make sure that the trainee has learned all of the critical pieces of information related to the physical characteristics of a territory prior to beginning their training at a dispatcher's desk. The checklist items that cover physical characteristics that are provided in this report cover some of the basic information that must be learned, but there likely will be many other characteristics that are unique to the territories of different railroads, and therefore, must be added to the checklist. In fact, it is likely that the checklist will have to be modified for every territory within a railroad to ensure that all of the differences across territories are covered. The final checklist should ensure that trainees (a) know the specific physical characteristics of their territory, and (b) know how to use, or apply, this information, as well as the information from the initial dispatcher training, when dispatching.

At the end of each checklist item there is a number which refers to the instructional objective that the checklist item addresses. Objectives are categorized into six (6) general units (in bold). These units are provided to help the dispatcher-instructor organize their observations of, and instruction to, the trainee. The checklist, presented in Table 5, includes a list of some example checklist items that could be included in initial territory training. Railroads are strongly encouraged to add many more items in their own checklists.

Dispatcher-instructors should check off, initial, and date each checklist item as the trainee accomplishes the associated activities. Trainees should be familiar with the checklist as well, and should help the dispatcher-instructors check off the items as the trainees complete each item. It is not necessary for trainees to complete the activities in a prescribed order, however; it is important that trainees become proficient at all of the activities by the end of the initial territory training. If a particular item is not applicable to a particular situation at a desk, the dispatcherinstructor may write N/A (not applicable) for that item.

\subsubsection{Issues Relevant to Initial Territory Training}

Issues that directly or indirectly affect use of the proposed checklist in training dispatchers on their initial territory include:

1. Instructor preparation.

2. Training delivery techniques.

3. Training aids.

4. Optimal class size.

5. Minimum training time to master objectives.

6. Costs for developing and delivering the training.

7. Accountability.

Each of these issues is discussed in detail, below. Prerequisite knowledge does not warrant further discussion, though, since it is assumed that trainees have acquired the necessary skills to dispatch by the time that they begin their initial territory training. 


\section{Table 5. Checklist for initial territory training}

1. Physical characte ristics of a te rritory

Retrieve information about the physical characteristics of the territory. (3.1)

Identify all bridges, tunnels, and ruling grades along the territory. (3.1)

Identify all grade-crossings along the territory. (3.1)

Recall any local/municipal restrictions (e.g., at grade-crossings) and where they apply (3.1)

Point out major yards, turnouts, sidings, and diamonds along the territory. (3.1)

Point out crew change points, away-from-home terminals, initial terminals, equipment layover facilities, and crew reporting points. (3.1)

Locate all passenger stations along the territory. (3.1)

Identify major customers along the territory, and the types of commodities that are moved across the territory. (3.1)

Properly place the helper engine (on the head-end to pull or on the rear to push). (3.1)

Explain the ramifications of the decision to pull or push the train. (3.1)

Determine train and engine crew qualifications on the territory. (3.1)

Determine when a pilot is necessary to guide a train over portions of territory on which the crew is not qualified. (3.1)

2. Familiarity with the dispatching desk

Identify the location of railroad operating and safety rules and emergency procedures information when needed. (3.12)

Identify who to apply to with questions/clarifications/interpretations of rules. (3.12)

Identify where to find additional information about the rolling stock (locomotives, car types, brake mechanics, etc.), or who to ask, when they lack the relevant knowledge necessary to make a decision regarding the rolling stock. (3.3)

Competently use each piece of equipment on the dispatcher's desk (computers, radios, phones, train sheet, etc.). (3.12)

3. The mechanics of dispatching: Controlling and protecting track occupancy

Correctly issue all forms of train movement and protective authority used within the limits of the territory being dispatched. [List every form of movement/protective authority used on the territory and provide a line to be checked off for each authority] (3.5)
- (List movement authority No. 1)
(List movement authority No. 2)
(List movement authority No. 3, etc.)

Apply and remove blocking devices. (3.8)

Issue and remove speed restrictions. (3.9)

Protect MOW crews, contractors, and others who work on or near the tracks (includes RWP rules). (3.11) 


\section{Table 5. Checklist for initial territory training (continued)}

\section{The art of railroad dispatching}

Read and interpret track usage requests and train schedules. (2.2)

Prioritize competing track users. (2.3)

Use planning aids (e.g., string chart) to schedule a meet or pass between two trains. (2.4)

Task prioritization. That is, when carrying out the day's activities, has the dispatcher demonstrated that they are able to avoid unnecessary delays or wrongly prioritize competing trains or requests for track time. $(2.3,2.5)$

Communicate relevant information that a dispatcher on an adjacent territory needs when a train departs the territory. (3.7)

Estimate travel times between two locations for a variety of train make-ups over a variety of road, track, and operating conditions. i.e., Can the trainee predict meets and passes well in advance in order to plan accordingly. (3.13)

Estimate train running times between stations, control points, interlockings, mileposts, and other railroad identifying points. (3.13)

Identify with the proper terms locations identified by their local or slang names, phrases and terms. (1.3)

Identify unofficial identifying points by their slang reference. (1.3)

Prioritize train meets with minimal delay in accordance with priorities established by schedule, crew on-duty times (e.g., HOS limitations), priority of the train's contents, in order to match up with a relief crew, etc. (3.14)

Monitor a train and engine crews' HOS. (2.6)

Provide relief to a train and engine crew whose HOS has expired. (2.6)

Identify when a helper engine is required. (F1.2)

Respond to a wayside defect detector that reports a problem. (4.1)

Manage an emergency (contact the necessary people; instruct the train and engine crew aboard the train, and others involved; coordinate rescue/evacuation/precaution activities, etc.). (4.3)

Develop and carry out contingency plans when unplanned and/or emergency events occur. (4.3)

5. Hazardous mate rials

List precautions to be taken when transporting hazardous materials ( $F 1.1)$

Explain emergency procedures to take in the case of a hazardous materials-associated derailment/collision. (F1.1)

Identify where, or how, to retrieve information about the specific contents of the hazmat car(s). (F1.1)

Use all precautions in managing trains that carry hazardous materials. (F1.1)

6. Administrative duties

Assume/relinquish dispatcher duties at the beginning or end of a shift. (2.1)

Initiate and complete records using the computer. (5.2)

Initiate and complete reports using the computer. $(5.5,5.7)$

Initiate and complete reports manually (in event of a computer/power failure). (5.6) 


\subsubsection{Instructor Preparation}

It is important for dispatcher-instructors to have at least some background in training methods. Railroads typically select dispatchers who have at least several years of experience to serve as dispatcher-instructors for the OJT portion of initial territory training. Railroads should train these individuals ("train the trainer"), or arrange for their training, to ensure that dispatcherinstructors have the proper skills to train others. As discussed in subsection 7.1.2.1, training has its own set of required skills. A "train the trainer" program also helps to maintain consistency and uniformity across different dispatcher-instructors by providing the same training framework to all dispatcher-instructors. Dispatchers should spend a minimum of two years working as a dispatcher and have at least six months experience on the territory before overseeing a trainee for on-the-job training.

\subsubsection{Training Delivery Techniques}

Physical characteristics of the territory should be learned prior to sitting down at a desk to train on-the-job, since many of a dispatcher's operating practices and decisions depend on this fundamental knowledge. The best method to learn the physical characteristics of a territory is to get out and ride the territory. Riding the head end of a train will give the trainee first-hand experience with the specific features of a territory such as ascending/descending grades and locations of highway-rail grade crossings. The trainee can also ask the engineer or conductor questions about a territory that affect the functioning of the train or its movements along the territory. This method is the one most frequently used by the railroads that were visited. An alternative method for trainees to learn the physical characteristics of a territory is to have them study videotapes of the territory. However, this method is not preferred because the trainee cannot directly and fully experience all of the territory's features. It can be expensive and timeconsuming to arrange for a trainee to travel thousands of miles away to ride a territory; however, knowledge of a territory's characteristics helps dispatchers make critical decisions about the movement of trains along that territory, which translates into saved lives and more efficient train movements, both of which result in increased revenues and decreased costs. Videotapes may be used as a supplemental training aid for those dispatchers or trainees who would like to review the physical characteristics of a particular territory, however, videotapes are not a substitute for riding a territory.

There are several considerations that must be made when choosing a training delivery technique for the on-the-job portion of initial territory training. To begin, training involves the application of previously learned material. In addition, it is hands-on, and takes place in a real operating environment. Thus, delivery techniques must not be obtrusive, and they must be flexible enough to accommodate the various workloads that a dispatcher-instructor experiences during a shift. Technique selection will depend on the current circumstances of a territory, but effort should be made when choosing a delivery technique to meet as many of the aforementioned criteria as possible. For example, lecturing is not an appropriate delivery technique for the OJT portion of initial territory training; however, discussions between a dispatcher-instructor and a trainee are appropriate, since discussions do not have to be preplanned, they are flexible in both timing and content, and if they begin to interfere with the job of dispatching, the discussions can be carried on elsewhere at a later time. 
Compared to initial dispatcher training, the OJT portion of initial territory training will be different for each trainee because of the variety of dispatcher-instructors and the array of different circumstances happening at each desk every day. As discussed above, one way in which to reduce such variance is through instructor preparation such as a "train the trainer" program.

A training delivery technique oriented toward trainee feedback is verbal debriefing, where a trainee, the dispatcher-instructor, the Chief dispatcher, and other operations personnel, convene once a week to evaluate and discuss the trainee's progress. Some railroads have implemented a system in which the dispatcher-instructor reports a trainee's progress on a written form. An oral briefing includes a dispatcher-instructor's input, but it also encourages dialogue between the trainee and the dispatcher-instructor and other railroad personnel. Such a verbal protocol can be used for trainee feedback, answering questions, and discussion.

\subsubsection{Training Aids}

Because of the constraints of OJT (the dispatcher-instructor still has the responsibility to dispatch trains while training, training occurs in real time, and it occurs in a safety-critical operating environment), dispatcher-instructors have an extremely limited selection of training aids available to them for use when training new dispatchers. Aids include tools of the trade and printed text materials. Since training is on-the-job, tools of the trade (e.g., paper train sheets and CTC computers) will be used out of necessity. Printed documents, such as rule book, track charts, and bulletins, that are also considered tools of the trade, will be used in carrying out dispatching tasks as well. Printed text references such as notes from initial dispatcher training, or a list of steps designed to aid a trainee in completing certain procedures used in initial dispatcher training, should also be used when necessary. In addition, videotapes of a territory's physical characteristics can be used to periodically re-familiarize a trainee with a territory's characteristics.

Workbooks, or "advanced organizers," may also be used to help structure the trainee's learning experience while on-the-job and during the learning of physical characteristics. A workbook or organizer can help by preparing trainees for what to look for during OJT or during a road trip, and can provide assignments that make the trainee answer questions about what they have observed or done. This increases a trainee's accountability for learning, and helps the trainee to focus on the critical elements of the job or territory.

\subsubsection{Optimal Class Size}

The current practice by all of the railroads that were visited was to place one trainee with one dispatcher at one desk for initial territory training. This practice is recommended, since more than one trainee may complicate the issue of authority at a desk for a given time (e.g., if a train crew speaks to multiple dispatchers over the course of $30 \mathrm{~min}$ ), and may overload the dispatcherinstructor. Furthermore, it is recommended, wherever possible, to assign a trainee to "post" with only one dispatcher-instructor on each territory to avoid potential confusion and conflicting advice. 


\subsubsection{Minimum Training Time to Master Objectives}

To determine a minimum training time for mastering the training objectives for initial territory training, training materials from multiple programs were reviewed. Railroads typically divide their initial dispatcher training into classroom training and OJT. OJT corresponds to training new dispatchers on their first (or second) territory. In some, but not all, of the programs that were reviewed, the time that was allotted for OJT also included learning the physical characteristics of a territory. To be conservative, the OJT times reported by the railroads will be treated as if they correspond only to the OJT portion of dispatcher training. Consequently, the time required to learn the physical characteristics of a territory (mostly accomplished via field trips) will be treated separately.

The range of minimum initial territory training times for the programs that were visited, or for which information was received, was between two and 17 weeks for training on a territory. Some railroad programs initially train railroad dispatchers on two or more territories, and therefore the time dedicated to territory training in these programs will be longer. For example, one Class 1 railroad that was visited devotes 18 total weeks to train on two territories; the time is divided into two nine-week training sessions. One additional railroad did not specify an amount of time allocated for territory training; rather, they reported that they trained their dispatchers "until qualified."

For the railroad programs that reported specific training time periods, the average initial dispatcher training program lasted seven weeks. The Class 1 railroads spent an average of 10 weeks of training per territory, while the shortline and regional railroads devoted an average of four weeks of training per territory.

Rather than recommending that all railroads devote a prescribed minimum time for the OJT portion of their initial territory training, railroads should establish criteria that determine when a dispatcher is qualified on a territory, such as completion of the checklist items developed in this section. As a rule of thumb for curriculum planning, however, railroads may want to devote at least seven weeks of initial territory training per territory to ensure that all of the checklist items (and therefore all of the training objectives) are covered. Seven weeks was the average duration of the railroad OJT programs that were examined.

In addition, one to two weeks should be allocated for the trainee to learn the physical characteristics of the particular territory. This amount of time primarily includes the time necessary to take field trips along the territory, but can also be used by the trainee to study and review track charts and other useful information that will help them learn the physical characteristics more effectively.

Thus, it is recommended that railroads spend a total of nine to ten weeks on initial territory training, covering both physical characteristics training (one to two weeks) and "posting" at a particular desk (minimum of seven weeks per desk). 


\subsubsection{Costs for Developing and Delivering the Training}

Instructors' salaries constitute the majority of the costs associated with developing and delivering initial territory training; however, if the territory that the dispatcher will be dispatching is remotely located, the costs of traveling to and from the physical territory should also be factors into the overall training costs. Instructors include dedicated trainers, dispatcherinstructors, chief dispatchers, other operations personnel, and anybody else involved in the development or delivery of initial territory training. An instructor's time may be spent up front developing the checklist, while a chief may spend some time each week providing feedback to the trainee and monitoring their performance in the form of a verbal debriefing.

\subsubsection{Accountability}

Success of the checklist depends upon accountability of the checklist users. Likely users of the checklist include the dispatcher-instructor, the trainee, and the individual overseeing the overall initial territory training (e.g., trainer, Chief dispatcher, or Supervisor of Train Operations). Some recommendations on how to share this responsibility follow.

Dispatcher-instructors will be the primary users of the checklist, and are encouraged to date each checklist item as they sign-off, and to make notes on their checklist. They should be able to answer any questions that the individual ultimately overseeing the trainee's progress during the initial territory training (trainer, Chief dispatcher, etc.) may have regarding the trainee's progress.

The trainee should also be provided with a checklist so that they may mark it up separately from the dispatcher-instructor. Trainees should sign and date each checklist item only after they believe that they have accomplished the task or mastered the skill specified by each checklist item. It should be made clear to the trainee that he or she will be evaluated upon "mastery" of the territory, so it is in their best interest to sign-off on checklist items only after they feel that they have mastered each one.

The individual overseeing the overall initial territory training (e.g., Chief dispatcher, Supervisor of Train Operations, or trainer) can also play a role in sharing the responsibility for initial territory training and for successful use of the checklist. The overseer can use the same checklist as a means and guide to spot test the trainee via observation, or as an impetus for discussion with the trainee. The individual responsible for the trainee's initial territory training can also sign-off each of the checklist items after observing the dispatcher accomplish the items or after meeting with the trainee and discussing their progress. The individual responsible for the initial territory training may also use the checklist to discuss the trainee's strengths and weaknesses and to solicit the dispatcher-instructor's opinion of the trainee's competencies in various areas covered by the checklist.

It is important to recognize that if dispatcher-instructors' involvement in training new dispatchers increases, however, there should be some form of compensation to match the increase in responsibility. Current practice by some railroads is to pay dispatchers an additional hour's wages each day that they have a "poster." Subsection 10.3.3 discusses some of the issues in compensating dispatchers for their increased responsibilities in training dispatcher trainees. 


\subsection{A Model Syllabus for Periodic Refresher Training}

A model syllabus for periodic refresher training is presented in this section. First, the development of the syllabus is discussed, then the syllabus is presented, and finally, issues relevant to using the periodic refresher syllabus are discussed.

\subsubsection{Syllabus Development and Use}

Periodic refresher training addresses the need for railroad dispatchers to maintain skills that are required to safely and efficiently dispatch. Periodic refresher training is based on the premise that people, and the circumstances of their lives, change. Lifestyles may be altered over time, and skills that are not used may be lost. The standards or methods of dispatching may change, particularly in automated environments. In addition, the amount of supervision that employees once received has decreased substantially in many work environments.

Periodic refresher training incorporates operational rules training (as required by 49 CFR 217.11) and hazardous materials training (as required by 49 CFR 172.704), but it also covers topics and skills that are critical to railroad dispatching but that are used infrequently. Two examples include completing paper forms and movement authorities manually when ordinarily completed on a computer and following emergency procedures that have not been used in over a year. Periodic refresher training also addresses interpersonal skills that are used when communicating with other departments, train and engine crews, and other dispatchers, as well as lifestyle training. Since periodic refresher training addresses the need to maintain skills over time, major changes in dispatching technology (e.g., computer-aided dispatching overhaul) typically are not covered by periodic refresher training, but rather they are usually addressed, and the dispatchers are trained, as the changes arise. Furthermore, routine procedural changes in dispatching are usually addressed through dispatcher bulletins and updated timetables as the changes arise, though this does not preclude them from being introduced during periodic refresher training. More often, periodic refresher training addresses maintenance of those dispatching procedures that have already been learned.

Subsection 5.2 identified specific objectives that periodic refresher training should address to maintain safe and efficient dispatching standards, and to ensure that dispatching skills are not lost or eroded over time. The following syllabus outline provides a logical order and structure to those instructional objectives that were identified. The same bottom-up approach used to organize the objectives for the initial dispatcher training syllabus outline was used to organize the instructional objectives for the periodic refresher training syllabus outline. Since there were fewer objectives in the refresher training syllabus, the process of structuring the objectives was very brief.

Objectives are grouped into four instructional units. Table 6 presents the syllabus outline for periodic refresher training. Three of the four instructional units contain subheadings which correspond to content-based categories. One of the instructional units, hazardous materials, however, does not contain any subheadings. Hazardous materials originated as a content-based category, but since it did not "belong" with any other content-based categories, it remained 


\section{Table 6. Syllabus outline for periodic refresher training}

Instructional Units and Subheadings

Instructional Objectives

1. Personal and interpersonal skills

1.1 Communications and interpersonal skills $\quad 1.7$

1.2 Adapting to the lifestyle of a dispatcher $\quad 1.8,1.9$

2. Hazardous materials

$1.4, \mathrm{~F} 1.1$

3. The mechanics and art of railroad dispatching

3.1 Controlling and protecting track occupancy

$1.4,3.3,3.6,3.4,3.5,3.11$

3.2 Managing track use

$1.4,2.4,2.3,2.5$

3.3 Managing unplanned and emergency events

3.4 Transferring responsibility of trains to/from adjacent territories

$1.4,4.2,4.3,4.4,4.5$

$1.4,3.7$

4. Administrative functions

4.1 Manage documents

1.10

4.2 Assuming/relinquishing duties at the beginning/end of a shift

$1.4,2.1$

4.3 Record keeping and report writing

$1.4,5.1,5.4,5.3,5.6,5.7$

separate and became its own instructional unit. The instructional objectives associated with each subheading are listed in the second column of Table 6; because the instructional unit 'hazardous materials' does not contain any subheadings, instructional objectives are directly associated with it.

Since this syllabus outline is essentially a subset of the syllabus outline developed in subsection 7.1, the order in which the instructional units are presented follows that of the subsection 7.1 syllabus. The instructional units are generally arranged so that the content contained within each unit becomes successively more complex as the training progresses. Thus, training begins with the simpler concepts and activities, such as communications skills, and progresses to more complex activities, such as managing emergencies. Furthermore, based on the results of the syllabus implementation tool described in subsection 6.3, the instructional objectives within each subheading are ordered according to the complexity of each objective's learning outcome. Instructional objectives that fall into the "low" complexity category should be addressed before objectives that fall into the "high" complexity category. For example, based on Table 3, it is recommended that within subheading 3.2, entitled "Managing Track Use," both objective 1.4, operating and safety rules, and objective 2.4 , demonstrate the ability to understand and use all manual and computer-based dispatcher planning aids employed by the railroad, be addressed before objective 2.3, judge train and track user priorities, and objective 2.5, demonstrate the ability to prioritize a dispatcher's own tasks when planning and carrying out the day's activities, since objectives 1.4 and 2.4 contain lower learning outcomes (comprehension and application, respectively) than objectives 2.3 and 2.5 (both are evaluation).

\subsubsection{Issues Relevant to Periodic Refresher Training}

Periodic refresher training consists essentially of a subset of instructional objectives from the initial dispatcher training. Thus, many of the same issues that are relevant to using the syllabus for initial dispatcher training are relevant to using the syllabus for periodic refresher training. 
Those issues include:

1. Instructor preparation.

2. Training delivery techniques.

3. Training aids.

4. Minimum training time to master objectives.

5. Optimal class size.

6. Costs for developing and delivering the training.

Each of these issues is addressed below. Where there is overlap with discussion of issues in subsection 7.1, reference simply will be made to that section rather than present the same information again. In addition, prerequisite knowledge or experience is not an issue since refresher training focuses on the maintenance of already-acquired skills and knowledge.

\subsubsection{Instructor Preparation}

Instructor preparation for periodic refresher training is similar to instructor preparation for initial dispatcher training. SMEs with dispatching experience should be used whenever possible and the instructor should have some background in training others. Since periodic refresher training is much more limited in scope than initial dispatcher training, it is likely that only dedicated instructors will be used. See subsection 7.1.2.1 for a discussion of the use of SMEs and a discussion of training the trainer.

\subsubsection{Training Delivery Techniques}

Almost all of the delivery techniques discussed in terms of initial dispatcher training can also be used for periodic refresher training. They include:

- Lectures.

- Discussion.

- Role-play.

- Computer-based training (CBT).

- Simulation.

Each of these techniques is discussed in subsection 7.1.2.2. Role-playing may be particularly appropriate for refreshing interpersonal skills, while CBT is ideal when reviewing alreadylearned rules and procedures. Simulation is particularly appropriate for skills practice.

\subsubsection{Training Aids}

All of the training aids that can be used in initial dispatcher training can be used for periodic refresher training as well. Some aids may be more likely to be used than others, however, depending on their ability to hone already-learned dispatcher skills, and their ability to facilitate training of individuals who already have a lot of experience and a basic framework in which to learn. The most likely candidate training aids for periodic refresher training are: 
- Printed text.

- Slides.

- Pictures and drawings.

- Computers/CBT.

- Games.

- Interactive simulation.

Any training aid can be used for refresher training; however, since dispatchers are already proficient at their job, many training aids may be unnecessary. Instructors can use very simple aids such as printed text and pictures to convey the training information to their expert subjects. Games can be used for interpersonal skills (along with role-playing). Interactive simulation can also be used, as discussed above, for honing operational skills. See subsection 7.1.2.3 for a complete discussion of various training aids.

\subsubsection{Minimum Training Time to Master Objectives}

None of the programs that were visited had refresher training programs other than annual rules training and hazardous materials training. Thus, in the absence of information with which to compare, periodic refresher training should last as long as necessary for trainees to complete the refresher training syllabus and address the related objectives. Dispatchers should be capable of learning quickly because they have already established a framework of knowledge and have been dispatching for at least a few years. It is estimated that periodic refresher training can be completed in as short as two to three full days.

\subsubsection{Optimal Class Size}

Optimal class size for periodic refresher training is similar to optimal class size for initial dispatcher training, depending primarily on access to resources such as classroom size, availability of instructors, facilities (e.g., simulators), and materials.

\subsubsection{Costs for Developing and Delivering Training}

Costs for developing and delivering periodic refresher training are tied directly to the salaries associated with the instructor's time and the dispatchers' time, since railroads are paying for dispatchers to be away from their desks during this time. The cost of training materials will be negligible, except if simulators are used. However, it is important to note that the costs associated with obtaining, operating and maintaining simulators for periodic refresher training will be shared with initial dispatcher training.

Railroads have the option of contracting out their rules training to an outside training organization, such as the Railway Education Bureau, which, as described in subsection 7.1.2.7, offers NORAC and GCOR rules training for up to 15 attendees at a cost of $\$ 4000$. 


\section{DEVELOPMENT OF TEST DESIGNS}

Section 8 is divided into two parts. Subsection 8.1 describes the four steps involved in developing a test design, while subsection 8.2 discusses some of the issues involved in designing tests. The designs and recommended practices are not intended to be a "one size fits all" rigid set of standards but rather a minimum foundation and "best practice" set of recommendations to be used as a starting point in the review or creation of testing for railroad dispatchers. The development of test instruments is beyond the scope of this study and must be done by each railroad to accommodate its unique characteristics and the nature of its dispatching environment. Each instructional objective will have several performance objectives associated with it. A railroad should base the actual test items on performance objectives specific to its operation.

\subsection{Test Design: Four Steps}

The development of a test design involves four steps. They are:

1. Select the appropriate objectives.

2. Create a table of specifications based on the objectives and their associated learning outcomes.

3. Adjust the number of test items in the table of specifications as necessary to reflect the relative importance of specific objectives, topic areas or skills.

4. Specify the number and format of test items in the table of specifications.

The general approach in test design is to create trials (test items, problem sets, check lists, etc.) which represent the activity associated with each entry in the table of specifications. The actual number of trials to prepare for each matrix cell are based on external criteria. The criteria used might include the perceived importance of the activity, the instruction time spent covering the activity, or the frequency with which the activity is performed in the real world.

This approach to test design is not the only one that may be used, although it is the one most commonly employed, particularly when driven by a system of instructional objectives. Readers desiring a broader discussion of the approach are directed to ()ㅡ, which presents a clear and easily read discussion of the relationship between Bloom's taxonomy of cognitive learning outcomes ( $\underline{5})$ and the conduct of evaluation. Readers with further interests in the subject of test construction and administration should search the topic area of Educational Tests and Measurements, which abounds with texts addressing the subject. 
In each test design, it is important to equate the type of skills required to answer the test items with the type of skills described in the instructional objectives. For example, an objective that calls for the understanding of a rule is not accurately measured by a question that requires the rote recitation of that rule.

\subsubsection{Step 1: Select Appropriate Objectives}

In test design, performance rather than instructional objectives are typically used as the basis for the creation of tests because instructional objectives do not provide the level of specificity necessary to craft appropriate test items. Performance objectives are written using observable, measurable vocabulary; thus, well-written performance objectives virtually dictate the form that their representative test item(s) will take. Instructional objectives were used as the basis for the test designs in this project, however, because the test designs must be applicable to the wide range of variations that exist in a dispatcher's tasks among all of the different railroads. Whereas performance objectives provide a desired measurable framework for test design, instructional objectives have the benefit of being broadly applicable. By selecting instructional objectives, it becomes possible to create a uniform framework for test design.

Thus, when choosing the content for the tests, individual railroads should begin by selecting the instructional objectives that they want to test. When developing the actual test designs, however, individual railroads should use the performance objectives associated with the instructional objectives as the basis for their test designs.

The instructional objectives that were selected for each of the three different training programs in subsection 5.2 were also the ones selected for each of the three test designs. While it might be reasonable in some cases to not use some of the instructional objectives selected for the test designs proposed in this report, great care should be taken before disregarding any objective covering safety or regulatory topics.

\subsubsection{Step 2: Create a Table of Specifications}

The purpose of this step is to ensure that the type and subject matter of test items created will reflect the nature of the course objectives. A table of specifications has two dimensions: instructional (or performance) objectives, and associated learning outcomes based on Bloom's taxonomy ( $\underline{5})$.

\subsubsection{Step 3: Adjust Table of Specifications to Reflect Relative Importance}

The next step in the test design process is to adjust the table of specifications. There are many ways in which to adjust the table, depending on the goals of the test and the criteria set

forth by the test designer. Three possible ways in which to adjust a table of specifications for a test design are:

1. To reflect the relative importance of the tasks specified by the objectives. 
2. To reflect the proportion of time a dispatcher spends in performing the tasks specified by the objectives.

3. To reflect the proportion of time spent during training to obtain mastery in performing the tasks specified by the objectives.

The tables of specifications presented in the following sections were revised to reflect only the first of the adjustment approaches discussed above - the relative importance of the tasks specified by the objectives. Specific dispatching center and training experience are required to implement the second and third adjustment methods. It is important to understand, however, that the table of specifications can be adjusted to reflect any number of approaches; furthermore, the table can be adjusted to reflect multiple approaches.

\subsubsection{Step 4: Specify the Format and Number of Test Items}

The actual number of test items to be asked on a given test depends on a host of different factors, including test reliability and time available for testing. The format of test items is determined by the nature of the objectives to be tested. These and other factors that influence the number and format of test items to use in a test are discussed in subsection 8.2.

\subsection{Considerations in Developing Test Designs}

This section discusses some of the issues involved in designing tests. Each issue is discussed in general terms here, while their specific applications are discussed after each test design in subsection 9 .

The following test design issues are discussed:

1. Reliability.

2. Selecting passing levels.

3. Cost and time of test administration.

4. Validity.

5. Speed versus power of a test.

6. Criterion-referenced versus norm-referenced testing.

7. Number of test items.

8. Format of test items.

9. Time permitted to take the test.

10. Formative versus summative tests.

11. Use of subject matter experts in test design.

\subsubsection{Reliability}

Reliability, as applied to test construction and use, refers to the consistency of scores a test produces. Simply stated, a reliable test will produce the same, or approximately the same, results every time it is used. There is no such thing as a perfectly reliable test. Even a highly refined 
and standardized test like the SAT examination taken by high school students as a condition of college entry, is not 100 percent reliable. The degree to which a test is reliable depends on its standard error of measurement.

\subsubsection{Measuring Reliability: the Standard Error of Measurement}

All tests have a certain amount of error in the accuracy of the individual scores they produce. This error is a result of problems in the design of a test as well as of chance factors. There are a number of ways in which the reliability of a test can be measured or estimated, however. Measuring the standard error of a test aids the test designer in reducing the error in subsequent tests, thereby increasing its reliability, and facilitates the selection of a passing test score. Subsections 8.2.1.2 and 8.2.2 address these latter two issues.

The standard error of measurement indicates the probable range into which a given individual's "true" score actually falls. If the standard error of measurement for a test is 3 points and an individual answers 87 test items correctly, that individual's "true" score falls somewhere between 84 and 90 points.

In those instances where 20 to 30 individuals at a time take a given test, it is possible to directly compute the standard error of measurement. Formulas such as those found in (10) may be used for this purpose, although this and similar approaches require an understanding of statistical analysis. For smaller programs, and in instances were the time is not available to perform the necessary calculations, the reader may wish to consider a simple rough estimate of the standard error of measurement (11):

$$
\mathrm{S}_{\mathrm{e}}=0.432 \sqrt{\mathrm{k}}
$$

where

$\mathrm{k}=$ number of test items

The results of this calculation must be understood to be a rough estimate at best, but should give some insight as to the amount of error that may well surround a score. Tests with a small number of test items are particularly at risk. For example, a 20 item test would have an estimated standard error of measurement of nearly 2 points (10 percent error) while a 100 point test would have an estimated $\mathrm{S}_{\mathrm{e}}$ of 4 points ( 4 percent error). If a "passing" level of 80 percent was set for the 20 point test (16 points), actual scores in the range of 14 to 18 points (70 percent to 90 percent) might be considered as passing when this estimation of standard error of measurement was taken into account. No specific recommendation for dispatcher training program testing is made here, but programs that determine employee retention on the basis of test scores may wish to take the concept of error in measurement under consideration.

Another method used to estimate the standard error of measurement involves randomly dividing a test in half (assuming that the test items are all of the same type), and then statistically comparing how people did on the two halves of the test. Individuals should do equally well (or 
poorly) on both halves. If this does not occur, it is likely that some of the test items are inconsistent, and the test may be said to have a high "standard error of measurement."

\subsubsection{Recommendations to Improve Reliability}

One of the simplest ways to maintain reliability is to ensure that what is being taught is that which is being tested. The use of a syllabus helps both the instructor and the trainee by formalizing the instructional process and providing an instructional "road map" to follow. When instruction diverges from the syllabus to which the test is tied, trainees begin to guess at more of the answers to the test items, and as a result, test reliability decreases.

In a statistical as well as a practical sense, reliability is reduced when an insufficient number of test items are asked on an examination. Following a test design when writing test items is helpful in this regard since it increases the likelihood that all of the pertinent material is represented. The actual number of test items asked should be a function of the number of specific skills and understandings to be assessed. Certainly, each important or complex skill should be tested by a number of test items to reduce the possibility that the outcome of the test is not heavily influenced by random guesses or misunderstandings of test items by a test taker. It makes no sense whatsoever, in this approach to evaluation, to prepare tests with a number of test items neatly divisible by 5 or 10 (such as the traditional 10 question quiz or 100 question final test). The appropriate number of test items for a test is the number of test items it takes to adequately represent the knowledge and skills being assessed.

One way to support the reliability of testing at the completion of training is to provide large amounts of practice of the skills during the course of study that will be covered by the final test. Unscored practice tests or quizzes can be especially valuable when students understand that the final test will require similar kinds of performance. It should be noted here that instructor lecture is generally considered to be a weak method for the teaching of skills. As a rough rule of thumb, no more than $1 / 3$ of instructional "air time" should be filled with the sound of the instructor's voice. The remaining $2 / 3$ of instructional time should be spent on what is sometimes termed "supervised practice" in which trainees are presented with problems to be solved or tasks to be completed with the support and interaction of the instructor. Trainers who have not been adequately prepared for their work sometimes assume they are not "teaching" unless they are talking and thus deprive trainees of the opportunity to develop their skills through practice. The popularity and effectiveness of computer-based training in comparison to typical instructor led training comes as a result of its "interactivity," that is, its ability to actively engage learners by requiring them to respond to problems and test items. (Badly prepared computer-based training modules are sometimes derisively referred to as "page turners" in reference to their lack of interactivity.)

The reliability of a test can also be influenced by the quality of writing in the test items. Poorly crafted test items either cause misunderstandings or give themselves away. The latter is the most common problem and one that is made worse by the presence of trainees who have high language and reading skills. In these instances, what ends up being tested is the reading ability of the trainees rather than the skill at the objective being tested. 
Another method to increase test reliability is to conduct an item analysis, which involves evaluating the tests themselves. One of the simplest test reliability evaluations is to compare the top 25 percent scoring test takers with the bottom 25 percent in regard to how they answered each of the test items. Logically, test takers in the upper quarter of the test results should tend to get test items right and persons in the lower quarter should tend to get them wrong. When an individual question is contrary to this trend, it suggests that something about the test item may be misleading the better students. Alternatively, the question may be adequate, but the material or skills it addresses may not have been adequately addressed during the class (and thus, students "guessed" at the answer and the question, as a result, appears to be poor). Whatever the cause, making any appropriate changes will improve the reliability of future administrations of the test.

\subsubsection{Selecting Passing Levels}

There is no purely objective standard in selecting a passing level. As a result, determining a passing score is extremely difficult. However, there are some general rules of thumb, or methods, that can be followed in the absence of an objective standard passing level to determine a passing score for both individual test items and entire tests. They include establishing a time limit (e.g., the trainee must complete a transfer of responsibility for his desk within 15 min); establishing a cutoff based on the precision of the answer(s) (e.g., the trainee must schedule the train meet within 10 miles of Atlanta) or establishing a passing score based on a percentage of correct responses (e.g., the trainee must successfully answer 80 percent of the test items).

Selecting a specific percentage can prove to be challenging, however. There are several methods for selecting a passing percentage level. One method is to assign a percentage based on historical or traditional information. While there are long-standing traditions of selecting specific passing levels ranging from 70 to 95 percent, it must be understood that there is no objective reason for choosing any level.

An alternative to using historical or traditional passing scores, or to adjusting these scores, is to administer a test to experienced, currently employed dispatchers who have clean job performance records. A newly trained dispatcher should be able to perform nearly as well as the "expert" dispatchers on the test, perhaps 90 to 95 percent of their level. In this scheme, if the "expert" dispatchers averaged 97 out of 112 possible test items correct, then the trainees would be expected to score 90 to 95 percent of 97 test items in order to pass. This example works out to 87 to 92 points out of 112 to pass the test ( 77 percent to 82 percent of the 112 points). This scheme obviously wouldn't work well if the trainees had special instruction for new equipment or procedures that the expert dispatchers had not shared.

An alternative approach to selecting a passing level is to assume that the minimum passing level should be set as some proportion of the average of the top two scores recorded by the other trainees. Determining a minimum passing level like "85 percent of the average of the top two scores" still is arbitrary, but is at least based in part on what someone actually was able to do with the test. Use of this approach with successive classes of trainees tempts test-takers into collusion to keep scores low, so it is better to set a passing level with a representative group of trainees and then use that level for successive tests (assuming that the test and the course format do not change). 
Another common sense approach is to identify all the test items which deal directly with critical skills (perhaps those which fall at the application level and above, plus critical safety issues at any level). The total number of test items identified in this way may give an insight as to where the passing level might be put. Ideally, none of the critical test items should be missed. Presumably, some of the non-critical test items might be missed and a trainee still be considered as adequate. The number of non-critical misses deducted from the total number of test items would then imply a minimum passing level. The last part of this review is to ask if trainees would be considered adequate if they obtained a passing score while missing only critical skills test items and then adjusting the passing level accordingly. If this procedure is followed, it is recommended that critical safety and performance test items constitute a majority of the test items, perhaps 70 or 80 percent of the total.

A variant of the method discussed above is to require a higher level of performance on critical test items than non-critical test items so that passing is defined as " $\mathrm{xx}$ percent of the critical test items plus yy percent on the test as a whole." The problem with this approach is that the number of test items affects the reliability of a test. A small number of test items will compromise the reliability of the results. If this approach is to be used, it is recommended that the critical test items constitute 70 to 80 percent of the total number of test items.

All of the strategies discussed above are preferred to arbitrarily picking a passing level solely on the basis of tradition or picking a passing level on the basis of a specific test and then applying the same passing level to unrelated tests. Readers with further interest in this area may wish to consult educational test and measurement texts or texts concerning statistical analysis in the social sciences. A particularly clear and practical discussion can be found in (12).

\subsubsection{Cost and Time of Test Administration}

The cost of administering the test is principally a function of the time spent to perform the following:

1. Test preparation.

2. Test administration.

3. Evaluation and posting of the test results.

4. Performance of an item analysis as an evaluation of the test.

5. Performance of a validity study of the test by creation of questionnaires or other assessment documents and then using these to gather data concerning the related post test field performance of examinees.

6. Test revisions consistent with the item analysis and validity follow-up analysis.

There is so much variability in individual test creation skills and unpredictable elements in the gathering of information and materials that it is not practical to propose standard time figures 
for these activities. The following observations and rules of thumb are offered with the caution that individual experiences will vary.

Given that the background information and materials are available, question writing is the driving time element in test preparation. Working from existing performance objectives, a rough estimate of time in writing is 2 to $3 \mathrm{~min}$ for each true/false or short answer item, 3 to $5 \mathrm{~min}$ for the typical multiple choice item, 5 to 7 min for the typical ( 5 to 7 elements) matching item and anywhere from 10 to 30 min for problem sets ("case study" test items). Extended length essay items are easy to write and are estimated to take 5 to 10 min each, depending on the complexity of the test item, but each essay item should be accompanied by a list of written criteria which will be used to judge the response.

The evaluation of test results is another time/cost factor, which can only be roughly estimated. In some settings, automated equipment may be used to score objective test results. In other cases, hand scoring may be necessary. The following rough estimates are offered with the caution that individual experience will vary.

Given that some form of answer key has been prepared and the scoring will be performed manually, a rough estimate for scoring of true/false and multiple choice test items is 20/min. Typical matching items may be scored at a rate of 3 to $5 / \mathrm{min}$, depending on complexity. Short answer test items may be scored at a 10 to $15 / \mathrm{min}$ rate. Essay test items of half a written page length may be scored at 1 to 2 min each by an experienced person with a set of judgment criteria in hand. The recording or computer entry of test results is estimated to take approximately $1 \mathrm{~min}$ per student record.

It is possible in some automated scoring systems to obtain an item analysis as part of the scoring output. In most cases, however, an item analysis is likely to be conducted manually. Using the procedures discussed earlier in this section, an experienced person might be expected to take 30 min to analyze a 50 item test taken by 20 examinees. Less experienced persons may take an hour or more.

The time estimate for validity/follow-up studies of summative test results is completely conjectural, and depends on the size of the dispatching class, how frequently the training course is taught and whether or not the trainer has access to current dispatchers (i.e., the training center is located at the same facility as the dispatching center). When a questionnaire is used, the time may be particularly difficult to track since the activities will be sporadic in nature, depending on the size and frequency of the training classes, or on access to current dispatchers to survey them. On the other hand, where training takes place at a dispatching center, the time expended may be less than an hour or two.

Test revision is another element for which a time estimate is difficult to provide. For tests given on an annual or periodic basis, a review and possible revision should take place at least once each test cycle. Given that support materials including item analyses from test administrations are on hand, a review and revision for a 50 item objectively scored summative test may take 2 to $4 \mathrm{hr}$. 
A good testing program should serve as the backbone for the training program it serves. While a return on investment may be difficult to calculate for the cost of these activities, nevertheless, the return will materialize in the form of the assurance of safety to the community at large, the potential for increased efficiency of railroad dispatching, and the avoidance of accidents and their attendant catastrophic costs.

\subsubsection{Validity}

Validity refers to the degree to which a test is meaningful and useful in predicting success in the actual domain or content area. In other words, the validity of a test is the degree to which the test items measure what they purport to measure. For example, a dispatcher test that covers track use authorities is considered a valid test if trainees who do well on the test now also perform well at authorizing track use on the job later. It is recommended that test designers periodically examine the validity of their tests by looking at the correlations between the success of testtakers with success on-the-job. Checking for validity is a lengthy process, but it is critical to ensure proper testing and instruction that produces safe railroad dispatchers.

\subsubsection{Speed Versus Power of a Test}

There are two views that can be taken in regard to determining the time allotted for administering a test. The first view is that everyone who takes the test should have sufficient time to complete it. The second view involves a consideration of the degree to which speed of execution is an essential part of the skills covered by a test. These two approaches to administering a test are discussed in test and measurement literature as "speed versus power" testing.

A test of keyboard skills that emphasizes the number of words correctly entered in a specific amount of time is an example of a speed test. Time is the critical element in a speed test; the difficulty level of the test items in this type of test is often low as a result.

A power test is one in which speed is not important since additional time beyond that needed to read and answer the test items will have no effect on the test results. The difficulty level of power test items can range from easy to hard. In practice, speed may be a part of some test items and not of others. The determination of speed versus power for a test item should be made on the basis of the performance objective for which the test item is being written. If the performance objective states a minimum rate of performance or time to conclude a task, then a time limit should be a part of the item. It is recommended that test administration for instances where both speed and power items are present, use timed intervals for the speed test items and a block of time adequate for the completion of the remaining power items by all examinees.

One danger to be avoided in test preparation is the conversion of a power test into a speed test by allotting insufficient time for its completion. Causing speed of test completion to become an evaluation factor for skills that do not require speed in the real world has the effect of reducing test validity by rewarding score points for a skill not related to real-world tasks. Similarly, the reliability of the scoring of a power test is also reduced when insufficient time is 
available for examinees to answer all of the test items. Especially in the case of written tests covering complex material, unrealistic time limits result in the test becoming one of reading ability rather than an evaluation of the skills for which the test was developed.

\subsubsection{Criterion-Referenced versus Norm-Referenced Testing}

Criterion-referenced tests are those in which learners are tested to determine their degree of mastery of specific areas. Norm-referenced tests are those in which learners are tested to determine how well they performed relative to other learners. Norm-referenced tests provide a ranking of how well a particular student has performed relative to other students (e.g., "John received the second highest grade in his class"). In contrast, criterion-referenced testing provides an absolute indication of content mastery by a particular student (e.g., "Mary successfully

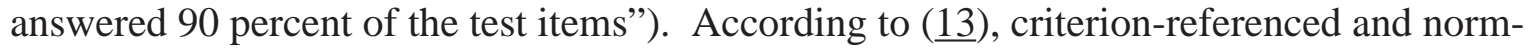
referenced refer to the interpretation of test scores. Thus, it is possible to interpret a test score in both a norm-referenced and a criterion-referenced manner (e.g., "John scored second best in his class, successfully answering 90 percent of the material").

However, it is important to note that a test designer can develop tests that are better suited for either norm-referenced or criterion-referenced tests. Norm-referenced tests typically use more difficult test items and eliminate easy test items to better discriminate among test scores, while criterion-referenced tests typically use any type of question that can adequately describe a student's performance. Criterion-referenced tests do not make any attempt to systematically eliminate easy test items or increase the number of difficult test items. Since the goal of railroad dispatcher training is to instill the skills necessary to dispatch trains, a criterion-referenced test and interpretation is recommended, since what is important is to determine whether or not a student has mastered the material, not how well a particular trainee performed in comparison to others in his/her class.

\subsubsection{Number of Test Items}

The number of test items depends on several factors, including the time allotted for the test and the format of test items that are used. As a general rule of thumb, for knowledge and comprehension learning outcomes, college-age and older trainees should be able to answer one to two multiple-choice test items, three true/false items, or three short-answer items in $1 \mathrm{~min}$ (13). As the complexity of the learning outcome increases (e.g., application, analysis), the time required to answer test items should be increased appropriately. The number of test items can be enumerated in the test specification, described below. In general, the greater the number of test items, the more reliable the test.

\subsubsection{Format of Test Items}

Test items may be created using many different formats, from the simplest true/false item, to the most complex problem set or essay. This section is limited to the different test item formats that are used in this report. They include, in ascending complexity, true/false items, matching items, lists, short answer items, identification multiple choice items, problem multiple choice 
items, and problem sets. The use of different formats depends on the complexity of the associated learning outcome of the specific objective being tested.

True/false, short answer, matching, and some multiple choice test items are typically used for recollection of factual information, as well as for the comprehension of some information. An identification multiple choice item requires the identification of a correct term or procedure from among several options. In other words, it requires a respondent to make a direct, associative relationship between the answer choices and the question. Problem multiple choice items require the selection of the correct answer, from among several alternatives, to a problem presented in the stem of the test item. Typically, the alternatives represent conclusions or premises to the test item stem, and the answer is not directly intuitive or clear. It should be clear that multiple choice items are very flexible, and can be used to address a variety of different learning outcomes. Problem sets involve providing the trainee with materials and information that require some kind of action that constitutes the skill represented by the objective being tested.

\subsubsection{Time Permitted to Take the Test}

The length of time permitted to take a test depends on many factors, including the time available to take the test, the format of the test items, and the number of test items. Based on considerations of some of these factors, subsections 9.1, 9.2, and 9.3 do provide some general guidance for developing test times for several test designs, but these numbers are meant to be only suggestions. Each test designer must use their own discretion in considering all of these factors when establishing an allotted time for trainees to take a particular test that they have developed.

\subsubsection{Formative versus Summative Tests}

There are primarily two types of trainee tests: formative and summative. Formative tests serve two purposes: to measure a trainee's mastery of a subject domain, and to diagnose any current deficiencies in learning the materials. Formative tests can help identify and diagnose areas of training where a trainee, or a group of trainees, is having difficulty. While trainees may successfully answer 90 percent of all test items, the trainees (some or many) may have difficulty mastering some content areas (the 10 percent of test items that trainees did not answer successfully), indicating that instruction has not been successful in conveying to the trainee the skills to complete the instructional objective(s), or perhaps that the trainee simply needs more training in an area. Knowing where trainees are having problems can aid the instructor to concentrate more in these areas to ensure trainee mastery of the subject area(s).

The principal purpose of a summative test is to determine overall mastery of a course's subject areas. The test designs in this project are intended to be used as summative tests of railroad dispatchers for three different types of training: initial training, territory qualification, and periodic reassessment. However, it is assumed that formative testing will take place throughout each of the training programs, and will precede any of the summative tests provided in this report in order to diagnose deficiencies and identify mastery of content areas as the trainees progress through their training. A trainee's performance on a summative test should 
come as no surprise to the trainer or trainee, since formative tests will have been used as benchmarks and guides to problem areas.

\subsubsection{Use of Subject Matter Experts in Test Design}

It is recommended that, to the extent possible, subject matter experts should be used in designing and testing the tests. Experienced railroad dispatchers can be used in a variety of ways to improve the test designs for training dispatchers. For example, experienced dispatchers can help the test designer to select a passing level by determining how well current dispatchers perform on a test (or a particular part of the test). They can also help by providing realistic scenarios to be used in the tests. The test designer should consider a dispatcher's experience, safety record, and willingness to help, among other factors, when securing the cooperation of current dispatchers. 


\section{TEST DESIGNS}

Subsection 9 presents test designs for the three railroad dispatcher training programs described in subsection 5.2. Subsection 9.1 presents a test design for the evaluation of initial dispatcher training, subsection 9.2 presents a test design for the evaluation of initial territory training, and subsection 9.3 presents a test design for periodic reassessment. The development of each test design is discussed first, followed by a discussion of its application.

\subsection{A Test Design for the Evaluation of Initial Dispatcher Training}

This section presents a test design with steps of development as presented in subsection 8.1. The test design created here is intended for the summative evaluation of trainee performance at the end of initial training. This test should be considered the last of a long series of evaluations in which the cumulative knowledge and skills covered in the training course are assessed. Throughout the training course, forms of evaluation similar to this test design should be employed for the purpose of evaluating both student progress and the appropriateness of instruction.

The summative test design described in this section should not come as a surprise to trainees. From the onset, and throughout the training course, trainees should be informed regarding what knowledge and skills they are expected to develop (the performance objectives), and the interim evaluations should be created in these terms. This section concludes with special considerations and recommendations regarding the use of the test.

\subsubsection{Selection of Objectives}

Since the original set of instructional objectives that was developed was intended to cover all aspects of dispatching, including objectives related to freight-specific operations, a summative evaluation includes all of the objectives except for those related to electrified territories. Thus, the number of instructional objectives selected for a summative evaluation for initial dispatcher training is 44. Element 3.1, "Characteristics of physical territory," is intended to cover the general parameters of interest in learning the physical characteristics, such as grades of hills, location of grade crossings, interlockings, sidings, etc., and is not intended to convey specific details of a particular territory. Specific territory qualification, which covers the explicit physical characteristics of a territory, is addressed in initial territory training, subsection 9.2.

The instructional objectives presented in subsection 5.1 intentionally included subject areas deemed necessary for railroad dispatcher trainees who lacked any prior railroad experience since it was determined that many railroads were training individuals who not only lacked tower 
operator experience but who also lacked prior railroad experience of any kind. For programs that are training individuals who do have at least some prior railroad experience, some objectives may be excluded as long as their removal does not compromise the assessment of safe operating skills. Furthermore, if certain objectives do not apply to a railroad's operation, those objectives may be excluded (e.g., a passenger operation that does not run any freight may elect not to use the instructional objectives related to freight operations).

\subsubsection{Table of Specifications}

Table 7 shows a basic table of specifications for all of the initial training objectives. The table of specifications displays the objectives that are to be addressed in the test design along with the associated learning outcome for each objective, and helps to ensure that the type and subject matter of test items created will reflect the nature of the course objectives. The table of specifications represents a selection of objectives for trainees who lack applicable railroad experience and who will eventually dispatch freight in an automated dispatching center.

The table totals in Table 7 represent raw sums for the objectives and associated learning outcomes. They do not reflect concerns of intrinsic importance of some objectives over others, although the proportional distributions imply where the training programs that were surveyed collectively place their emphasis. Table 8 is a summary of the distribution of instructional objectives contained in Table 7.

The summary indicates that 46 percent of the training's emphasis is on planning and controlling track use. Additionally, almost two-thirds (64 percent) of the objectives require the examinee to demonstrate more than simple rote memory (knowledge) or understanding (comprehension) of the content. As noted above, however, this distribution does not take into account the relative importance of specific objectives.

\subsubsection{Adjustments to Table of Specifications}

A report by the FRA (므) characterized a dispatcher's principal duties as:

- Scheduling the movement of trains to provide for safe meeting and passing with minimum delay.

- Managing unexpected events and emergency situations to protect the public, railroad employees, and railroad property.

- Arranging for the use of track by engineering forces to permit timely maintenance and renewal while minimizing train delay and providing protection for such operations.

Some of the railroad training programs that were reviewed as part of the project reflect an independent validity of this summary. Training programs should, therefore, clearly spend a substantial amount of time preparing students for these duties. Tests should be prepared in such a way as to produce scores which predict the ability of an individual to schedule the movement 
Table 7. Table of specifications for a typical initial training program

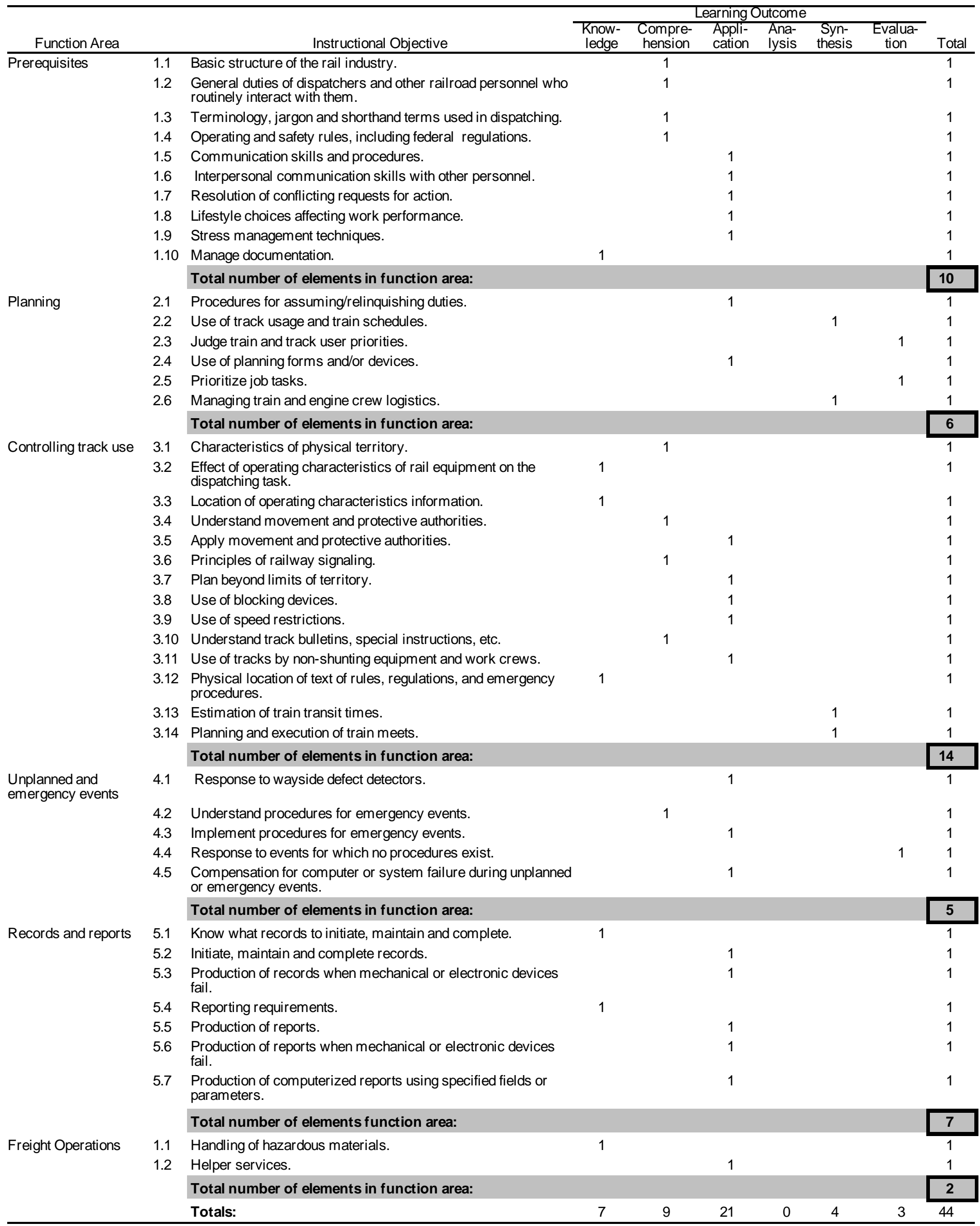


Table 8. Summary of a table of specifications for initial dispatcher training

\begin{tabular}{|c|c|c|c|c|c|c|c|}
\hline Function Area & Knowledge & $\begin{array}{l}\text { Compre- } \\
\text { hension }\end{array}$ & $\begin{array}{l}\text { Applica- } \\
\text { tion }\end{array}$ & Analysis & Synthesis & Evaluation & Total \\
\hline 1. Prerequisites & 1 & 4 & 5 & 0 & 0 & 0 & $23 \%$ \\
\hline 2. Planning & 0 & 0 & 2 & 0 & 2 & 2 & $14 \%$ \\
\hline 3. Controlling track use & 3 & 4 & 5 & 0 & 2 & 0 & $32 \%$ \\
\hline $\begin{array}{l}\text { 4. Unplanned and } \\
\text { emergency events }\end{array}$ & 0 & 1 & 3 & 0 & 0 & 1 & $11 \%$ \\
\hline 5. Records and reports & 2 & 0 & 5 & 0 & 0 & 0 & $16 \%$ \\
\hline Freight Operations & 1 & 0 & 1 & 0 & 0 & 0 & $5 \%$ \\
\hline Totals: & $16 \%$ & $20 \%$ & $48 \%$ & $0 \%$ & $9 \%$ & $7 \%$ & $100 \%$ \\
\hline
\end{tabular}

of trains, manage unexpected events, and arrange for the use of track by maintenance of way departments and inspectors. This implies that emphasis should be placed on objective areas that directly address performance, rather than knowledge or comprehension.

In addition, interpersonal skills and lifestyle skills (e.g., fatigue management, stress management) are becoming more and more important in the job of a railroad dispatcher, since dispatchers communicate with so many different departments and individuals, and encounter such a variety of situations through the course of a shift. Thus, emphasis should also be placed on those objectives that target interpersonal and lifestyle skills.

Test designers may choose to highlight or focus on particularly important objectives by increasing the number of test items associated with those objectives in the table of specifications. In this test design, and the two that follow, test elements that correspond to important objectives for initial dispatcher training were multiplied by two. The decision to double the number of some test elements was arbitrary; its intention is simply to show the relative importance of the associated objectives compared to other objectives in the table of specifications.

Therefore, the number of test elements in the table of specifications was doubled for those instructional objectives that had learning outcomes with complexity levels greater than or equal to application (i.e., application, analysis, synthesis, or evaluation), and that were concerned with interpersonal skills, planning, managing and controlling track use, and managing unplanned and emergency events. As a result, the number of test elements increased from 44 to 66 . The adjustment to the table of specifications is presented in Table 9.

\subsubsection{Number and Format of Test Items}

This section makes specific recommendations concerning the number of test items, test length (time), passing levels, and test item format for a summative test to be given at the conclusion of initial dispatcher training, and based on the selected instructional objectives. 
Table 9. Revised table of specifications for initial dispatcher training

\begin{tabular}{|c|c|c|c|c|c|c|c|c|c|}
\hline & & & & & Lear & ming Outcc & ome & & \\
\hline Function Area & & Instructional Objective & $\begin{array}{l}\text { Know- } \\
\text { ledge }\end{array}$ & $\begin{array}{l}\text { Compre- } \\
\text { hension }\end{array}$ & $\begin{array}{l}\text { Applica- } \\
\text { tion }\end{array}$ & Analysis & Synthesis & $\begin{array}{c}\text { Evalua- } \\
\text { tion }\end{array}$ & Total \\
\hline Prerequisites & $\begin{array}{l}1.1 \\
1.2\end{array}$ & $\begin{array}{l}\text { Basic structure of the rail industry. } \\
\text { General duties of dispatchers and other railroad personnel who } \\
\text { routinely interact with them. }\end{array}$ & & $\begin{array}{l}1 \\
1\end{array}$ & & & & & $\begin{array}{l}1 \\
1\end{array}$ \\
\hline & 1.3 & Terminology, jargon and shorthand terms used in dispatching. & & 1 & & & & & 1 \\
\hline & 1.4 & Operating and safety rules, including federal regulations. & & 1 & & & & & 1 \\
\hline & 1.5 & Communication skills and procedures. & & & 2 & & & & 2 \\
\hline & 1.6 & Interpersonal communication skills with other personnel. & & & 2 & & & & 2 \\
\hline & 1.7 & Resolution of conflicting requests for action. & & & 2 & & & & 2 \\
\hline & 1.8 & Lifestyle choices affecting work performance. & & & 2 & & & & 2 \\
\hline & 1.9 & Stress management techniques. & & & 2 & & & & 2 \\
\hline & 1.10 & Manage documentation. & 1 & & & & & & 1 \\
\hline & & Total number of elements in function area: & & & & & & & 15 \\
\hline Planning & 2.1 & Procedures for assuming/relinquishing duties. & & & 2 & & & & 2 \\
\hline & 2.2 & Use of track usage and train schedules. & & & & & 2 & & 2 \\
\hline & 2.3 & Judge train and track user priorities. & & & & & & 2 & 2 \\
\hline & 2.4 & Use of planning forms and/or devices. & & & 2 & & & & 2 \\
\hline & 2.5 & Prioritize job tasks. & & & & & & 2 & 2 \\
\hline & 2.6 & Managing train and engine crew logistics. & & & & & 2 & & 2 \\
\hline & & Total number of elements in function area: & & & & & & & 12 \\
\hline Controlling track use & 3.1 & Characteristics of physical territory. & & 1 & & & & & 1 \\
\hline & 3.2 & $\begin{array}{l}\text { Effect of operating characteristics of rail equipment on the } \\
\text { dispatching task. }\end{array}$ & 1 & & & & & & 1 \\
\hline & 3.3 & Location of operating characteristics information. & 1 & & & & & & 1 \\
\hline & 3.4 & Understand movement and protective authorities. & & 1 & & & & & 1 \\
\hline & 3.5 & Apply movement and protective authorities. & & & 2 & & & & 2 \\
\hline & 3.6 & Principles of railway signaling. & & 1 & & & & & 1 \\
\hline & 3.7 & Plan beyond limits of territory. & & & 2 & & & & 2 \\
\hline & 3.8 & Use of blocking devices. & & & 2 & & & & 2 \\
\hline & 3.9 & Use of speed restrictions. & & & 2 & & & & 2 \\
\hline & 3.10 & Understand track bulletins, special instructions, etc. & & 1 & & & & & 1 \\
\hline & 3.11 & Use of tracks by non-shunting equipment and work crews. & & & 2 & & & & 2 \\
\hline & 3.12 & $\begin{array}{l}\text { Physical location of text of rules, regulations, and emergency } \\
\text { procedures. }\end{array}$ & 1 & & & & & & 1 \\
\hline & 3.13 & Estimation of train transit times. & & & & & 2 & & 2 \\
\hline & 3.14 & Planning and execution of train meets. & & & & & 2 & & 2 \\
\hline & & Total number of elements in function area: & & & & & & & 21 \\
\hline Unplanned and & 4.1 & Response to wayside defect detectors. & & & 2 & & & & 2 \\
\hline & 4.2 & Understand procedures for emergency events. & & 1 & & & & & 1 \\
\hline & 4.3 & Implement procedures for emergency events. & & & 2 & & & & 2 \\
\hline & 4.4 & Response to events for which no procedures exist. & & & & & & 2 & 2 \\
\hline & 4.5 & $\begin{array}{l}\text { Compensation for computer or system failure during unplanned } \\
\text { or emergency events. }\end{array}$ & & & 2 & & & & 2 \\
\hline & & Total number of elements in function area: & & & & & & & 9 \\
\hline Records and reports & 5.1 & Know what records to initiate, maintain and complete. & 1 & & & & & & 1 \\
\hline & 5.2 & Initiate, maintain and complete records. & & & 1 & & & & 1 \\
\hline & 5.3 & $\begin{array}{l}\text { Production of records when mechanical or electronic devices } \\
\text { fail. }\end{array}$ & & & 1 & & & & 1 \\
\hline & 5.4 & Reporting requirements. & 1 & & & & & & 1 \\
\hline & 5.5 & Production of reports. & & & 1 & & & & 1 \\
\hline & 5.6 & Production of reports when mechanical or electronic devices fail. & & & 1 & & & & 1 \\
\hline & 5.7 & $\begin{array}{l}\text { Production of computerized reports using specified fields or } \\
\text { parameters. }\end{array}$ & & & 1 & & & & 1 \\
\hline & & Total number of elements in function area: & & & & & & & 7 \\
\hline Freight Operations & 1.1 & Handling of hazardous materials. & 1 & & & & & & 1 \\
\hline & 1.2 & Helper services. & & & 1 & & & & 1 \\
\hline & & Total number of elements in function area: & & & & & & & 2 \\
\hline & & Totals: & 7 & 9 & 36 & 0 & 8 & 6 & 66 \\
\hline
\end{tabular}




\subsubsection{Number of Test Items and Length of Test}

There are a total of 66 elements in the table of specifications, so 66 is the absolute minimum number of test items that should be asked (i.e., every element would be represented by 1 test item). At an estimated adult answering rate of approximately 1 test item every $30 \mathrm{sec}$ for objectively scored items, the test would take approximately $30 \mathrm{~min}$. This few test items is not recommended, however, due to the broad amount of information covered by the test. Since an average student could cover twice the number of test items in an hour, the recommended number of test items for the test is 132, with two test items to be written for each single element count. Since the test is essentially a "final examination," $2 \mathrm{hr}$ is recommended for testing time during the initial use of the test.

It is likely that the conventional passing level of 90 percent is probably too high for the test as a whole, since the typical difficulty level of these types of test items is relatively high. Over three-quarters (76 percent) of the test items will fall at the application complexity level or greater. Subsection 8.2.2 of this report addresses the various methods that can be used to determine appropriate passing levels. Of these methods, it is recommended that the approach be used which validates a passing level by giving the test to experienced, currently employed dispatchers who are considered by all parties to be experts.

\subsubsection{Format of the Test Items}

In every instance where test items address the use of specific materials or equipment, the use of these materials or equipment is encouraged. The next best alternative to hands-on testing is to use paper forms and paper-based simulated computer screens with sample situations (i.e., case studies) to which examinees must respond. If time and resources permit, development of computer-administered tests should be considered.

A test item format matrix recommended for the sample typical initial dispatcher training test is shown in Table 10. The matrix is directly tied to the level of cognitive learning outcome and element counts provided in the revised table of specifications (Table 9). The actual wording and presentation of each test item should reflect the specific instructional objectives to the extent possible.

Reference is made to specific types of test items in Table 10. An IMC, or identification multiple choice, notation indicates that a multiple-choice item which requires the identification of a correct term or procedure is recommended. The PMC notation indicates that a problem multiple choice item is recommended, requiring the selection of the correct answer to a problem presented in the stem of the test item. The PS, or problem set, notation refers to the description or presentation of a problem situation requiring the student to manipulate forms or make computer inputs in a simulation setting (as compared to selecting a response). 
Table 10. Question matrix for initial dispatcher training test design

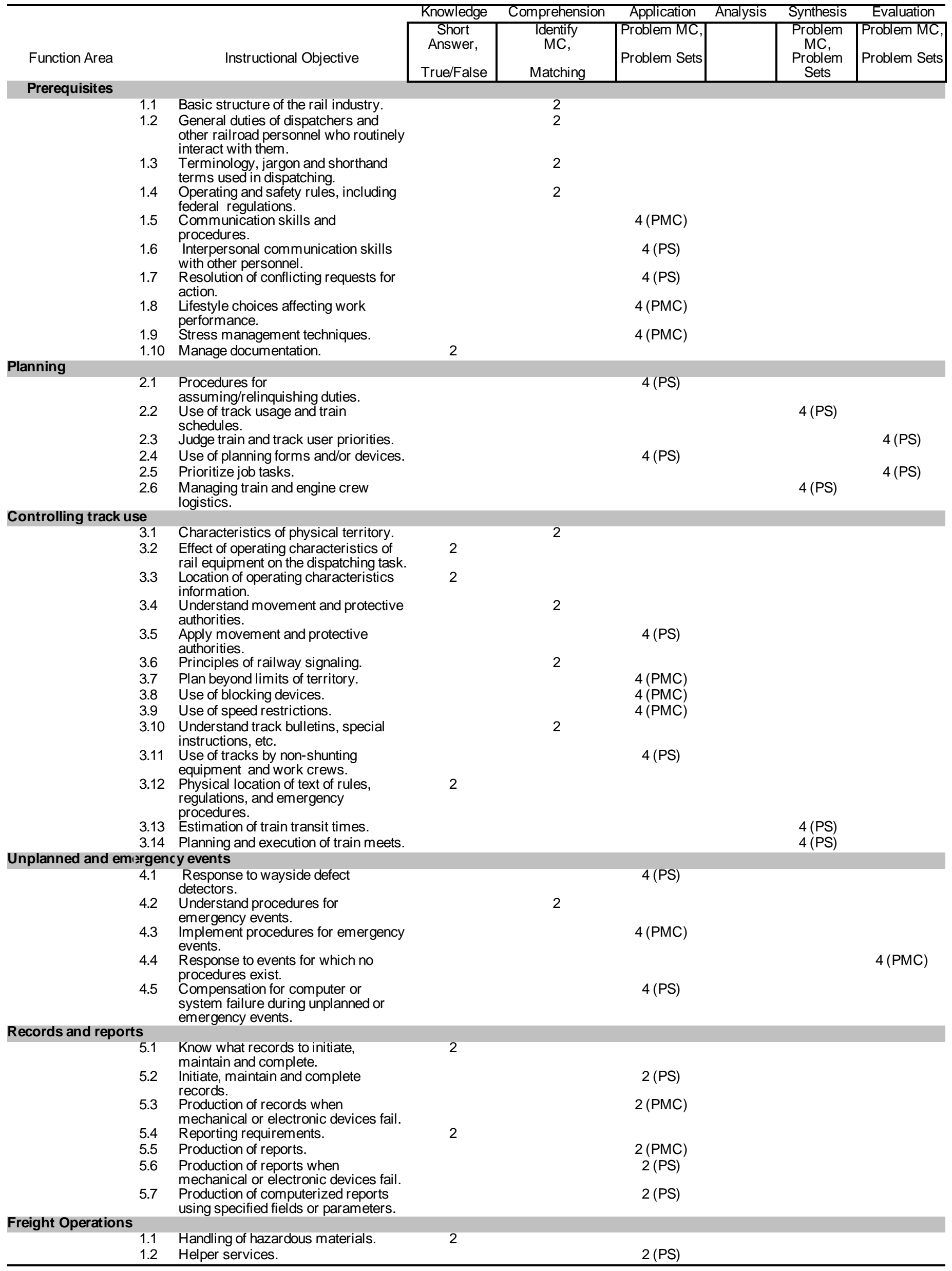




\subsubsection{Use of the Question Matrix}

Test items must be appropriate to both the specific skill or piece of information that they are intended to reflect, and the associated learning outcome for that test item's objective. For example, it would be difficult to measure an application-oriented objective that addresses a specific skill with a true/false test item. Even a simple multiple choice test item might not be adequate for this purpose.

The lowest level in Bloom's taxonomy of cognitive learning outcomes (ㅁ) is knowledge. Knowledge refers to the simple recollection or identification of factual information. Short answer and true/false test items are recommended in the matrix for this level, although multiple choice and matching test item formats can be used as well.

Comprehension, the next level in the taxonomy, refers to the understanding of concepts or procedures. While short answer or true/false items might be manipulated to measure objectives at this level, it is far easier to use identification multiple choice and matching test items. Identification multiple choice describes a test item that calls on the examinee to identify the meaning or implication of a sample term or statement. An example of an identification multiple choice test item is:

A dispatcher says, "A local is out there ahead of Amtrak 515 on track 1." A "local" is:
a. A repair vehicle.
b. A reference to a local resident.
c. A train that makes stops at stations and industrial tracks along the route to pick up, set out, switch, spot and pull cars.

d. A train that is 5 to 15 min ahead of schedule.

In order to answer the test item correctly, the examinee not only must know the definition of the term, but must also understand the implication of what the term means: that a local train is one that is dispatched from its terminal and, as a consequence, will probably return there at the end of the shift. If a simple definition of "local train" was one of the choices, the item would then have been functioning at the knowledge, rather than comprehension level. Matching items may also be written at the comprehension level, although the more common use is at the knowledge level with the matched terms written in the form of simple definitions.

Application, synthesis, and evaluation learning outcomes in the question matrix warrant the use of problem multiple-choice test items and problem sets. Problem multiple-choice questions require examinees to employ their understanding and skills to solve a problem. If the multiple choice item covering terminology, jargon and frequently applied shorthand terms" (instructional objective 1.3) were recast as an application level test item, it might take the following form: 
A dispatcher says, "A local is out there ahead of Amtrak 515 on track 1." The dispatcher knows that:

a. Repair work is being performed on the track.

b. A local resident is stalled on a highway crossing ahead of Amtrak 515. Amtrak 515 must be notified immediately.

c. A train committed to picking up and setting out cars is occupying track that will probably be needed soon.

d. Amtrak 515 will have to reduce speed so the local doesn't have to worry.

In this example, the examinee has to know what a local train is, what it does, what the implications of its movements are and what must be done in the current situation as a consequence ("c. A train committed to picking up and setting out cars is occupying track that will probably be needed soon.”).

A problem set refers to providing the examinee with materials and information that require some kind of action that constitutes the skill represented by the selected objective. For example, instructional objective 5.3 in the matrix, "Production of records when mechanical or electronic devices fail," recommends the use of a problem set. In this case, the test item would provide information about the current state of operations in a dispatcher's territory and would require the use of alternate means to create the correct report. Readers should note that having the examinee explain how to do the report/s or (even worse) selecting a multiple-choice description is not intended here. Performing a skill tests that skill. Explaining a skill tests the ability to explain. The object of a problem set is to cause the examinee to display a specific skill. If the desired performance has multiple parts or steps, it is appropriate to award test points for each step or part. This is preferred to awarding a number of points for the performance of the problem set as a whole on an "all or none" basis.

Problem sets typically call for open-ended responses in which a correct response might take any number of forms. In these cases, the test designer should write a short list of criteria to be used in judging the correctness of examinee responses.

\subsubsection{Specific Recommendations}

The previous section provides basic information about writing test items in the context of the instructional objectives. They are general principles. The following section provides specific recommendations for some of the objectives found in the question matrix for the initial dispatcher training test design. Although recommendations are made, it is not necessary to follow them, and often, it will not be practical or even possible. In these instances, the guidelines provided in subsection 8.2 should be helpful in lieu of specific recommendations. 
Objectives 1.6 and 1.7 concentrate on dispatcher communication skills in conflict situations. Problem sets are recommended to address both objectives. The use of actual recordings, previously unheard by the examinees, is recommended. In a test situation, these items would be placed first on the test. The recordings could be played at the beginning of the test and the examinees would write their individual responses. In a situation where only one individual is tested at a time, the examinee's response could be sound recorded, if desired.

Objective 2.1 focuses on assuming/relinquishing duties. Problem sets are suggested here. Capturing the status of a dispatcher's desk at shift end is suggested as a source of material.

Objective 2.3 concentrates on prioritizing various track users. Problem sets at the evaluation level are recommended. This means that actual situations, with varying degrees of detail should be used. The problem should be framed in such a way as to require evaluation and decisions by the examinee.

Objective 2.4, "Use of planning forms": see item 2.5, below.

Objective 2.5, "Prioritizing job tasks" is considered to be a skill of the highest order. In an ideal testing situation, a simulation exercise could be used for this evaluation, complete with telephone calls and other typical interruptions. More realistically, the materials used for item 2.1 might be used as a starting point. More than one item could be developed from these materials by asking the trainee to develop an initial plan of action and then require adjustments to be made in subsequent test items. Test item 2.4 may also be assessed by these means.

Objective 2.6, "Managing train and engine crew logistics," is categorized as a high level skill. Problem sets in this area should include the necessary records so that elements of train crew hours of service, deadheading, use of extra board crewmen and trainmaster's orders can be addressed.

Objective 3.1 test items regarding physical territory should use graphic images (photos, track charts) as cue materials. For example, some railroads have videotapes of track geometry which could be sampled using a personal computer and "frame grabber" software. Test items can either show graphics of locations which require responses or provide written statements that require the identification of graphics taken from the actual location.

Objective 3.5 test items regarding movement and protective authorities should involve actual situations that call for issuance of the proper authority in the proper form. In doing so, the form of the test closely matches the actual dispatching situation.

Objective 3.11 recommends the use of problem sets to assess the skill of dispatching and protecting work crews and non-shunting equipment. Work orders and tape recordings of actual dispatcher communications with work crews can be used here. The recommendation at the application level here is that examinees should be called upon to solve the kinds of dispatching problems caused by the presence of work crews and equipment. 
Objective 3.13 calls for the estimation of train transit times. The use of representations of real territory as cue materials for the test items is encouraged.

Objective 3.14, Planning and executing train meets is one of the most critical elements of dispatching and is considered to be a very high level skill. Problem set test items that consist of realistic source materials with situations involving differential transit times, equipment failures and special speed restrictions are recommended.

Objective 4.1 involves the use of problem sets, such as situations involving overheated axles or dragging equipment.

Objectives 4.2 and 4.3 involve responses to unplanned emergency events. It is recommended that the comprehension level test items for these items use realistic contexts (computer displays or messages to the dispatcher) as cue materials.

Objective 4.4, "Response to events for which no procedures exist," is classified, in part, as a high level skill. As in all other instances in which problem sets are recommended, realistic materials should be used. At the evaluation level, the item should call for review of a situation and a judgment as to whether an emergency exists, and/or a decision as to which elements in a situation require the most immediate response. The examinee should create a practical solution to an emergency situation for which no procedure exists. The test designer should be especially careful here to write out a list of criteria for judging responses to this item prior to the administration of the test.

Objective 4.5, "Compensation for computer or system failure," is another item requiring a problem set. In this case, "last known information" should be provided, with the requirement that the dispatcher should indicate what should be done next. As in the test item for instructional objective 4.4, the test designer should write out a list of criteria for judging responses to this item.

Objective 5.2, "Maintaining records," calls for problem sets which should use actual records and record forms as the cue materials. Where electronic methods are used, the use of computerized testing of this skill is encouraged.

Objectives 5.3 and 5.6 deal with the production of reports and records when mechanical or electronic devices fail. Problem sets should outline realistic situations and then require the actual responses to be produced in the problem situation. One possibility is to use problem sets that consist of "last known information prior to system failure," where the examinee must indicate what should be done next. A list of criteria for judging responses should be created prior to administering the test.

Objective 5.7 addresses computerized report production. Use of actual equipment is recommended where possible. It is tempting to use paper representations here in the interest of time, but the skills being evaluated are ones that involve specific keyboard actions that are difficult to represent in other ways. 
Freight Objective 1.2 involves the dispatch of helper services. Trainees should be tested on their recognition of times when helper services are needed, as well as what types of service (e.g., motive power, qualified pilot, etc.) are needed.

\subsubsection{Writing and Use of the Test}

This section discusses two separate issues in writing and using a test based on this test design. The first subsection distinguishes between testing general versus specific territory knowledge, while the second subsection discusses some time considerations in designing the test.

\subsubsection{General Versus Specific Territory Knowledge}

A distinction should be made in the regard to test items that will be written regarding physical characteristics of territory for the test design in this section. This report makes a distinction between test items concerning aspects of physical territory as covered in initial training as compared to specific aspects of physical territory which would be covered in a separate initial territory qualification exam (see subsection 9.2).

Test items regarding physical territory in this examination should be general in nature. An example of a general territory question would be one which presented a segment of unidentified track chart showing a number of signals and a siding and prompted the student to "circle the signal(s) which might display an approach diverging aspect." As a contrast, an example of a specific territory question asked on a territory qualification exam would be one which provided no chart and asked "nearest what milepost does the first signal occur which can show an approach diverging aspect for the siding at Chana?"

\subsubsection{Time Considerations}

The amount of time necessary to prepare the test described in this section is daunting compared with the tradition of simply sitting down at a typewriter and randomly generating 50 to 100 test items. Indeed, if the test designer has to "start from scratch," designing the test is a large task. In an integrated course design, however, the "problem sets" and "problem multiple choice" test items are nothing more than additional versions of materials which are prepared for practice and demonstration during course instruction. Even under these conditions, more effort is clearly required than that expended in generating a test of randomly written test items. The payoff, however, is that the course materials will be more meaningful and the test will be fair in determining trainee skills at the tasks they are to undertake as a dispatcher. Proper instruction gives trainees practice at the duties they will eventually undertake. Proper testing allows trainees to demonstrate the skills they have learned as a result of the instruction.

Using some of the general rules of thumb given in subsection 8.2, the time estimates for creating, administering, scoring, and revising the sample test were calculated.

The total time required to prepare the tests is about $27 \mathrm{hr}$. (See Table 11 for specific details for preparing the test.) The time required to administer the test is approximately $2 \mathrm{hr}$. The time 
Table 11. Test preparation activities for initial training

\begin{tabular}{lccc}
\hline \multicolumn{1}{c}{ Item Type } & $\begin{array}{c}\text { Number of } \\
\text { Items }\end{array}$ & $\begin{array}{c}\text { Time per Item } \\
\text { (min) }\end{array}$ & $\begin{array}{c}\text { Total Time } \\
\text { (hr) }\end{array}$ \\
\hline True/False and Short Answer & 14 & 2.5 & 0.6 \\
Multiple Choice & 54 & 6 & 5.4 \\
"Problem Sets" & 64 & $20^{*}$ & 21.3 \\
Total & & 27.3 \\
*Note: The generous time estimate for this type is a consequence of the time \\
spent arranging materials or computer simulation runs into a form which can be \\
used for evaluation.
\end{tabular}

required to evaluate and post the test scores is about 70 min per test. Table 12 provides specific details of the test evaluation and posting.

A formal item analysis on the test is estimated to take between an hour and a half ( $80 \mathrm{~min}$ ) and $3 \mathrm{hr}(160 \mathrm{~min})$ for 20 tests. In order for an item analysis to be meaningful, 15 to 20 tests are suggested as a minimum. Based on the recommendations of subsection 8.2, and keeping the total number of tests required in mind, 33 question responses can be evaluated in 1 min. Thus, the evaluation rate is about 4 min per student test; evaluation of 20 tests would take $80 \mathrm{~min}$. In cases where 15 to 20 tests is an impractical number due to limited numbers of trainees, collecting test results over a number of classes is recommended. In cases where even this approach cannot be used, a direct interview of students and their results is appropriate.

The time it takes to conduct a validity study is completely conjectural since it depends on the ease with which follow-up information can be found. It is recommended that at least some time be allotted for this activity.

Table 12. Test evaluation and posting activities for initial training

\begin{tabular}{lccc}
\hline \multicolumn{1}{c}{ Activity } & $\begin{array}{c}\text { Number of } \\
\text { Items }\end{array}$ & $\begin{array}{c}\text { Time per Item } \\
(\mathrm{min})\end{array}$ & $\begin{array}{c}\text { Total Time } \\
(\mathrm{min})\end{array}$ \\
\hline True/False and Short Answer & 14 & 0.1 & 1.4 \\
Multiple Choice & 54 & 0.05 & 2.7 \\
"Problem Sets" & 64 & 1 & 64.0 \\
Posting* & 2 & 2.0 \\
Total & & 70.1 \\
& & \\
*Note: The time for posting the test results is very conjectural. An estimate of 2 min \\
pertest is suggested, although the actual time will depend on the method and \\
requirements of recording and posting the tests.
\end{tabular}


Test revision is another conjectural time estimate, dependent on circumstances. If, as suggested in subsection 8.2, a 50 item test might require an annual review which lasts $3 \mathrm{hr}$, the sample test portrayed in Table 11, with 132 test items, may take about $8 \mathrm{hr}$. When only a few individuals are involved, test revision may be as simple as making changes based on direct interviews.

\subsection{A Test Design for the Evaluation of Initial Territory Training}

The test design for summative evaluation of initial trainees, subsection 9.1, is not intended to convey qualification to dispatch on any particular territory. A separate training process, and consequently, a separate testing process, is necessary for this purpose. The process of qualifying a dispatcher on their initial territory is similar to that of qualification upon subsequent territories, except that a larger number of objectives must be tested for the initial territory since this will be the first time that the dispatcher will apply their training to actually dispatch trains. A test design was developed for qualification upon a trainee's initial territory; qualification upon subsequent territories is beyond the scope of this project.

Creating a test for territory qualification involves a special consideration. Qualification testing should be specifically created for each territory, and should cover not only the special features of the territory, but also the way in which those features affect the performance of the dispatcher's duties.

This section begins with the creation of a test design using the steps of development as presented in subsection 8.1. The section concludes with special considerations and recommendations in regard to use of the test.

\subsubsection{Selection of Objectives}

The selection of objectives for this area is conditioned by, among other factors, the volume and type of traffic on the territory, the physical characteristics of the territory, and amount of track miles controlled by the dispatcher. Upon completion of initial training the student will have demonstrated dispatching skills in a classroom or simulator environment. The process of qualification on his/her first territory must include demonstrating these same skills in the actual dispatching environment. Twenty-four instructional objectives were identified which the trainee should be able to master at the conclusion of their initial territory training. The 24 objectives, which also influenced the syllabus checklist for initial territory training, are identified in Table 2 in subsection 5.2.

\subsubsection{Table of Specifications}

The purpose of this step is to ensure that the type and subject matter of test items created will reflect the nature of the course (initial territory training) objectives. Table 13 presents a table of specifications for an initial territory qualification exam. 
Table 13. Table of specifications for initial territory qualification

\begin{tabular}{|c|c|c|c|c|c|c|c|c|c|}
\hline Function Area & & Instructional Objective & $\begin{array}{l}\text { Know- } \\
\text { ledge }\end{array}$ & $\begin{array}{l}\text { Compre- } \\
\text { hension }\end{array}$ & $\begin{array}{l}\text { Applica- } \\
\text { tion }\end{array}$ & $\begin{array}{l}\text { Ana- } \\
\text { lysis }\end{array}$ & $\begin{array}{l}\text { Syn- } \\
\text { thesis }\end{array}$ & $\begin{array}{c}\text { Evalua- } \\
\text { tion }\end{array}$ & Total \\
\hline \multirow[t]{7}{*}{ Planning } & 2.1 & $\begin{array}{l}\text { Procedures for assuming/relinquishing } \\
\text { duties. }\end{array}$ & & & 1 & & & & 1 \\
\hline & 2.2 & Use of track usage and train schedules. & & & & & 1 & & 1 \\
\hline & 2.3 & Judge train and track user priorities. & & & & & & 1 & 1 \\
\hline & 2.4 & Use of planning forms and/or devices. & & & 1 & & & & 1 \\
\hline & 2.5 & Prioritize job tasks. & & & & & & 1 & 1 \\
\hline & 2.6 & Managing train and engine crew logistics. & & & & & 1 & & 1 \\
\hline & & $\begin{array}{l}\text { Total number of elements in } \\
\text { function area: }\end{array}$ & & & & & & & 6 \\
\hline \multirow[t]{11}{*}{ Controlling track use } & 3.1 & Characteristics of physical territory. & & 1 & & & & & 1 \\
\hline & 3.3 & $\begin{array}{l}\text { Location of operating characteristics } \\
\text { information. }\end{array}$ & 1 & & & & & & 1 \\
\hline & 3.5 & Apply movement and protective authorities. & & & 1 & & & & 1 \\
\hline & 3.7 & Plan beyond limits of territory. & & & 1 & & & & 1 \\
\hline & 3.8 & Use of blocking devices. & & & 1 & & & & 1 \\
\hline & 3.9 & Use of speed restrictions. & & & 1 & & & & 1 \\
\hline & 3.11 & $\begin{array}{l}\text { Use of tracks by non-shunting equipment } \\
\text { and work crews. }\end{array}$ & & & 1 & & & & 1 \\
\hline & 3.12 & $\begin{array}{l}\text { Physical location of text of rules, } \\
\text { regulations, and emergency procedures. }\end{array}$ & 1 & & & & & & 1 \\
\hline & 3.13 & Estimation of train transit times. & & & & & 1 & & 1 \\
\hline & 3.14 & Planning and execution of train meets. & & & & & 1 & & 1 \\
\hline & & $\begin{array}{l}\text { Total number of elements in } \\
\text { function area: }\end{array}$ & & & & & & & 10 \\
\hline \multirow{3}{*}{$\begin{array}{l}\text { Unplanned and } \\
\text { emergency events }\end{array}$} & 4.1 & Response to wayside defect detectors. & & & 1 & & & & 1 \\
\hline & 4.3 & $\begin{array}{l}\text { Implement procedures for emergency } \\
\text { events. }\end{array}$ & & & 1 & & & & 1 \\
\hline & & $\begin{array}{l}\text { Total number of elements in } \\
\text { function area: }\end{array}$ & & & & & & & 2 \\
\hline \multirow[t]{5}{*}{ Records and reports } & 5.2 & Initiate, maintain and complete records. & & & 1 & & & & 1 \\
\hline & 5.5 & Production of reports. & & & 1 & & & & 1 \\
\hline & 5.6 & $\begin{array}{l}\text { Production of reports when mechanical or } \\
\text { electronic devices fail. }\end{array}$ & & & 1 & & & & 1 \\
\hline & 5.7 & $\begin{array}{l}\text { Production of computerized reports using } \\
\text { specified fields or parameters. }\end{array}$ & & & 1 & & & & 1 \\
\hline & & $\begin{array}{l}\text { Total number of elements in } \\
\text { functional area: }\end{array}$ & & & & & & & 4 \\
\hline \multirow[t]{4}{*}{ Freight Operations } & 1.1 & Handling of hazardous materials. & 1 & & & & & & 1 \\
\hline & 1.2 & Helper services. & & & 1 & & & & 1 \\
\hline & & $\begin{array}{l}\text { Total number of elements in } \\
\text { functional area: }\end{array}$ & & & & & & & 2 \\
\hline & & Totals: & 3 & 1 & 14 & 0 & 4 & 2 & 24 \\
\hline
\end{tabular}




\subsubsection{Adjustments to Table of Specifications}

The process of adjusting the table of specifications that was used for the initial dispatcher training test design was applied here as well. That is, the number of test elements in the table of specifications was doubled for those instructional objectives that had learning outcomes with complexity levels greater than or equal to application (i.e., application, analysis, synthesis, or evaluation), and that were concerned with planning, controlling or managing track use, and managing unplanned and emergency events. In addition, since the physical characteristics of the territory constitute such a central interest in this training, the count associated with learning the physical characteristics was also doubled. As a result, the number of test elements increased from 24 to 40. (See Table 14.)

\subsubsection{Number and Format of Test Items}

This section makes specific recommendations concerning the number of test items, test length (time), passing levels, and test item format for a summative test to be given at the conclusion of initial territory training, and based on the selected instructional objectives.

\subsubsection{Number of Test Items and Length of Test}

For a summative evaluation of initial territory training, an absolute minimum of 40 test items should be written, corresponding to the 40 elements found in the adjusted table of specifications. However, since there are only 40 elements, and since the training is quintessential to railroad dispatching (applying newly learned skills), it is suggested that at least three test items be written for each element. Since the number of territory features is of primary interest to learning how to dispatch on a territory, the physical features should influence the total number of test items. In the case of a feature-dense territory, such as that encountered in passenger rail dispatching in an urban environment, for example, more than 20 test items may be necessitated just to address the physical characteristics of that territory. Each railroad will have to determine the exact number of test items that should be devoted to the physical characteristics of a territory. Given the revised table of specifications with 40 elements, the number and distribution of test items totals 120. Such a test should be successfully completed in $2 \mathrm{hr}$ or less.

\subsubsection{Format of the Test Items}

The focus of initial territory training is on the application of new skills to real situations. The content of the test items, therefore, should concentrate on the application of skills, and the specific characteristics of the territory. There is considerable value in having dispatchers who are currently qualified on a given desk propose facts and situations to be used as the content of test items to be asked of trainees attempting to qualify for that desk. Every question written for a qualification test should make a practical reference to the desk being tested. This does not mean, however, that a test for one desk cannot be used as an initial template for another desk. The content of the test items would change, but the structure of many of the test items might remain. The only caution in the "template" approach is that it not be blindly applied to the exclusion of factors that are unique to the desk for which the qualifying test is written. 
Table 14. Revised table of specifications for initial territory training

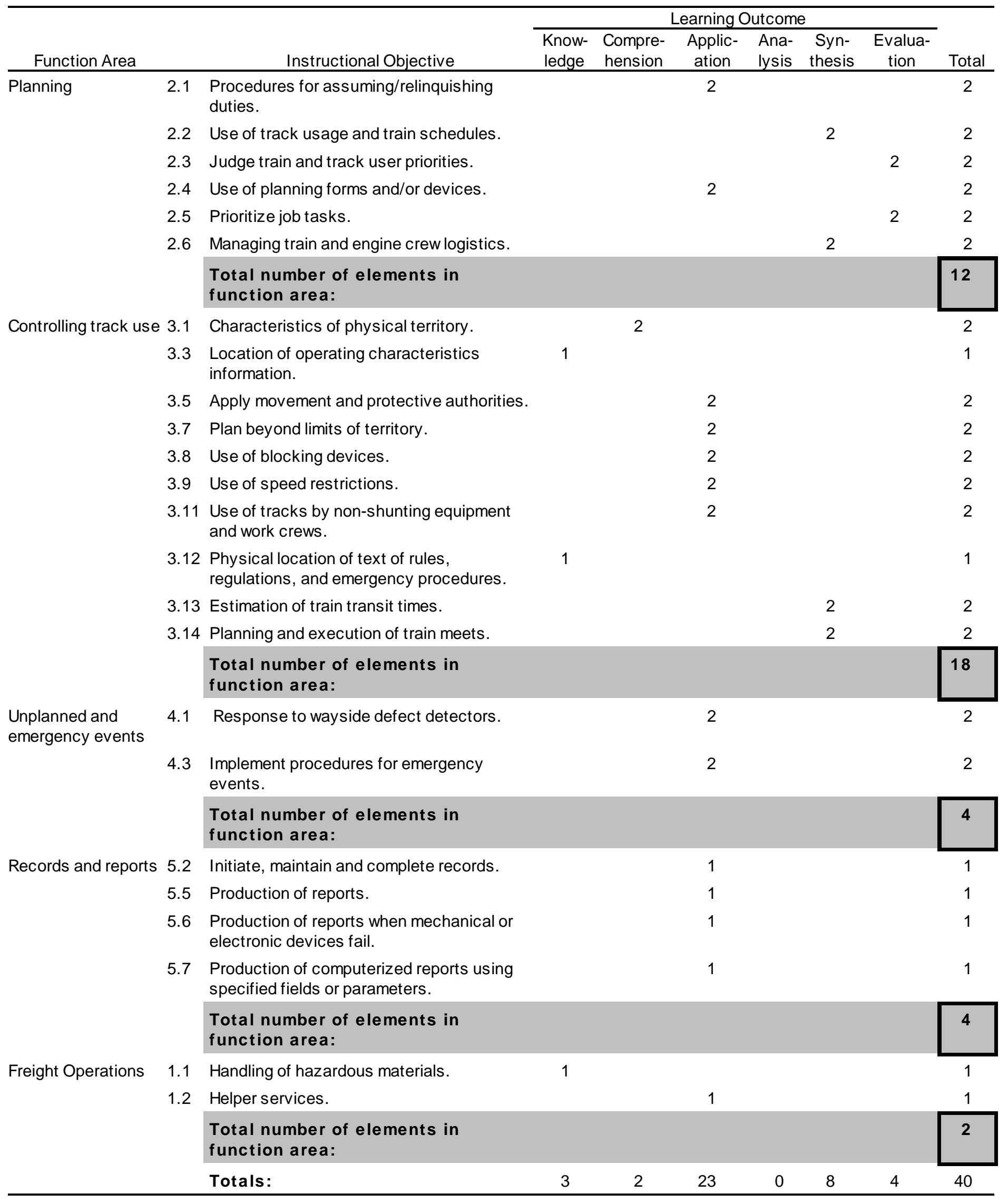


Following the format conventions introduced in subsection 9.1.4.2, which describes the different test item formats appropriate for the different types of learning outcomes, Table 15 presents a question matrix for initial territory qualification. Table 15 shows the number of test items that correspond to each instructional objective that is addressed in initial territory training, as well as shows the suggested format for those test items. Subsection 9.1.4.4 provides some test item format recommendations when using the question matrix.

\subsubsection{Writing and Use of This Test}

Using the general rules of thumb given in subsection 8.2.3, the time required to prepare a test using the test design described in this section is about $30 \mathrm{hr}$. Table 16 provides a breakdown of the times it takes to develop specific parts of the test.

At an estimated average adult answering rate of approximately 1 question every $30 \mathrm{sec}$ for objectively scored items, the 120 item test would take $1 \mathrm{hr}$. This time should be doubled to $2 \mathrm{hr}$ to give ample time for everyone to complete the test, particularly since there are many problem set-type test items which typically take longer to answer. Experience may be used to readjust the time as necessary. The time required to evaluate the test scores, shown in Table 17, is less than $1.5 \mathrm{hr}$.

Item analysis for this type of test is not practical, given the limited number of persons who would take this form of test. A post-test interview with each examinee is recommended to determine if any test items were misleading or inappropriate. The feedback from this exchange will aid both the instructor (in revising tests) and the examinee (understanding where mistakes were made and reinforcing correct responses). Estimated time for this activity is 5 min per test.

Validity study of the test is also difficult for the same reason that formal item analysis is impractical. In practice, it would be advisable for a supervisor to observe persons for some period of time after they have been assigned to new territory. The outcome of the qualification test should agree with the supervisor's evaluation of individual performance. No estimate is provided for this activity, as it is assumed to be an appropriate part of routine operations.

Test revision for this type of test can be an integral part of item analysis and an outcome arising out of any disagreement between test performance and subsequent supervisor's evaluation. Consequently, no time estimate is provided for test revision.

\subsection{A Test Design for Periodic Reassessment}

Though 49 CFR 217.11 does not require a specific frequency with which railroads must test its employees on the railroad's operational rules, it does require rules testing to occur. In practice, most railroads administer a rules test annually. Subsection 9.3 presents a test design for a test of dispatching knowledge and skills, which is intended to be given to dispatchers every few years (periodic). The test design for periodic reassessment includes objectives that are included in an annual rules test, but covers additional skills and knowledge bases, and in more detail. The issue of periodic refresher training frequency is addressed in subsection 9.3.6. 


\section{Table 15. Question matrix for initial territory qualification}

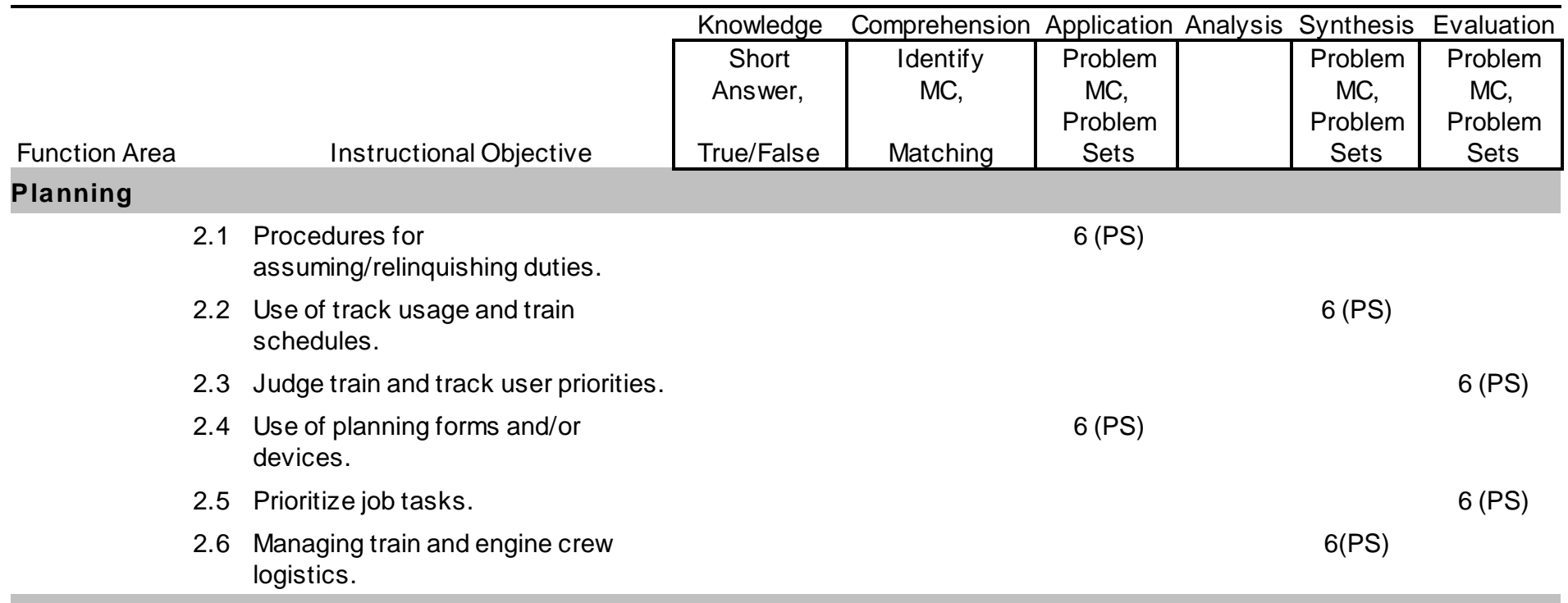

\section{Controlling track use}

3.1 Characteristics of physical territory.

6

\subsection{Location of operating characteristics information.}

3

3.5 Apply movement and protective authorities.

6 (PS)

6 (PMC)

3.7 Plan beyond limits of territory.

6 (PMC)

6 (PMC)

6 (PS)

3.11 Use of tracks by non-shunting equipment and work crews.

3.12 Physical location of text of rules, regulations, and emergency procedures.

3.13 Estimation of train transit times.

3.14 Planning and execution of train meets.

\section{Unplanned and einergency events}

4.1 Response to wayside defect detectors.

4.3 Implement procedures for

6 (PMC) emergency events.

\section{Records and reports}

5.2 Initiate, maintain and complete records.

5.5 Production of reports.

5.6 Production of reports when mechanical or electronic devices fail.

5.7 Production of computerized reports using specified fields or parameters.

\section{Freight Operations}

1.1 Handling of hazardous materials.

1.2 Helper services.
3

3 (PS) 
Table 16. Test preparation activities for initial territory qualification

\begin{tabular}{lccc}
\hline \multicolumn{1}{c}{ Item Type } & $\begin{array}{c}\text { Number of } \\
\text { Items }\end{array}$ & $\begin{array}{c}\text { Time per Item } \\
(\mathrm{min})\end{array}$ & $\begin{array}{c}\text { Total Time } \\
(\mathrm{hr})\end{array}$ \\
\hline True/False and Short Answer & 9 & 2.5 & 0.4 \\
Multiple Choice & 33 & 6 & 3.3 \\
"Problem Sets" & 78 & 20 & 26.0 \\
Total & & & 29.7 \\
\hline
\end{tabular}

Table 17. Test evaluation and posting activities for initial territory qualification

\begin{tabular}{lccc}
\hline \multicolumn{1}{c}{ Activity } & $\begin{array}{c}\text { Number of } \\
\text { ltems }\end{array}$ & $\begin{array}{c}\text { Time per Item } \\
(\mathrm{min})\end{array}$ & $\begin{array}{c}\text { Total Time } \\
(\mathrm{min})\end{array}$ \\
\hline True/False and Short Answer & 9 & 0.1 & 0.9 \\
Multiple Choice & 33 & 0.05 & 1.8 \\
"Problem Sets" & 78 & 1 & 78.0 \\
Total & & & 80.7 \\
\hline
\end{tabular}

This section begins with the creation of a test design with steps of development presented in subsection 8.1. This section concludes with special considerations and recommendations in regard to the use of the test for periodic reassessment.

\subsubsection{Selection of Objectives}

Twenty-five instructional objectives were selected for the periodic refresher training, based on an understanding that people, and the circumstances of their lives, change. Lifestyles may be altered over time. Skills that are not used may be lost. The standards or methods of dispatching may change, particularly in automated environments. In many work environments, the amount of supervision that employees once received has decreased substantially. In these circumstances, work habits are in danger of erosion. Given all of these factors, the objectives were chosen as a means to maintain safe and efficient standards of work.

\subsubsection{Table of Specifications}

The purpose of this step is to ensure that the type and subject matter of test items created will reflect the nature of the course objectives. Table 18 presents a table of specifications for the 25 objectives selected for a periodic reassessment for freight dispatchers.

The table totals in Table 18 are raw sums. They do not reflect concerns of intrinsic importance of some objectives over others, although the proportional distributions imply an emphasis on higher levels of associated learning outcomes for these elements. Table 19 is a summary of the distribution of instructional objectives selected for periodic reassessment as shown in Table 18. 
Table 18. Table of specifications for periodic reassessment

\begin{tabular}{|c|c|c|c|c|c|c|c|c|c|}
\hline \multirow[b]{2}{*}{ Function Area } & \multirow{2}{*}{\multicolumn{2}{|c|}{ Instructional Objective }} & \multicolumn{6}{|c|}{ Learning Outcome } & \multirow[b]{2}{*}{ Total } \\
\hline & & & $\begin{array}{l}\text { Know- } \\
\text { ledge }\end{array}$ & $\begin{array}{l}\text { Compre- } \\
\text { hension }\end{array}$ & $\begin{array}{l}\text { Applica- } \\
\text { tion }\end{array}$ & $\begin{array}{l}\text { Ana- } \\
\text { lysis }\end{array}$ & $\begin{array}{c}\text { Syn- } \\
\text { thesis }\end{array}$ & $\begin{array}{c}\text { Evalua- } \\
\text { tion }\end{array}$ & \\
\hline \multirow[t]{6}{*}{ Prerequisites } & 1.4 & $\begin{array}{l}\text { Operating and safety rules, including federal } \\
\text { regulations. }\end{array}$ & & 1 & & & & & 1 \\
\hline & 1.7 & Resolution of conflicting requests for action. & & & 1 & & & & 1 \\
\hline & 1.8 & Lifestyle choices affecting work performance. & & & 1 & & & & 1 \\
\hline & 1.9 & Stress management techniques. & & & 1 & & & & 1 \\
\hline & 1.10 & Manage documentation. & 1 & & & & & & 1 \\
\hline & & $\begin{array}{l}\text { Total number of elements in function } \\
\text { area: }\end{array}$ & & & & & & & 5 \\
\hline \multirow[t]{5}{*}{ Planning } & 2.1 & Procedures for assuming/relinquishing duties. & & & 1 & & & & 1 \\
\hline & 2.3 & Judge train and track user priorities. & & & & & & 1 & 1 \\
\hline & 2.4 & Use of planning forms and/or devices. & & & 1 & & & & 1 \\
\hline & 2.5 & Prioritize job tasks. & & & & & & 1 & 1 \\
\hline & & $\begin{array}{l}\text { Total number of elements in function } \\
\text { area: }\end{array}$ & & & & & & & 4 \\
\hline \multirow[t]{7}{*}{ Controlling track use } & 3.3 & $\begin{array}{l}\text { Location of operating characteristics } \\
\text { information. }\end{array}$ & 1 & & & & & & 1 \\
\hline & 3.4 & $\begin{array}{l}\text { Understand movement and protective } \\
\text { authorities. }\end{array}$ & & 1 & & & & & 1 \\
\hline & 3.5 & Apply movement and protective authorities. & & & 1 & & & & 1 \\
\hline & 3.6 & Principles of railway signaling. & & 1 & & & & & 1 \\
\hline & 3.7 & Plan beyond limits of territory. & & & 1 & & & & 1 \\
\hline & 3.11 & $\begin{array}{l}\text { Use of tracks by non-shunting equipment and } \\
\text { work crews. }\end{array}$ & & & 1 & & & & 1 \\
\hline & & $\begin{array}{l}\text { Total number of elements in function } \\
\text { area: }\end{array}$ & & & & & & & 6 \\
\hline \multirow{5}{*}{$\begin{array}{l}\text { Unplanned and } \\
\text { emergency events }\end{array}$} & 4.2 & Understand procedures for emergency events. & & 1 & & & & & 1 \\
\hline & 4.3 & Implement procedures for emergency events. & & & 1 & & & & 1 \\
\hline & 4.4 & $\begin{array}{l}\text { Response to events for which no procedures } \\
\text { exist. }\end{array}$ & & & & & & 1 & 1 \\
\hline & 4.5 & $\begin{array}{l}\text { Compensation for computer or system failure } \\
\text { during unplanned or emergency events. }\end{array}$ & & & 1 & & & & 1 \\
\hline & & $\begin{array}{l}\text { Total number of elements in function } \\
\text { area: }\end{array}$ & & & & & & & 4 \\
\hline \multirow[t]{6}{*}{ Records and reports } & 5.1 & $\begin{array}{l}\text { Know what records to initiate, maintain and } \\
\text { complete. }\end{array}$ & 1 & & & & & & 1 \\
\hline & 5.3 & $\begin{array}{l}\text { Production of records when mechanical or } \\
\text { electronic devices fail. }\end{array}$ & & & 1 & & & & 1 \\
\hline & 5.4 & Reporting requirements. & 1 & & & & & & 1 \\
\hline & 5.6 & $\begin{array}{l}\text { Production of reports when mechanical or } \\
\text { electronic devices fail. }\end{array}$ & & & 1 & & & & 1 \\
\hline & 5.7 & $\begin{array}{l}\text { Production of computerized reports using } \\
\text { specified fields or parameters. }\end{array}$ & & & 1 & & & & 1 \\
\hline & & $\begin{array}{l}\text { Total number of elements in function } \\
\text { area: }\end{array}$ & & & & & & & 5 \\
\hline \multirow[t]{3}{*}{ Freight Operations } & 1.1 & Handling of hazardous materials. & 1 & & & & & & 1 \\
\hline & & $\begin{array}{l}\text { Total number of elements in function } \\
\text { area: }\end{array}$ & & & & & & & 1 \\
\hline & & Totals: & 5 & 4 & 13 & 0 & 0 & 3 & 25 \\
\hline
\end{tabular}


Table 19. Summary of a table of specifications for periodic reassessment

\begin{tabular}{|c|c|c|c|c|c|c|c|}
\hline \multirow[b]{2}{*}{ Function Area } & \multicolumn{6}{|c|}{ Learning Outcome } & \multirow[b]{2}{*}{ Total } \\
\hline & Knowledge & $\begin{array}{c}\text { Comp- } \\
\text { rehension }\end{array}$ & $\begin{array}{l}\text { Applica- } \\
\text { tion }\end{array}$ & Analysis & Synthesis & Evaluation & \\
\hline Prerequisites & 1 & 1 & 3 & 0 & 0 & 0 & $20 \%$ \\
\hline Planning & 0 & 0 & 2 & 0 & 2 & 0 & $16 \%$ \\
\hline Controlling track use & 1 & 2 & 3 & 0 & 0 & 0 & $24 \%$ \\
\hline $\begin{array}{l}\text { Unplanned and } \\
\text { emergency events }\end{array}$ & 0 & 1 & 2 & 0 & 1 & 0 & $16 \%$ \\
\hline Records and reports & 2 & 0 & 3 & 0 & 0 & 0 & $20 \%$ \\
\hline Freight Operations & 1 & 0 & 0 & 0 & 0 & 0 & $4 \%$ \\
\hline Totals: & $20 \%$ & $16 \%$ & $52 \%$ & $0 \%$ & $12 \%$ & $0 \%$ & $100 \%$ \\
\hline
\end{tabular}

The summary dictates that a test of this material should place almost 25 percent of its emphasis on controlling track use. Additionally, 64 percent of the test items should require the examinee to demonstrate more than simple rote memory (knowledge) or understanding (comprehension) of the content. However, this distribution does not take into consideration the relative importance of some objectives over others.

\subsubsection{Adjustments to Table of Specifications}

As has been the practice in the other test designs, the number of test elements associated with any skill objective (an objective at or above the application learning outcome) in a performance area are double counted. The result on the proportional distribution of elements is shown in the revised table of specifications presented in Table 20.

Table 21 presents a summary of test element percentages within each learning outcome and within each functional area. Subsequent to revision, the number of items at the application level and above has risen to 77 percent. A majority of test items at the application level and above imply that the test primarily should be practical in nature, requiring the performance of dispatching skills rather than the recall of knowledge.

\subsubsection{Number and Format of Test Items}

This section makes specific recommendations concerning the number of test items, test length (time), passing levels, and test item format for a periodic reassessment to be given at the conclusion of refresher training.

\subsubsection{Number of Test Items and Length of Test}

The total element count in the sample table of specifications (Table 20) is 38 , so 38 is the absolute minimum of test items which could be asked. At an estimated adult answering rate of 
Table 20. Revised table of specifications for periodic reassessment

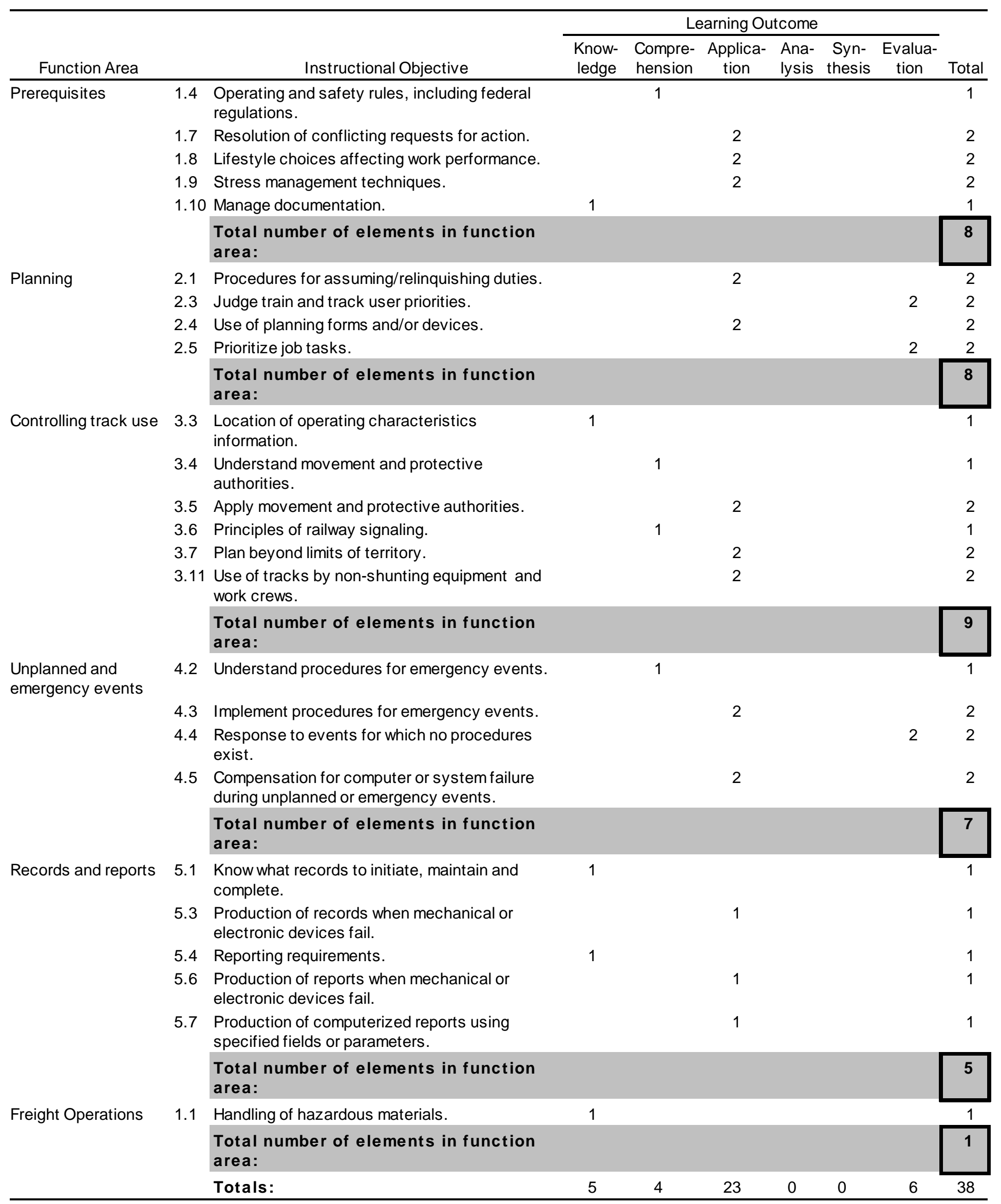




\section{Table 21. Summary of a revised table of specifications for periodic reassessment}

\begin{tabular}{|c|c|c|c|c|c|c|c|}
\hline \multirow[b]{2}{*}{ Function Area } & \multicolumn{6}{|c|}{ Learning Outcome } & \multirow[b]{2}{*}{ Total } \\
\hline & Knowledge & $\begin{array}{l}\text { Compre- } \\
\text { hension }\end{array}$ & $\begin{array}{l}\text { Applica- } \\
\text { tion } \\
\end{array}$ & Analysis & Synthesis & Evaluation & \\
\hline Prerequisites & 1 & 1 & 6 & 0 & 0 & 0 & $21 \%$ \\
\hline Planning & 0 & 0 & 4 & 0 & 4 & 0 & $21 \%$ \\
\hline Controlling track use & 1 & 2 & 6 & 0 & 0 & 0 & $24 \%$ \\
\hline $\begin{array}{l}\text { Unplanned and } \\
\text { emergency events }\end{array}$ & 0 & 1 & 4 & 0 & 2 & 0 & $18 \%$ \\
\hline Records and reports & 2 & 0 & 3 & 0 & 0 & 0 & $13 \%$ \\
\hline Freight Operations & 1 & 0 & 0 & 0 & 0 & 0 & $3 \%$ \\
\hline Totals: & $13 \%$ & $11 \%$ & $61 \%$ & $0 \%$ & $16 \%$ & $0 \%$ & $100 \%$ \\
\hline
\end{tabular}

approximately 1 question every $30 \mathrm{sec}$ for objectively scored items, it would take trainees about $20 \mathrm{~min}$ to complete the test. Slower responders may require $40 \mathrm{~min}$. A broader sampling of skills would provide more reliability, yet the total scheduled time probably should be held under an hour in the interests of practicality. For this test, therefore, the minimum total number of elements will be held to 38 and the recommended initial testing time set at one hour.

Since the test includes so many performance items that apply directly to the work of a dispatcher, it is recommended that the test be reviewed with examinees after the testing session. Ample time should be scheduled to review test results with each person who takes the test. This review increases the reliability of future tests by providing corrective feedback to the test designer, and will serve to immediately address any critical errors made by examinees. Test results should be reviewed with the trainees immediately after the testing session. An immediate review tends to reinforce correct responses and increases attention to items that were missed. Subsection 8.2.2 addresses the various methods which can be used to determine appropriate passing levels.

\subsubsection{Format of the Test Items}

A question format matrix recommended for the sample periodic refresher test is shown in Table 22. The matrix, as a whole, is directly tied to the associated learning outcomes and element counts provided in the revised table of specifications (Table 20). Subsection 9.1.4.4 provides some test item format recommendations when using the question matrix.

\subsubsection{Writing and Use of This Test}

Using the general rules of thumb given in subsection 8.2, the time estimates for creating, administering, scoring, and revising the proposed test are presented below.

The total time required to prepare the tests is under $8 \mathrm{hr}$. See Table 23 for specific details for preparing the test. 
Table 22. Question matrix for periodic reassessment

\begin{tabular}{|c|c|c|c|c|c|c|c|}
\hline $\begin{array}{l}\text { Function } \\
\text { Area }\end{array}$ & Instructional Objective & $\begin{array}{l}\text { Knowledge } \\
\begin{array}{|c|}\text { Short } \\
\text { Answer, } \\
\text { True/False } \\
\end{array}\end{array}$ & $\begin{array}{c}\text { Comprehension } \\
\text { Identify } \\
\text { MC, } \\
\text { Matching } \\
\end{array}$ & \begin{tabular}{|c|} 
Application \\
Problem \\
MC, \\
Problem \\
Sets \\
\end{tabular} & Analysis & $\begin{array}{l}\text { Synthesis } \\
\text { Problem } \\
\text { MC, } \\
\text { Problem } \\
\text { Sets } \\
\end{array}$ & $\begin{array}{c}\text { Evaluation } \\
\text { Problem } \\
\text { MC, } \\
\text { Problem } \\
\text { Sets } \\
\end{array}$ \\
\hline \multicolumn{8}{|l|}{ Prerequisites } \\
\hline 1.4 & $\begin{array}{l}\text { Operating and safety rules, } \\
\text { including federal regulations. }\end{array}$ & & 1 & & & & \\
\hline 1.7 & $\begin{array}{l}\text { Resolution of conflicting requests } \\
\text { for action. }\end{array}$ & & & 2 (PS) & & & \\
\hline 1.8 & $\begin{array}{l}\text { Lifestyle choices affecting work } \\
\text { performance. }\end{array}$ & & & 2 (PMC) & & & \\
\hline 1.9 & Stress management techniques. & & & $2(\mathrm{PMC})$ & & & \\
\hline 1.10 & Manage documentation. & 1 & & & & & \\
\hline \multicolumn{8}{|l|}{ Planning } \\
\hline 2.1 & $\begin{array}{l}\text { Procedures for } \\
\text { assuming/relinquishing duties. }\end{array}$ & & & 2 (PS) & & & \\
\hline 2.3 & $\begin{array}{l}\text { Judge train and track user } \\
\text { priorities. }\end{array}$ & & & & & & 2 (PS) \\
\hline 2.4 & $\begin{array}{l}\text { Use of planning forms and/or } \\
\text { devices. }\end{array}$ & & & 2 (PS) & & & \\
\hline 2.5 & Prioritize job tasks. & & & & & & 2 (PS) \\
\hline \multicolumn{8}{|c|}{ Controlling track use } \\
\hline 3.3 & $\begin{array}{l}\text { Location of operating } \\
\text { characteristics information. }\end{array}$ & 1 & & & & & \\
\hline 3.4 & $\begin{array}{l}\text { Understand movement and } \\
\text { protective authorities. }\end{array}$ & & 1 & & & & \\
\hline 3.5 & $\begin{array}{l}\text { Apply movement and protective } \\
\text { authorities. }\end{array}$ & & & 2 (PS) & & & \\
\hline 3.6 & Principles of railway signaling. & & 1 & & & & \\
\hline 3.7 & Plan beyond limits of territory. & & & $2(\mathrm{PMC})$ & & & \\
\hline 3.11 & $\begin{array}{l}\text { Use of tracks by non-shunting } \\
\text { equipment and work crews. }\end{array}$ & & & 2 (PS) & & & \\
\hline \multicolumn{8}{|c|}{ Unplanned and emergency events } \\
\hline 4.2 & $\begin{array}{l}\text { Understand procedures for } \\
\text { emergency events. }\end{array}$ & & 1 & & & & \\
\hline 4.3 & $\begin{array}{l}\text { Implement procedures for } \\
\text { emergency events. }\end{array}$ & & & $2(\mathrm{PMC})$ & & & \\
\hline 4.4 & $\begin{array}{l}\text { Response to events for which no } \\
\text { procedures exist. }\end{array}$ & & & & & & $2(\mathrm{PMC})$ \\
\hline 4.5 & $\begin{array}{l}\text { Compensation for computer or } \\
\text { system failure during unplanned or } \\
\text { emergency events. }\end{array}$ & & & 2 (PS) & & & \\
\hline \multicolumn{8}{|c|}{ Records and reports } \\
\hline 5.1 & $\begin{array}{l}\text { Know what records to initiate, } \\
\text { maintain and complete. }\end{array}$ & 1 & & & & & \\
\hline 5.3 & $\begin{array}{l}\text { Production of records when } \\
\text { mechanical or electronic devices } \\
\text { fail. }\end{array}$ & & & 1 (PMC) & & & \\
\hline 5.4 & Reporting requirements. & 1 & & & & & \\
\hline 5.6 & $\begin{array}{l}\text { Production of reports when } \\
\text { mechanical or electronic devices } \\
\text { fail. }\end{array}$ & & & 1 (PS) & & & \\
\hline 5.7 & $\begin{array}{l}\text { Production of computerized } \\
\text { reports using specified fields or } \\
\text { parameters. }\end{array}$ & & & 1 (PS) & & & \\
\hline
\end{tabular}

\section{Freight Operations}


Table 23. Test preparation activities for periodic reassessment

\begin{tabular}{lccc}
\hline \multicolumn{1}{c}{ Item Type } & $\begin{array}{c}\text { Number of } \\
\text { Items }\end{array}$ & $\begin{array}{c}\text { Time per Item } \\
(\mathrm{min})\end{array}$ & $\begin{array}{c}\text { Total Time } \\
(\mathrm{hr})\end{array}$ \\
\hline True/False and Short Answer & 5 & 2.5 & 0.2 \\
Multiple Choice & 15 & 6 & 1.5 \\
"Problem Sets" & 18 & 20 & 6.0 \\
Total & & & 7.7 \\
\hline
\end{tabular}

At an estimated average adult answering rate of approximately 1 question every $30 \mathrm{sec}$ for objectively scored items, the test would take roughly $20 \mathrm{~min}$ to complete. This time is typically doubled to $40 \mathrm{~min}$ to allow ample time for everyone to complete the test. Because of the presence of the problem sets, a full hour is recommended for the initial use of the test. Experience may be used to readjust the time as necessary.

The time required to evaluate and post the test scores is under $30 \mathrm{~min}$ per test. Table 24 provides specific details of the test evaluation and posting times.

An informal item analysis, in the form of post-test interviews with examinees, is recommended as a means of determining if any test items were misleading or inappropriate. Estimated time for this activity is 5 min per test. Periodically, a formal item analysis should also be performed. In order for an item analysis to be meaningful, 15 to 20 tests are suggested as a minimum. Based on the recommendations of subsection 8.2.3, and keeping the total number of tests required in mind, 33 question responses may be evaluated per minute. The evaluation rate is around $1 \mathrm{~min}$ per student test. Therefore, $1 \times 20$ tests $=20 \mathrm{~min}$, or under a half hour.

The time it takes to study the validity of the training is completely conjectural since it depends on the ease with which follow-up information may be found. The individual performing the study should try to find the correlation between training success and dispatching success. If training is located near the dispatching center, those dispatchers who have completed the

Table 24. Test evaluation and posting activities for periodic reassessment

\begin{tabular}{lccc}
\hline \multicolumn{1}{c}{ Activity } & $\begin{array}{c}\text { Number of } \\
\text { Items }\end{array}$ & $\begin{array}{c}\text { Time per Item } \\
(\mathrm{min})\end{array}$ & $\begin{array}{c}\text { Total Time } \\
(\mathrm{min})\end{array}$ \\
\hline True/False and Short Answer & 5 & 0.1 & 0.5 \\
Multiple Choice & 15 & 0.05 & 0.8 \\
"Problem Sets" & 18 & 1 & 18.0 \\
Posting* & & 2 & 2.0 \\
Total & & & 21.3
\end{tabular}

${ }^{*}$ Note: The time for posting the test results is very conjectural. An estimate of 2 min per test is suggested, although the actual time will depend on the method and requirements of recording and posting the tests. 
particular training course can be surveyed. If the training is located far away from a dispatching center, data about a dispatcher's success may be more difficult to obtain.

Test revision is another conjectural time estimate, dependent on circumstances. If, as suggested in subsection 8.2, a 50-item test might require an annual review that lasts $3 \mathrm{hr}$, a review of the sample test suggested in Table 22 might take as little as $2.5 \mathrm{hr}$. Where only a few individuals are involved, test revision might be as simple as making changes based on direct interviews as discussed above.

\subsubsection{Frequency of Reassessment}

The only type of periodic reassessment that is currently required of railroad dispatchers is operational rules training and testing; however, there is no mandated frequency with which this training and testing must occur. To fulfill this requirement, railroads that were visited typically provided an annual rules training followed by a rules test. However, the FRA does currently require locomotive engineers to pass a recertification examination and be observed on-the-job by a supervisor every three years. Thus, while there is currently no federally-mandated recertification or reassessment requirement for railroad dispatchers, similar requirements have been established for locomotive engineers.

As part of the site visits, railroads were asked about their policies regarding dispatcher reassessment. One railroad indicated that if a dispatcher has not worked a territory in a year, s/he must be reviewed by a supervisor before assuming responsibility for that territory. Other railroads indicated that it was up to the dispatcher to request time to review the characteristics of a territory that s/he had not worked recently. However, no railroad indicated that it had a formal periodic reassessment process.

Since the instructional design literature does not offer any guidance on determining an appropriate period for reassessment (it is context-driven), the policies governing employees in other modes of transportation - specifically the aviation and maritime communities - were examined. Watchstanders in the U.S. Coast Guard's Vessel Traffic Service have a job that is similar to that of a railroad dispatcher. They are responsible for monitoring and guiding ships in the nation's ports and harbors. Air Traffic Control specialists perform a similar function for the national airspace. Ship pilots and commercial air carrier pilots perform a job that is similar to that of a locomotive engineer, so recertification policies for these two occupations were also explored. The following sections describe the recertification policies for each of these four positions. Table 25 summarizes the four occupations that were examined. Based on this information, subsection 9.3.6.5 offers some recommendations regarding periodic reassessment for railroad dispatchers.

\subsubsection{Vessel Traffic Service (VTS) watchstanders (U.S. Coast Guard)}

At the national level, the U.S. Coast Guard does not currently require recertification of VTS watchstanders as long as they meet a currency requirement of having worked any period within the last five years. If an individual has not worked as a VTS watchstander in the last five years, 
Table 25. Recertification policies in other modes of transportation

\begin{tabular}{|c|c|c|c|c|}
\hline & $\begin{array}{c}\text { VTS } \\
\text { Watchstanders }\end{array}$ & Ship Pilots & ATC Specialists & Air Carrier Pilots \\
\hline $\begin{array}{l}\text { Recertification/ } \\
\text { proficiency } \\
\text { requirement }\end{array}$ & If not current & If not recent & If not current & Every six months \\
\hline $\begin{array}{l}\text { Currency/ } \\
\text { recency } \\
\text { requirement }\end{array}$ & $\begin{array}{l}\text { Must work any } \\
\text { time within the last } \\
\text { five years }\end{array}$ & $\begin{array}{l}\text { Must work four of } \\
\text { the last five years }\end{array}$ & $\begin{array}{l}\text { Must work } \\
16 \text { hramonth }\end{array}$ & $\begin{array}{l}\text { Must pilot for three } \\
\text { takeoffs and three } \\
\text { landings during } \\
\text { the last } 90 \text { days }\end{array}$ \\
\hline $\begin{array}{l}\text { Format of } \\
\text { recertification }\end{array}$ & $\begin{array}{l}\text { Complete national } \\
\text { VTS training } \\
\text { program }\end{array}$ & $\begin{array}{l}\text { Score } 90 \% \text { or } \\
\text { better on an open } \\
\text { book exam } \\
\text { covering ship } \\
\text { handling, stability, } \\
\text { navigation, etc. } \\
\text { Score } 90 \% \text { or } \\
\text { better on a Rules } \\
\text { of the Road test }\end{array}$ & $\begin{array}{l}\text { Complete an over- } \\
\text { the-shoulder } \\
\text { review by a } \\
\text { supervisor }\end{array}$ & Use a simulator \\
\hline Other & $\begin{array}{l}\text { Local VTS } \\
\text { certification } \\
\text { separate; format } \\
\text { depends on the } \\
\text { location }\end{array}$ & & $\begin{array}{l}\text { Over-the-shoulder } \\
\text { check by } \\
\text { supervisor } \\
\text { Periodic "tape } \\
\text { talk" }\end{array}$ & $\begin{array}{l}\text { Random FAA en- } \\
\text { route inspection }\end{array}$ \\
\hline
\end{tabular}

they must recertify by completing a national VTS training program. However, though not mandated at the national level, recertification at the local level does occur and varies according to each location. Local recertification might include some or all of the following: facility visits, ship rides, supervised sector watches (no formal procedure), and a navigation rules test, in which watchstanders typically must score 90 percent or better to pass.

\subsubsection{Ship Pilots (U.S. Coast Guard)}

Ship pilots must renew their license every five years in order to remain certified by the U.S. Coast Guard. If pilots meet a recency requirement of working four of the last five years, they are not required to take any knowledge-based or skills-based tests to renew their license; it is automatically renewed. When a pilot does not maintain recency, however, s/he must pass two tests in order to renew the license. They must take an open-book exam that covers general topics such as ship handling, stability, and navigation. Pilots must score 90 percent or better to pass. Pilots are given a book of several hundred questions to help them study and prepare for the exam; 50 of these questions will be chosen for any particular exam. Thus, pilots know what to prepare for, but they do not know the specific questions that will be selected. In addition to this exam, pilots must also pass a Rules of the Road test by scoring 90 percent or better. 


\subsubsection{Air Traffic Control Specialists (FAA)}

Currently, FAA does not require recertification of Air Traffic Control specialists (ATC or ATCs) as long as they meet a currency requirement of working traffic at least $16 \mathrm{hr}$ a month, and have not committed any errors. If an ATC fails to maintain his/her currency in air traffic, or if s/he commits an error while on duty, the ATC must be recertified by a supervisor before resuming duties. The recertification process involves an over-the-shoulder review by a supervisor. The content and time involved in the recertification vary according to the gravity of the error, the ATC's experience, and other factors. The supervisor uses his/her own discretion in recertifying an ATC. At the conclusion of the recertification, the supervisor completes a recertification evaluation and records it in the ATC's personal file.

In addition to over-the-shoulder recertification, ATC supervisors do conduct periodic overthe-shoulder checks on all ATCs to evaluate communications and operational procedures. Supervisors also conduct periodic "Tape Talks" in which a supervisor will record, and later review with the ATC, 30 to 60 min of communications between the ATCs and the aircraft within the sector which the ATC was controlling. The supervisor will discuss with the ATC such issues as the ATC's phraseology.

\subsubsection{Air Carrier Pilots (FAA)}

All pilots are required to undergo a minimum biennial flight check. Air carrier pilots are more heavily monitored. Rather than undergoing a flight check every two years, air carrier pilots must undergo a pilot proficiency check by a certified flight instructor every six months. The pilot proficiency check typically involves evaluating the pilot in simulated flight. Air carrier pilots (and all other pilots carrying passengers) must also maintain a currency requirement of piloting an aircraft for three takeoffs and three landings during the last 90 days. Furthermore, air carrier pilots are subject to random en route FAA inspections. All other pilots, including air taxi pilots and corporate pilots, are subject to recertification procedures, the frequency of which depends on the particular service.

\subsubsection{Recommendations}

The limited review of recertification policies in the aviation and maritime industries indicates that other modes of transportation require testing or retraining only in circumstances where the employee has not been actively working the job. Air carrier pilots are the exception. However, the nature of their responsibilities is more akin to those of a locomotive engineer than a dispatcher.

Based on the current policies regarding VTS watchstanders and ATC specialists, occupations which perform vigilance and control tasks similar to a railroad dispatcher, and the practice at some railroads to offer or require time to review a territory not worked within the past year, it is recommended that dispatchers undergo some form of territory-specific requalification prior to working on a territory that they have not worked in over a year. 
More research needs to be undertaken before any recommendations can be made with regard to frequency of general periodic reassessment for railroad dispatchers. Information from recertification policies in additional modes of transportation (e.g., transit, motor carrier) and additional railroads, as well as in other industries with vigilance tasks, may be used to help formulate an appropriate guideline for periodic reassessment frequency.

\subsection{Alternative Approaches to Test Design}

There are several alternatives to traditional formal testing, including on-the-job evaluation and trainee narratives. Several alternative approaches are discussed in this section.

\subsubsection{On-the-Job Evaluation (OJE)}

An alternative method of assessing railroad dispatcher skills and knowledge involves on-thejob evaluation (OJE) rather than formalized testing. OJE, mostly conducted through observation directly on-the-job or in a simulator, can be quite subjective, both in terms of the evaluator's perceptions and the lack of specificity in the performance criteria used to judge the trainee. The advantage of formal testing is that it applies a consistent standard that can be easily communicated to others in terms of the performance objectives upon which the test is based.

There are several methods that can help to increase objectivity during OJE. They include formal checklists and quantitative scales, which can be used to observe and measure behaviors, procedures, and skills (i.e., the desirable outcomes). The checklists can be used to determine whether or not the trainee completes particular steps of a procedure, or is successful in mastering part, or all, of an objective. The quantitative scale can then be used to assign a grade to the behavior, skill, or procedure, for example, by recording how well the trainee performed a task using a five-point scale ranging from "very poor" to "excellent." It is important that clear and concise directions are written for the use of the checklists and scales to reduce the likelihood of rater/observer misunderstandings. Furthermore, explicitly written directions will increase consistency across different raters/observers.

If OJE is used, it is also recommended that the training is broken down into "mastery units" of instruction, with each of the units of instruction culminating in a mastery test written in terms of the instructional (or performance) objectives. Like the formal test designs in this report, all of the objectives should be addressed.

OJE is particularly appropriate for application-oriented objectives and skills testing, such as that used in initial territory training, though OJE can be used in any of the three training areas delineated in this report: initial dispatcher training, initial territory training, and periodic refresher training. However, OJE should not completely substitute for an objectively scored test based on a test design such as those developed in this report. Rather, it is recommended that formalized tests be used in conjunction with an OJE, and that the OJE be based on written explicit guidelines developed by the railroad and tailored to the railroad's unique environment. Locomotive engineer recertification currently follows this practice, where engineers must complete both a written knowledge test and a practical skills test (see 49 CFR 240). 


\subsubsection{Diagrams and Narratives}

To test a trainee's knowledge of the physical characteristics of a particular territory, a trainee can be asked to draw a schematic diagram of the territory, indicating all of the important features such as grade crossings, turnouts, stations, grades, etc. Alternatively, a trainee can be asked to provide a narrative description of the territory. Information from either method can be checked against a detailed track chart. Though not a traditional instructional design methodology, both methods are common evaluation techniques among today's railroads. 


\section{CONCLUSIONS AND RECOMMENDATIONS}

This section includes some brief conclusions to the report, offers some lessons learned and recommendations based on the research, and suggests some future research to further enhance and improve railroad dispatcher training as the twenty-first century approaches.

\subsection{Conclusions}

The wide variety of dispatching operations which characterizes the U.S. railroad industry makes it impossible to design training objectives, course syllabi and test designs that are appropriate for all railroads. However, it is possible to structure a process that makes allowances for these differences and offers a standard approach to developing training objectives, course syllabi and test designs. This report documents current training activities among some of the nation's passenger and freight railroads, and endeavors to provide a means and foundation for the creation of training objectives, model syllabi and test designs for three distinct railroad dispatcher training programs: initial dispatcher training, initial territory training, and periodic refresher training. Using a familiar analogy, the goal of the report is to teach a person how to fish rather than to provide the person with the fish.

First, training objectives were developed which acted as the raw material for the formulation

of model course syllabi and test designs. Instructional objectives were then selected for the three different training programs. Next, model syllabi and test designs were formulated, and serve as examples only. Both the bottom-up process in which the syllabi were developed, and the fourstep process used to develop the test designs, are described in detail in the body of this report. Lastly, recommended training practices and guidelines that will likely contribute to a more successful training program are proposed. The recommendations and guidelines are based on observations as well as trainer, trainee and dispatcher interviews.

\subsection{Factors Contributing to a Successful Program}

Discussions with railroad training officials and dispatchers highlighted aspects of the individual training programs that contributed to its success. At the same time, these individuals described changes to the ongoing program which they felt would make it more effective in instructing the next generation of railroad dispatchers. In some cases the suggested changes were already in the process of being explored. Limited resources for training prevented others from being implemented. All of this information is reflected in the following sections, which describe the factors that contribute to a successful dispatcher training program. 


\subsubsection{Development of Non-Technical Skills}

Dispatcher training programs should develop the trainee's abilities with respect to time management, leadership and prioritization. Because the job of a railroad dispatcher usually results in a lifestyle change for the trainee, the training program should also include discussion of these issues. Each of these skills has been included in the training objectives developed as part of this project.

- Time management. This includes teaching a dispatcher how to manage and plan the train and track activity during their shift so that they may successfully complete the other tasks that they must do on a regular basis in a timely fashion.

- Leadership. Dispatchers control and orchestrate all movement on the tracks for which they are responsible. Part of their job is to balance the demand for competing resources and to respond to unplanned and emergency events. Dispatchers serve as a central source of information for both storage and dispensation, and have an authoritative role in controlling the movement of trains and other on-track activity. Leadership skills enable dispatchers to more effectively delegate and manage resources.

- Prioritization. Dispatchers must coordinate a day's activities and balance simultaneously competing resources throughout the shift. These duties require that the dispatcher prioritize from among many different activities, and in "real time," adjust train movement schedules when necessary.

- Lifestyle management. Shiftwork and irregular schedules tend to disrupt a lifestyle, and can have negative affects on circadian rhythms, resulting in reduced attention and increased fatigue. Both reduced attention and increased fatigue are potential precursors to errors. Teaching dispatchers effective countermeasures for reducing fatigue can decrease their chances of making mistakes. Furthermore, preparing dispatchers for the disruptions and discontinuity of shift work and irregular schedules can help dispatchers to lead healthy lives outside of work.

\subsubsection{Integration of Initial Dispatcher (Mostly Classroom) Training and Initial Territory (Mostly OJT) Training}

Integration among all of the components of a training program will serve to increase trainee performance, since knowledge and skills acquired in one part of training will carry over to the next part with little or no difficulty. Furthermore, without integration, skills learned during an earlier part of training may erode or be replaced by other skills or habits which may not necessarily lead to optimal performance.

- Make training unified between the classroom portion of training and the OJT portion. In some of the larger Class 1 railroads, the classroom training (initial dispatcher training) was conducted by one department while the OJT (initial territory training) was overseen by another department (usually the Operations department), resulting in potentially 
inconsistent teaching. In organizations where the classroom training and OJT are conducted by two different departments, a process is needed to assure that the procedures and knowledge delivered in the classroom are reinforced during OJT.

- Provide clear goals or objectives for trainees as they do their OJT. Tell trainees what they will be evaluated on, and what they are expected to learn and do during their OJT portion of training.

- As much as possible, provide clear goals for the trainees as they learn the physical characteristics of a territory, including what landmarks to look for and what aspects of physical characteristics are most important to dispatching trains through that specific territory.

- Provide a manual of railroad terminology, jargon, and lingo that will serve as a reference to dispatcher trainees who do not have prior railroad operations experience. Additional material covering the railroad business could also be included, and would be particularly useful to trainees coming off the street who do not have any railroad experience.

\subsubsection{Simulation and Computer-Based Instruction}

Technology is constantly improving. Computers are becoming more powerful; their capabilities are being expanded; and their prices are ever decreasing. As a consequence, simulation and computer-based instruction/training will likely play a greater and greater role in railroad dispatcher training in the near future. Simulation and CBT can increase training effectiveness while at the same time decrease costs. Some specific observations and recommendations are:

- Use simulators and other computer-based training tools for CADS training and remediation.

- Maximize the availability of simulators. Ideally there should be one simulator per student. Simulators should be made available during non-training hours for practice and remediation.

- Make CADS simulators (including AVTEC radio communication) as interactive as possible to maximize the training experience. Currently, simulators are used primarily to teach isolated procedures using the computer-aided dispatching system. Interactivity increases real-world fidelity and increases learning of more complex procedures/training (multiple tasks, simultaneous activities on a segment of rail, communications back and forth between dispatcher and train crew/MOW, and critical incident training).

- Use computer-based multimedia training aids. Interactive multimedia training aids have several potential benefits, such as self-paced learning, privacy, in-depth remedial instruction, contextual instruction, and multi-modal, multi-format feedback (e.g., sound, words, and pictures all used in conjunction). The multimedia training aid must also be 
enjoyable to use. Multimedia training aids can be used for rules training and safety training, as well as for training on some prerequisite topics. Consider providing the rules, pertinent CFR regulations and other material on a fully searchable CD-ROM.

\subsubsection{Integration of Real-World Dispatcher Experience}

To promote the transfer of knowledge and skills acquired during training to the actual dispatching environment, build a bridge between trainees and dispatchers early in the initial dispatcher training program. Such a bridge will facilitate learning, and will provide a context for the training. For example, talking with an experienced dispatcher or "posting" with them early in the program will help the trainee develop a framework in which to learn how to dispatch.

- Implement a mentoring program, where trainees are teamed with experienced dispatchers. Experienced dispatchers can provide guidance and advice, and can provide a "real-world" validation of the trainee's learning experience during the classroom portion of training. A mentoring system may also help to bridge the gap between the classroom portion of the training and the OJT portion of the training, by introducing an interpersonal relationship between a trainee and a current dispatcher working on the job.

- Have dispatchers share their experiences with trainees. Dispatchers encounter unusual circumstances every day. It would be useful for dispatchers to share some of their experiences with trainees, as well as their solutions, so that trainees can begin to prepare for the variety of different situations that they will soon encounter.

- Enable dispatcher trainees to get out and view the territory for which they will dispatch. A library of narrated videotapes of the territory does not substitute for first-hand experience. However, videotapes can be used as an additional source of information when learning the physical characteristics of a territory. Knowledge of the physical characteristics of the territory being dispatched is critical to railroad dispatching, and testimony from dispatchers and instructors during each of the site visits confirmed this.

\subsubsection{Contextual Rules Training}

A trend that was observed at many of the railroads that were visited was a change from rote rules learning and recall to contextual rules training that required a trainee's comprehension of the rules and their applications, rather than just knowledge of the various rules.

- Teach and test rules and procedures in their context. Make rule learning contextual, and test rules knowledge in an application-oriented framework, such as on a simulator or in a situation-based test.

\subsubsection{Program Effectiveness}

As time permits, maximize training effectiveness by examining training materials, tests, methods, etc., before, during, and after the training. 
- Conduct a formative evaluation of the training materials before they are implemented, to determine whether or not they are effective and efficient in meeting the objectives of the training program. In doing so, poor training materials can be replaced by more effective ones before they are used.

- Conduct periodic meetings between trainees and instructors to provide feedback to the trainee on his or her progress and to provide constructive information to the instructor on the success of the training.

- Perform a summative evaluation of the training materials to determine the effectiveness of the training materials in achieving the objectives after they have been implemented for some time.

\subsubsection{Instructor Preparation}

Since instructors play such an essential role in railroad dispatcher training, it is imperative that they be intimately familiar with railroad dispatching and all technologies that are used in dispatching, and at the same time, be familiar with training methods and procedures.

- Subject matter experts should be used whenever possible. Instructors who are former dispatchers can provide a wealth of valuable experience, insight, and "lessons learned."

- Railroads should offer, or provide access to, a "train the trainer" program for their instructors. Since training requires special skills, instructors who are properly equipped with the appropriate instructional methods and techniques to railroad dispatchers will make training that much more effective. Furthermore, if a checklist is used, it is advisable to train those individuals responsible for using it. A train-the-trainer program will help to increase uniformity of training, too, especially when many dispatcherinstructors are used to train trainees during initial territory training.

- Instructors should make the training environment as similar to the real environment as possible to facilitate transfer of learning and to maximize learning experience.

- Instructors should incorporate a variety of training methods and aids during training. Different methods and aids are appropriate for different types of content and skills learning. Matching the right training methods and aids with particular types of skills that are being learned will facilitate effective dispatcher training.

- Computer-based training (CBT) will probably play an increasing role in dispatcher training as costs drop and computers become more powerful. It may be advantageous for railroads to begin to explore the possibility of implementing at least some CBT as part of railroad dispatcher training.

- Have supervisors who did not receive formal dispatcher training go through refresher training or selected modules from initial dispatcher training program. Some supervisors 
may have never received formal dispatcher training, or may have dispatched so long ago that they are not familiar with computer-aided dispatching and the most recent dispatching procedures. Supervisors should be able to perform the dispatching duties for territories under their jurisdiction in the event of an emergency.

\subsubsection{Duration of Training}

Some guidelines are suggested here as a result of evaluating the training programs of several Class 1, shortline, and regional railroads. Both freight and passenger operations were represented.

- It is recommended that a minimum of 10 weeks be spent on initial dispatcher training, though there can be some allowance for prior railroad experience (perhaps one week less). Ten weeks corresponds to the average time that the Class 1 railroads that were visited spent on initial dispatcher training.

- It is recommended that an average of eight to nine weeks be spent on initial territory training. Seven weeks corresponds to the average amount of time spent on OJT by the railroad programs that were examined. An additional week or two should be factored in to cover learning the physical characteristics of the territory.

- It is recommended that approximately two to three days be spent on periodic refresher training. Periodic refresher training should last as long as necessary for trainees to complete the refresher training syllabus and address the related objectives. Given that dispatchers should be capable of learning quickly because they have already established a framework of knowledge and have been dispatching for at least a few years, it is likely that periodic refresher training could be completed in as short as two to three days.

\subsubsection{Class Size}

Historically, class size was determined by the need for railroad dispatchers. However, as railroad dispatching centers increase in size, and as the need for railroad dispatchers rapidly increases, other factors will dictate class size. For example, as the use of computers and simulators increases, access to these resources will become a greater and greater determinant of class size.

- Optimal class size depends on access to resources. During initial dispatcher and periodic refresher training, the maximum class size should be limited to two trainees per simulator when simulators are used; otherwise, resources such as access to a trainer, classroom size, and number of computers will influence class size. During initial territory training, as is the current practice, it is best to have only one trainee assigned to a dispatching desk with a dispatcher-instructor. Furthermore, where possible, a trainee should be assigned to "post" with only one dispatcherinstructor for each territory that is learned. 


\subsubsection{Training Alternatives}

The model syllabi and test designs presented in this report represent only one way in which to carry out railroad dispatcher training. New and original training methods and techniques (e.g., computer-based training) have been developed to complement or replace more traditional training methods. It is up to each railroad to determine which methods are most appropriate to their needs. Simulation and computer-based training are two new training and evaluation methods. Other options are:

- Use a checklist and/or trainee workbook/“advanced organizer" in addition to, or instead of, a course outline for initial territory training. A checklist does not prescribe an order in which the items must be addressed, but does prescribe the requisite skills and information that must be learned by the conclusion of the training. A checklist can be used as a guide to aid learning the physical characteristics of a territory, and/or to facilitate learning how to dispatch while on-the-job. A trainee workbook, or "advanced organizer," could be used as a training aid to support learning the physical characteristics of the territory by requiring the trainee to discover specific details about the territory, details that have been predetermined to be important to dispatching the territory. A workbook or "advanced organizer" could also be used during OJT by requiring the trainee to answer questions about what they have observed or accomplished. Use of checklists and/or workbook in initial territory training also assures some level of uniformity in the training.

- Use a checklist, rating scale, or other means of observation to help evaluate trainees while they learn how to dispatch on-the-job (OJE). Checklists can be used to determine whether or not trainees have completed particular steps of a procedure, or are successful in mastering part, or all, of an objective. Quantitative scales can be used to assign grades to behaviors, skills, or procedures, for example, by recording how well a trainee performs a task using a five-point scale ranging from "very poor" to "excellent." It is important that clear and concise directions are written for the use of the checklists and scales to reduce the likelihood of rater/observer misunderstandings. Furthermore, explicitly written directions will increase consistency across different raters/observers. Subsection 9.4 provides further discussion of alternative OJE methods.

- As a training aid to facilitate learning, or as a test to indicate mastery over, the physical characteristics, have the trainee draw a schematic diagram of the territory indicating all of the important features such as grade crossings, turnouts, stations, grades, etc. Alternatively, have the trainee provide a narrative description of the territory. Information from either method can be checked against a detailed track chart.

- Use a non-railroad organization as an option for some dispatcher training. JCCC offers a 24 week dispatcher training program (14 weeks initial dispatcher training and 10 weeks initial territory training), while the Railroad Education Bureau offers rules training to up to 15 trainees, ideal for either initial dispatcher training, and/or periodic refresher training. 


\subsection{Recommendations}

This report documents findings and observations from a sample of railroad dispatcher training programs across the country, and applies instructional design methodologies to the formulation of top-level instructional objectives, model syllabi and test designs. Dispatching centers are increasing in size, dispatchers are taking on increasingly more responsibilities, dispatcher trainees are being hired "off-the-streets" rather than from within the ranks, and technology is playing an increasing role in dispatching. All of these factors make it likely that training will play a more and more significant role in railroad dispatching. Though many of the training programs appear to suffice, if not excel, improvements can always be made. The FRA, in its mandate to ensure safe rail transportation, can support safety efforts through two means: research and regulations (standards, laws, etc.). It is possible to implement a governmentsponsored research program that will increase rail safety and benefit railroads. Some possible areas of future research are discussed in the following sections.

\subsubsection{Develop Refresher Training Guidelines}

Currently the only mandated refresher training qualification for railroad dispatchers is periodic rules training. Research can be conducted to determine both the need and frequency of periodic refresher training. Using models from other modes of transportation, guidelines for periodic refresher training (e.g., what topics to cover, how often) can be developed. The guidelines can be presented in the same way that this report offers guidelines for developing a railroad dispatcher training program.

\subsubsection{Determine the Need for Railroad Dispatcher Certification}

Unlike locomotive engineers, railroad dispatcher trainees do not need to pass a standard certification before working. Issues involved in railroad dispatcher certification could be explored. Certification procedures and policies from other, similar industries both within transportation and outside can be examined, as well as jobs that share similar duties or responsibilities as railroad dispatchers. After researching certification issues in other modes, and discussion with the FRA, railroad and Union officials, a recommendation could be made to the FRA regarding whether or not to further consider railroad dispatcher certification.

\subsubsection{Review of Dispatcher-Instructor Compensation Practices}

Interviews with dispatcher-instructors revealed that one of the problems in the current dispatcher-instructor role is that they are only minimally rewarded for their time and effort in training new dispatchers. Railroads expect dispatchers to train new trainees on-the-job. In fact, railroads often make the dispatcher-instructor responsible for a trainee's dispatching actions while the trainee is "posting" with him or her. Current practice in many railroads is to pay a dispatcher-instructor up to one extra hour per day. Based on informal conversation with various railroad employees, it was determined that in some circumstances this practice was unsatisfactory. It is recommended that compensation practices be explored more fully to determine 1) what is the best method of compensation to match dispatcher-instructors' increased 
involvement in training railroad dispatchers, and 2) if the increased compensation will result in more effective training.

\subsubsection{Develop an Information Exchange Workshop}

Experience from site visits and interviews revealed that many of larger Class 1 railroads have developed quite comprehensive railroad dispatcher training programs, at least for initial dispatcher training. The knowledge and experiences of those who helped to develop the training programs would no doubt help railroads that are now either developing or modifying their own programs. A workshop would facilitate the exchange of ideas, lessons learned, and knowledge among those responsible for developing or maintaining railroad dispatcher training programs. A workshop or conference style gathering could also promote potential partnerships among railroads, the FRA and professional trainers to advance training effectiveness and success.

\subsubsection{Examine the Feasibility of Developing a State-of-the-Art Interactive Railroad Dispatching Simulator}

Though useful in a variety of different training situations, current railroad dispatching simulators are functionally and operationally limited. A high-fidelity, fully interactive operatorin-the-loop railroad dispatching simulator promises to increase training effectiveness by fully simulating a whole range of rail traffic conditions and desk and territory configurations. A fully interactive railroad dispatching simulator can be used for critical incident training as well as for advanced concept training (e.g., team training), and it can bridge the gap between initial dispatcher training, which is mostly classroom-based, and initial territory training, which is mostly on-the-job. The first step is to examine the feasibility of developing a state-of-the-art simulator, including a needs analysis, an in-depth review of current railroad dispatcher simulator technology, and an examination of other transportation modes' uses of simulation in training. FAA, for example, currently utilizes several different interactive simulators to train and evaluate ATC specialists. If a strong need for a state-of-the-art interactive simulator exists, one should be developed and built. 


\section{REFERENCES}

1. U.S. Department of Transportation, Federal Railroad Administration, Office of Safety. Report to Congress (1990). Train Dispatcher Training Standards Inquiry.

2. U.S. Department of Transportation, Federal Railroad Administration, Office of Safety. Report to Congress (1995). Train Dispatchers Follow-up Review.

3. Smith, P.L., and Ragan, T.J. (1993). Instructional Design. Macmillan Publishing Company: New York, NY.

4. Devoe, D.B. (1974). An Analysis of the Job of Railroad Train Dispatcher. Technical Report, FRA-ORD\&D-74-37. National Technical Information Service. Springfield, VA.

5. Bloom, B.S. (Ed.), Englehart, M.D., Furst, E.J., Hill, W.H., and Krathwohl, D.R. (1956). Taxonomy of Educational Objectives: Handbook I, Cognitive Domain. New York: David McKay.

6. Grunlund, N.E. (1995). How to Write and Use Instructional Objectives, 5th ed. New Jersey: Prentice Hall.

7. Reiser, R.A., and Gagne, R.M. (1983). Selecting Media for Instruction. Englewood Cliffs, NJ: Educational Technology Publications.

8. Wittrock, M.C. (1974). Learning as a generative process. Educational Psychologist, Vol. 11, pp. 87-95.

9. Chase, C.I. (1978). Measurement for Educational Evaluation. Reading, MA: AddisonWesley.

10. Kuder, G.F., and Richardson, M.W. (1937) The Theory and Estimation of Reliability. Psychometrika, 2, 151-160.

11. Lord, F.M. (1959). Tests of the same length do have the same standard error. Educational and Psychological Measurement, 19, 233-239.

12. Vockell, E.L. (1983). Educational Research. New York: MacMillan.

13. Gronlund, N.E. (1993). How to Make Achievement Tests and Assessments, 5th ed. Boston, MA: Allyn and Bacon.

14. U.S. Department of Transportation, Federal Railroad Administration (1996). Accident/ Incident Bulletin, No. 164, Calendar Year 1995. 


\section{APPENDIX A}

\section{GLOSSARY}

\section{A.1 Railroad Terms}

Absolute block. A control method that permits occupancy of a single train to a block at one time.

Accident. A collision, derailment, or other event involving the operation of railroad on-track equipment resulting in damages that exceed the reporting threshold (14).

Automatic block signal (system), or ABS. A series of consecutive blocks governed by block signals actuated automatically by a train, engine or other certain conditions.

Automatic train control. If a train passes a restricted signal, and the engineer does not comply with the speed within $20 \mathrm{sec}$, automatic train control will automatically reduce the train speed to that required by the signal indication.

Automatic train stop system. If a train passes a restricted signal, and the engineer does not acknowledge the signal within $20 \mathrm{sec}$, a penalty brake application is administered, which reduces the speed of the train until it comes to a complete stop.

Ballast. The underlying materials that support the rail structure, typically composed of small rocks or packed dirt.

Blocking device. A blocking device is a device that prevents a controlled signal from being changed to show an indication less restrictive than stop or prevents the movements of a controlled switch. It is a means of sectioning off, or protecting, a segment of track for a specific purpose such as to protect maintenance of way crews, or to route traffic around an accident.

Blue flag protection. Protection provided to protect people working on, under, or between rolling equipment, in yards, main lines, or servicing areas, typically through the use of a clearly distinguishable blue light or blue flag, and/or the lining and locking of switches to prevent access to the equipment.

Book of rules. A set of operating rules that govern a particular railroad's operating procedures and practices. 
Car. Any number of vehicles that are used to transport goods, materials, or passengers over rail. Car types include box cars, refrigerator cars, gondola cars, hopper cars, flat cars, tank cars, and passenger coaches.

Catenary. The overhead contact wire and the associated system of support wires used on an electric railway. A catenary system transmits electrical current to a locomotive via pantograph.

Centralized traffic control (CTC). A signal system controlled from a remote location in which an operator or dispatcher routes the movement of trains through the use of switches and signals. It is a specific form (i.e., a brand name) of a traffic control system (TCS).

Class I railroad. Any railroad operation that has an annual revenue in excess of 255.9 million dollars.

Class II railroad. Any railroad operation that has an annual revenue between 20.5 million and 255.8 million dollars.

Class III railroad. Any railroad operation that has an annual revenue less than 20.5 million dollars.

Consist. The makeup of a train, including locomotives and cars, and described by its locomotive power, tonnage, number and type of cars, and location and type of hazardous materials.

Cubbing. The process of learning to dispatch trains by sitting with a qualified dispatcher during his or her shift through the process of observing and/or hands-on supervised dispatching.

Dark territory. A section of track that is unsignaled.

Direct train control. Dispatcher-directed authority issued to permit track usage not contained in the operating rules using specified blocks to identify the limits of the track authorization.

Electrification/electrified territory. A segment of track over which trains powered by an external source of electricity, such as a third rail or overhead catenary system, operate.

Form D. A written or electronic record of track usage authority issued by a railroad dispatcher. Form D's permit trains and other track users to occupy specific segments of track identified by the railroad dispatcher, and are primarily used by railroads governed by NORAC rules.

GCOR. General Code of Operating Rules.

General order. A means of communicating information pertaining to train operations that is not contained elsewhere (i.e., not contained in a rule book, timetable, special instructions, etc.). It is a means of modifying the rule book, timetable, and special instructions, and is second behind Train orders (or their equivalent) in the hierarchy of the application of instructions. 
Hand brake. A hand-operated brake located on rail cars and locomotives and applied to keep a car, locomotive, or train, from rolling.

Hazardous materials. Cargo that poses a risk to individuals and/or the environment, the movement of which is governed by Department of Transportation regulations. Hazardous materials (hazmat) include corrosive materials, poisons, and explosives, among other substances.

Helper service. Additional locomotive power used to assist trains while climbing ascending grades.

Hi-rail equipment. Equipment designed to travel on rail as well as on pavement, used primarily for the inspection of track conditions and for maintenance of way.

Highway-rail grade crossing. An intersection between railroad track(s) and a street (or highway), including associated pedestrian sidewalks. Warnings at grade crossings ranges from passive crossbuck signs to automatic gates and flashing lights.

Incident. Any event involving the movement of railroad on-track equipment that results in a death, a reportable injury, or a reportable illness, but in which railroad property damage does not exceed the reporting threshold (14).

Interlocking (manual or automatic). A configuration of switches and signals interconnected to direct trains along different routes, the limits of which are governed by interlocking signals.

Locomotive. An on-track vehicle that uses diesel, diesel-electric, or electric power to move trains and other on-track equipment.

Maintenance-of-way (MOW). On-track maintenance for repairing, testing, and inspecting track, including ties, ballast and rail. MOW work is usually conducted by the Engineering department of a railroad.

Manual block signal (system). A system of track blocks that are controlled and operated manually, and which relies on communications between the beginning and end of block limits to determine when a block is clear.

NORAC. Northeast Operating Rules Advisory Committee.

Non-shunting equipment. On-track equipment that does not activate automatic block or interlocking signals.

Normal speed. The maximum authorized speed allowed on a segment of track.

Operating rules. Rules that govern the operating practices and procedures of a particular railroad. 
Pantograph. Collector bar extending up from the locomotive to make contact with the overhead catenary wires to receive electrical current.

Regional railroad. A class of railroads that operate over at least 350 miles, and/or earn between 40 million and the 255.9 million (Class I threshold) dollars in revenue. Regional railroads cover smaller territories and have fewer trains than Class 1 railroad operations, but are still a part of the of general railroad transportation system.

Restricted speed. An authorized speed at which a train must be able to stop within one half the range of vision, short of any trains, obstructions, and switches not properly lined. The speed must not exceed $20 \mathrm{mph}$.

Shortline railroad. A shortline, or local, railroad operates over less than 350 miles and/or earns less than 40 million dollars in annual revenue.

Siding. An auxiliary track off the main line which is used to perform a variety of different functions, such as to allow the meeting or passing of trains, to set off cars, or to change crews.

Signal block. A mechanism applied to prevent clearing a signal.

Speed restriction. An imposed speed restriction of a train to below the maximum speed for the railroad, division, or subdivision, caused by track, signal, train equipment, or environmental conditions.

Special instructions. Instructions located in a timetable or other publication that modify railroad operating rules and procedures.

Stringline chart. A graphical representation of occupancy and positioning of trains on a railroad, used to indicate capacity and to determine scheduling.

Switch block. A mechanism applied to prevent lining a switch into a segment of track.

Territory. A section of railroad for which a dispatcher is responsible for the safe and efficient movement of trains and other on-track equipment. A territory is also referred to as a "desk" by some dispatchers.

Timetable. A publication of train schedules, speed restrictions, special instructions, and other information that govern the movement of trains.

Track warrant. Same as a Form D. Track warrants are primarily used by railroads governed by GCOR procedures.

Traction power. The power a locomotive generates for the movement of trains. 
Traffic control system (TCS). A signal system controlled from a remote location in which an operator or dispatcher routes the movement of trains through the use of switches and signals.

Train. A locomotive operated singly or in combination with other locomotives, with or without rail cars.

Train movement authority. Authorization necessary for a train to occupy a segment of track.

Train order. Mandatory directive issued by a railroad dispatcher to convey train movement authority.

Wayside defect detector (a.k.a trackside warning detector). Any mechanism or device for identifying potential train-based or trackside hazardous conditions. Detectors include hot box detectors, rock slide detectors, dragging equipment detectors, wide load detectors, and broken wheel detectors. Some detectors automatically notify the train crew and/or the railroad dispatcher via message, while other detectors are connected to ABS and will effect a change in the signal if a hazard is detected (e.g., rock slide).

\section{A.2 Instructional Design Terms}

Formative evaluation (1). Examination of the instructional, or training, materials to determine whether they are effective and efficient in achieving the specified objectives. The purpose of formative evaluation is to eliminate those materials that prove to be ineffective or inefficient, replacing them with more appropriate materials. Formative evaluation occurs during the design phase of the instruction, before the materials are implemented.

Formative test/evaluation (2). A test or evaluation which measures a trainee's mastery of a subject domain. It enables a trainer to diagnose current deficiencies in learning the materials. Formative evaluations can help identify and diagnose areas of training where a trainee, or a group of trainees, is having difficulty. Knowing where trainees are having problems can aid the instructor to concentrate more in these areas to ensure trainee mastery of the subject area(s).

Instruction. The intentional delivery of activities, ideas, and information that facilitate attainment of specific learning objectives.

Instructional design. A systematic process of translating principles of learning and instruction into plans for instructional materials and activities ()ㅡ).

Instructional objectives. Instructional objectives are broad sets of intended learning outcomes, written from the trainee's perspective, that should result from training. Instructional objectives are one of two types of objectives that make up the general class of training objectives.

Objectives. Goals, or specified outcomes, that are achieved by intentional effort. 
Performance objectives. Performance objectives are specific, measurable (i.e., observable) trainee outcomes that result from the training and, when accomplished, indicate achievement of instructional objectives. Performance objectives are the second type of objectives that make up training objectives (instructional objectives are the first type).

Summative evaluation (1). Summative evaluation involves a determination of whether or not to continue using the instructional or training materials after they have been implemented for some time, or adopt other materials to achieve the objectives of the instruction or training.

Summative test/evaluation (2). The principal purpose of summative evaluation is to determine overall mastery of a course's subject areas. Summative tests should be used in conjunction with formative tests (which identify mastery of a smaller content area and point out deficiencies in student learning) so that a trainee's performance on a summative evaluation at the conclusion of training should come as no surprise to the trainer or trainee.

Table of specifications. A table of specifications is part of a test design, and is tied directly to the specific objectives that are to be tested and their associated learning outcomes based on Bloom's taxonomy (ㅁ). Development of a table of specifications is described more fully in subsection 8.1.

Test design. A test design is the blueprint for formulating tests. It involves four steps. Briefly, they are:

1. Select the appropriate objectives.

2. Create a table of specifications based on the objectives and their associated learning outcomes.

3. Adjust the number of test items in the table of specifications as necessary to reflect the relative importance of specific objectives, topic areas or skills.

4. Specify the number and format of test items in the table of specifications.

Training. Goal-oriented instruction targeted to specific skills that will likely be applied immediately. Training is one type of instruction.

Training objectives. Goals that are to be achieved as a result of training. Training objectives are made up of two other types of objectives: instructional objectives and performance objectives. 


\section{APPENDIX B}

\section{DISPATCHER TRAINING PROGRAM DESCRIPTIONS}

This appendix contains summaries of nine railroad programs that were examined for this project.

Table B-1. (Former) Southern Pacific (SP) Railroad

\begin{tabular}{|c|c|}
\hline $\begin{array}{l}\text { System size and dispatching } \\
\text { technology }\end{array}$ & $\begin{array}{l}\text { Approximately } 22,000 \text { track miles; } 300 \text { total dispatchers; operate } \\
45 \text { desks during } 1 \mathrm{st} \text { shift, and about } 30 \text { on } 2 \text { nd and } 3 \text { rd shifts } \\
\text { (reconfigured desks). Range of miles per desk is } 57 \text { to } 461 \\
\text { depending on volume of traffic. Use computer-aided dispatching } \\
\text { system (CADS). }\end{array}$ \\
\hline Duration of training & 11 weeks classroom + OJT (until "qualified on the position"). \\
\hline Training methods & Classroom, field trips, simulator, OJT. \\
\hline Student profile & $\begin{array}{l}\text { Large range of student backgrounds, from military personnel to } \\
\text { salesmen and a chef. }\end{array}$ \\
\hline Class size & 4 to 18 per class. \\
\hline Dispatcher proficiency testing & $85 \%$ or better. \\
\hline Territory qualification & $\begin{array}{l}\text { Consensus must be reached by the General Director, Chief Train } \\
\text { Dispatcher, and the dispatcher who has been overseeing the } \\
\text { trainee. }\end{array}$ \\
\hline Target audience & $\begin{array}{l}\text { Experienced or inexperienced (training is abbreviated for } \\
\text { experienced individuals). Inexperienced students have recently } \\
\text { come from military background, from JCCC, and "off the streets." }\end{array}$ \\
\hline Candidate screening & Panel interview, Train Dispatcher Aptitude Test, and physical. \\
\hline Trainer's experience & Subject matter experts. \\
\hline Refresher training & Yes. Developing more complete program for 1997. \\
\hline
\end{tabular}




\section{Table B-2. CSX Transportation}

\begin{tabular}{|c|c|}
\hline $\begin{array}{l}\text { System size and dispatching } \\
\text { technology }\end{array}$ & $\begin{array}{l}\text { Over } 18,000 \text { route miles; } 321 \text { total dispatchers; operate } 47 \text { desks } \\
\text { each shift; average track mileage per desk is } 300 \text { to } 500 \text { miles. Use } \\
\text { CADS. }\end{array}$ \\
\hline Duration of training & $\begin{array}{l}22 \text { weeks classroom }+18 \text { weeks OJT ( } 9 \text { weeks per desk, } 2 \text { desks } \\
\text { minimum). }\end{array}$ \\
\hline Training methods & Classroom, field trips, simulator, OJT. \\
\hline Student profile & $\begin{array}{l}\text { Last } 3 \text { classes were all off-the-street; the class before that were all } \\
\text { internal hires. }\end{array}$ \\
\hline Class size & 12 to 18 per class. \\
\hline Dispatcher proficiency testing & $90 \%$ or better. \\
\hline Territory qualification & $\begin{array}{l}\text { Subjective evaluations by dispatcher; Sign-off by Chief Dispatcher. } \\
\text { Meeting at end of period with management. }\end{array}$ \\
\hline Target audience & No experience necessary. \\
\hline Candidate screening & $\begin{array}{l}\text { Psychological assessments, interviews, and physical requirements } \\
\text { (e.g., color blindness). }\end{array}$ \\
\hline Trainer's experience & Subject matter experts. \\
\hline Refresher training & Yes, but currently developing more comprehensive program. \\
\hline
\end{tabular}

Table B-3. Providence and Worcester Railroad (P\&W)

System size and dispatching technology

Duration of training

Training methods

Student profile

Class size

Dispatcher proficiency testing

Territory qualification

Target audience

Candidate screening

Trainer's experience

Refresher training
Approximately 180 track miles, 1 dispatcher desk. Total of 7 dispatchers, though others in organization keep qualified in case they are needed. All non-signaled territory; control is by verbal authority and Form D's. Technology includes a radio and 1 computer for lights and switch heaters.

4 weeks classroom +4 weeks OJT.

Classroom, field trips, OJT.

No new students in last year.

$\mathrm{N} / \mathrm{A}$ *

$85 \%$ or better.

Feedback from dispatcher sitting with trainee; trainee observation by Director of Operating Rules and Safety and Superintendent of Transportation.

No experience necessary.

Yes (N/A specific information).

Subject matter experts.

Yes.

${ }^{*} \mathrm{~N} / \mathrm{A}$ - Not ascertained. 


\section{Table B-4. Union Pacific (UP) Railroad}

\begin{tabular}{ll}
\hline $\begin{array}{l}\text { System size and dispatching } \\
\text { technology }\end{array}$ & Approximately 31,000 track miles. \\
Duration of training & 12 weeks classroom + minimum 4 weeks OJT. \\
Training methods & Classroom, field trips, simulator, OJT. \\
Student profile & N/A. \\
Class size & N/A. \\
Dispatcher proficiency testing & $85 \%$ or better. \\
Territory qualification & Performance evaluation by Program Manager and/or subject matter \\
& expert, and at the end, Program Manager will conduct interview. \\
Target audience & N/A. \\
Candidate screening & Aptitude tests, interviews, and physical requirements (e.g., color \\
perception). & Subject matter experts. \\
Trainer's experience & Yes - Personal Development Plan. \\
Refresher training &
\end{tabular}

Table B-5. Norfolk Southern (NS) Corporation

\begin{tabular}{|c|c|}
\hline $\begin{array}{l}\text { System size and dispatching } \\
\text { technology }\end{array}$ & $\begin{array}{l}\text { Approximately } 14,000 \text { route miles; } 9 \text { dispatching divisions; each } \\
\text { division has between } 4 \text { to } 7 \text { desks; about } 200 \text { total dispatchers. }\end{array}$ \\
\hline Duration of training & $\begin{array}{l}8 \text { weeks classroom }+10 \text { weeks field trips to home division }+9 \text { to } \\
19 \text { weeks OJT. }\end{array}$ \\
\hline Training methods & Classroom, field trips, OJT. \\
\hline Student profile & $\begin{array}{l}\text { Both new hires and those with prior RR experience (e.g., clerks, } \\
\text { conductors). }\end{array}$ \\
\hline Class size & 6 to 10 per class. \\
\hline Dispatcher proficiency testing & $\mathrm{N} / \mathrm{A}$. \\
\hline Territory qualification & $\begin{array}{l}\text { Depends on the division. Training Center is currently working on } \\
\text { qualification guidelines. }\end{array}$ \\
\hline Target audience & $\begin{array}{l}\text { No experience necessary. If a trainee has prior RR experience, } \\
\text { they start at the beginning of the } 2 \text { nd week of the class. }\end{array}$ \\
\hline Candidate screening & Psychological tests, an interview, and a physical. \\
\hline Trainer's experience & Subject matter experts. \\
\hline Refresher training & Yes. \\
\hline
\end{tabular}


Table B-6. New Jersey Transit

\begin{tabular}{|c|c|}
\hline $\begin{array}{l}\text { System size and dispatching } \\
\text { technology }\end{array}$ & $\begin{array}{l}\text { Over } 500 \text { track miles; } 5 \text { desks operate during first and second shifts } \\
\text { during weekdays, } 4 \text { desks operate during third shift and weekends; } \\
\text { Approximately } 34 \text { total dispatchers; Use CADS. }\end{array}$ \\
\hline Duration of training & $\begin{array}{l}\text { Approximately } 10 \text { weeks classroom }+17 \text { weeks ( } 4 \text { months) OJT }+ \\
60 \text { working day probation period. }\end{array}$ \\
\hline Training methods & Classroom, field trips, OJT. \\
\hline Student profile & $\begin{array}{l}\text { Hiring comes from within entire New Jersey Transit system - some } \\
\text { have prior RR experience, others do not. }\end{array}$ \\
\hline Class size & 8 maximum. \\
\hline Dispatcher proficiency testing & $85 \%$ or better. \\
\hline Territory qualification & $\begin{array}{l}\text { At the end of the OJT, there is an oral exam given by a panel of } \\
\text { experts. }\end{array}$ \\
\hline Target audience & No experience necessary. \\
\hline Candidate screening & Interview, psychological tests, and a physical. \\
\hline Trainer's experience & Subject matter experts. \\
\hline Refresher training & Yes. \\
\hline
\end{tabular}

Table B-7. Steamtown National Historic Site Railroad

\begin{tabular}{ll}
\hline $\begin{array}{l}\text { System size and dispatching } \\
\text { technology }\end{array}$ & About 30 miles of track, all non-signaled territory. \\
$\begin{array}{l}\text { Duration of training } \\
\text { Training methods }\end{array}$ & 3 weeks classroom + 2 weeks OJT. \\
Classroom, field trips, OJT. & All internal hires. Range of experience: limited to very experienced \\
in RR operations. & 10 to 12. \\
Class size & $85 \%$ or better. \\
Dispatcher proficiency testing & N/A. \\
Territory qualification & Experienced. \\
Target audience & None (since all were internal hires). \\
Candidate screening & Instructor had over 20 years experience as engineer, but no direct \\
Trainer's experience & dispatching experience. \\
Refresher training & Yes.
\end{tabular}


Table B-8. Springfield Railway Terminal Company

\begin{tabular}{|c|c|}
\hline $\begin{array}{l}\text { System size and dispatching } \\
\text { technology }\end{array}$ & $\begin{array}{l}\text { About } 475 \text { route miles, } 4 \text { desks operate during first shift, } 3 \text { during } \\
2 \text { nd and third ( } 2 \text { desks merge into } 1 \text { for } 2 \text { nd and } 3 \text { rd shifts); Total of } \\
17 \text { dispatchers. Use CADS. }\end{array}$ \\
\hline Duration of training & Approximately 6 weeks classroom +6 weeks OJT. \\
\hline Training methods & Computer-based training, OJT, field trips. \\
\hline Student profile & $\begin{array}{l}\text { Experienced: train conductors, engineers, and tower operators } \\
\text { Inexperienced: food industry, ATC. }\end{array}$ \\
\hline Class size & One at a time, though occasionally there have been two in a class. \\
\hline Dispatcher proficiency testing & $90 \%$ or better. \\
\hline Territory qualification & $\begin{array}{l}\text { Train Dispatcher's Review Committee (Director of Train Operations, } \\
\text { Director of Operations Training, and Director of Operating Rules) } \\
\text { conducts oral review with trainee. }\end{array}$ \\
\hline Target audience & $\begin{array}{l}\text { Currently, prior experience in railroad operations is preferred, } \\
\text { though not necessary. }\end{array}$ \\
\hline Candidate screening & $\begin{array}{l}\text { None (drug testing done prior to working for railroad as engineer or } \\
\text { conductor). }\end{array}$ \\
\hline Trainer's experience & Subject matter experts. \\
\hline Refresher training & Yes. \\
\hline & Table B-9. $\quad$ Metra Railroad \\
\hline $\begin{array}{l}\text { System size and dispatching } \\
\text { technology }\end{array}$ & $\begin{array}{l}\text { Currently } 4 \text { desks ( } 3 \text { on weekends, and third shift M-F); territories } \\
\text { range from } 8 \text { to } 32 \text { miles. Some CTC control; still use many tower } \\
\text { operators. }\end{array}$ \\
\hline Duration of training & Approximately 4 weeks classroom +2 weeks OJT. \\
\hline Training methods & Classroom, simulation, OJT, fieldtrips. \\
\hline Student profile & All were previously tower operators. \\
\hline Class size & Maximum of 6. \\
\hline Dispatcher proficiency testing & $85 \%$ or better. \\
\hline Territory qualification & $\mathrm{N} / \mathrm{A}$. \\
\hline Target audience & $\begin{array}{l}\text { Currently, all trainees must have tower experience, and have had } \\
\text { worked in a tower in the last } 12 \text { months. }\end{array}$ \\
\hline Candidate screening & Yes. \\
\hline Trainer's experience & Ex-dispatchers. \\
\hline Refresher training & Territory re-qualification every 6 months. \\
\hline
\end{tabular}




\section{APPENDIX C}

\section{PROGRAMS AT COMMUNITY COLLEGES}

There are 16 programs across the United States that offer an Associate's Degree in Railroading (Associate of Science degree or Associate of Applied Science degree). Table C-1 provides a list of the community colleges offering the degree, as well as contact information. 
Table C-1. Community colleges offering associates degree in railroading

\begin{tabular}{|c|c|c|c|c|}
\hline & College & City and State & Contact & Phone No. \\
\hline 1 & $\begin{array}{l}\text { Western lowa Tech } \\
\text { Community College }\end{array}$ & Sioux City, IA & Mr. Ray Kindler & (712) 274-8733 \\
\hline 2 & Carl Sandburg College & Galesburg, IL & Ms. Sherry Berg & (309) 344-2518 \\
\hline 3 & $\begin{array}{l}\text { University of Montana- } \\
\text { Northern }\end{array}$ & Helena, MT & Mr. Virgil Hawkinson & (406) 265-4161 \\
\hline 4 & $\begin{array}{l}\text { Salt Lake Community } \\
\text { College }\end{array}$ & Salt Lake City, UT & Mr. Scott Herd & (801) 957-6609 \\
\hline 5 & $\begin{array}{l}\text { Johnson County } \\
\text { Community College }\end{array}$ & Overland Park, KS & Mr. Andy Burton & (913) 469-3978 \\
\hline 6 & $\begin{array}{l}\text { Pellissippi St. Tech. } \\
\text { College }\end{array}$ & Knoxville, TN & Dr. Rayburn D. McKnight & (423) 694-6426 \\
\hline 7 & $\begin{array}{l}\text { St. Paul Technical } \\
\text { College }\end{array}$ & St. Paul, MN & Mr. John King & (612) 221-1316 \\
\hline 8 & $\begin{array}{l}\text { Tidewater Comm. } \\
\text { College Norfolk Campus }\end{array}$ & Norfolk, VA & Mr. John Massey & (804)683-9414 \\
\hline 9 & $\begin{array}{l}\text { Virginia Western } \\
\text { Community College }\end{array}$ & Roanoke, VA & Mr. Wayne R. Michie & (540) 857-7375 \\
\hline 10 & $\begin{array}{l}\text { Northern Wyoming } \\
\text { Community College }\end{array}$ & Gillette, WY & Mr. Ron Moss & $\begin{array}{l}(307) 686-0254 \\
\text { Ext. } 5\end{array}$ \\
\hline 11 & $\begin{array}{l}\text { Western Nebraska } \\
\text { Community College }\end{array}$ & Alliance, NE & Mr. Willie Quindt & (308) 635-1661 \\
\hline 12 & $\begin{array}{l}\text { Forrest Community } \\
\text { College-Jacksonville } \\
\text { (FCCJ) }\end{array}$ & Jacksonville, FL & Mr. John G. Sumner & (904) 633-8289 \\
\hline 13 & $\begin{array}{l}\text { Metropolitan Community } \\
\text { College of Omaha- } \\
\text { Elkhorn Valley Campus }\end{array}$ & Elkhorn Valley, NE & Mr. Ronald J. Erlbacher & (402) 289-1233 \\
\hline 14 & $\begin{array}{l}\text { Cuyahoga Community } \\
\text { College }\end{array}$ & Cleveland, $\mathrm{OH}$ & Ms. Cheryl Thompson-Stacy & (216) 987-3029 \\
\hline 15 & $\begin{array}{l}\text { Waubonsee Community } \\
\text { College }\end{array}$ & Sugar Grove, IL & Mr. Vincent Carney & (630) 466-7900 \\
\hline 16 & $\begin{array}{l}\text { Community College of } \\
\text { Allegheny County }\end{array}$ & Pittsburgh, PA & Mr. Martin Olshinsky & (412) 921-2042 \\
\hline
\end{tabular}




\section{APPENDIX D}

INTERVIEW GUIDES FOR SITE VISITS

Three similar interview guides were used to collect information during the site visits to the various railroads. The three guides, presented in this Appendix, were used to interview railroad dispatchers, instructors (trainers), and where available, railroad dispatcher trainees. 


\section{Dispatcher Interview Guide}

Railroad

Name

Position

\section{Candidate Dispatcher Selection}

1. How long have you been a dispatcher?

2. What job did you hold prior to becoming a dispatcher?

3. How many years have you worked in the railroad industry?

\section{Initial Training}

4. How were you trained?

5. What teaching methods were used (classroom, videotapes, computers, simulators, road trips, OJT)?

6. Did the training you received adequately prepare you for the job?

7. How were you tested or evaluated to determine that you were qualified to perform the duties of railroad dispatcher?

8. Could your initial training have been improved to better prepare you to become a railroad dispatcher? If so, how?

9. Were there any specific topics or skills that the training should have covered in more detail? Less detail?

\section{Refresher Training}

10. How are you retrained on a position (a change in shift time, such as 3rd to 1st; or a change in territory that you dispatch) you haven't worked for a certain period of time? What is that time period?

11. If your railroad has undergone a change in dispatching technology, how were you trained to use the new system?

12. If there is a change in the rules or regulations, how are you trained to incorporate this new information? 
13. What type of refresher training (e.g., a new operating rule, or "rule of the day") have you received in the last 12 months?

14. What training methods were used (classroom, OJT, videotapes, computers, simulators, road trips)?

15. What determines successful completion of the refresher/retraining program?

16. Do you have an opportunity to take "road days"?

17. If dispatchers are represented by a union, what does the union contract require regarding the training/retraining of railroad dispatchers?

\section{Dispatcher Opinion}

18. Could you use more training right now to help you do a better job? If so, what type? What skills or subjects?

19. What is the greatest challenge you face as a railroad dispatcher? Can this be addressed by training? If so, how? 


\section{Instructor Interview Guide}

Railroad

Name

Position

Number of years at position?

Phone

Address

\section{Candidate Dispatcher Selection}

1. Are eligible candidates given any kind of screening test or psychological assessment to determine ability (e.g., with respect to problem solving capability and strategic planning)?

2. Are there any physical requirements to be eligible for the job (e.g., doctor's certification that individual can withstand stress of the job, visual and hearing acuity)?

3. What types of jobs did trainees hold prior to becoming a dispatcher trainee?

4. If the candidate is a railroad employee, is there a procedure for evaluating the employee's prior safety conduct?

\section{Content of Training Program}

5. Can you please describe your current training program, including the time spent on each topic/area?

6. What types of teaching methods are employed (classroom, videotapes, road trips, simulators, OJT)?

7. What has been your experience with each of the methods that you utilize?

8. Are trainees with prior railroad experience exempted from any portion of the training?

9. What standards are used for a dispatcher's evaluation (i.e., how well do students have to perform on tests, and what happens if they score below the minimum requirements)?

10. What methods are used to test knowledge of rules (task)? 
11. What methods are used to test knowledge of physical characteristics (territory)?

12. What methods are used to test knowledge of dispatching methods (technology) for supervision of train movements and other dispatcher tasks?

13. How do you determine that the trainee is finally ready to be assigned to a territory?

14. How do you evaluate the trainee's ability to deal with the "randomness" of the tasks which a dispatcher must accomplish over the day?

\section{Course Development}

15. How is your training curriculum/program developed, and who provides input into developing the training program?

\section{Refresher Training}

16. What is your program for periodic retraining (including the maximum interval between training, what topics are covered, how dispatchers are tested, what performance standards must they meet, and what happens if a dispatcher falls below the minimum performance requirements)?

17. How is determination made on the need for refresher training on a position when a railroad dispatcher hasn't worked it for some time period? (Does the individual dispatcher have input? Does the dispatcher say s/he no longer feels qualified to work the position, etc.?)

18. How do you handle refresher training when new dispatching technology, new rolling stock or new signal systems are introduced into a territory?

19. If a qualified dispatcher is assigned to a new territory, how is physical characteristics qualification on this new territory accomplished?

20. If government regulations or rules change between training, how are employees notified (e.g., change in hazmat regulations)?

\section{Information about Instructors}

21. Who does the teaching and what is their background?

22. Have they been formally trained as instructors?

23. Are instructors required to pass any certification process? 
Instructor Opinion

24. What is the greatest challenge you face in your dispatcher training program?

25. If you could make changes to your training program, what would you do to improve it? 


\section{Dispatcher Trainee Interview Guide}

Railroad

Name

Position

\section{Candidate Dispatcher Selection}

1. What job did you hold prior to entering dispatcher training?

2. If you have worked in the railroad industry before, how many years have you worked in it?

3. What selection or screening process did you go through at the beginning of the training program?

\section{Initial Training}

4. What types of initial training have you received?

\begin{tabular}{|l|l|l|l|l|l|}
\hline & \multicolumn{5}{|c|}{ Teaching Method } \\
\hline Subject Area & Classroom & OJT & Videotapes & Simulator & Road Trips \\
\hline Task & & & & & \\
\hline Territory & & & & & \\
\hline Technology & & & & & \\
\hline
\end{tabular}

5. How have you been tested or evaluated to determine that you were qualified to perform the duties of railroad dispatcher?

6. Have you been informed whether or not you can help decide when you feel ready to be assigned to a desk (i.e,. when you have had sufficient training)?

7. Who is overseeing your training?

\section{Dispatcher Trainee Opinion}

8. What dispatcher duties or functions have posed the greatest challenge thus far in the training? 


\section{APPENDIX E}

EXAMPLE LIST OF ILLUSTRATIVE VERBS

The following table provides the reader with a brief description of the six learning outcomes based on Bloom's (ㅁ) cognitive domain of educational objectives, and a list of verbs that can be used when writing instructional and performance objectives associated with the six cognitive learning outcomes. The table has been slightly modified; the original table can be found in (므). 

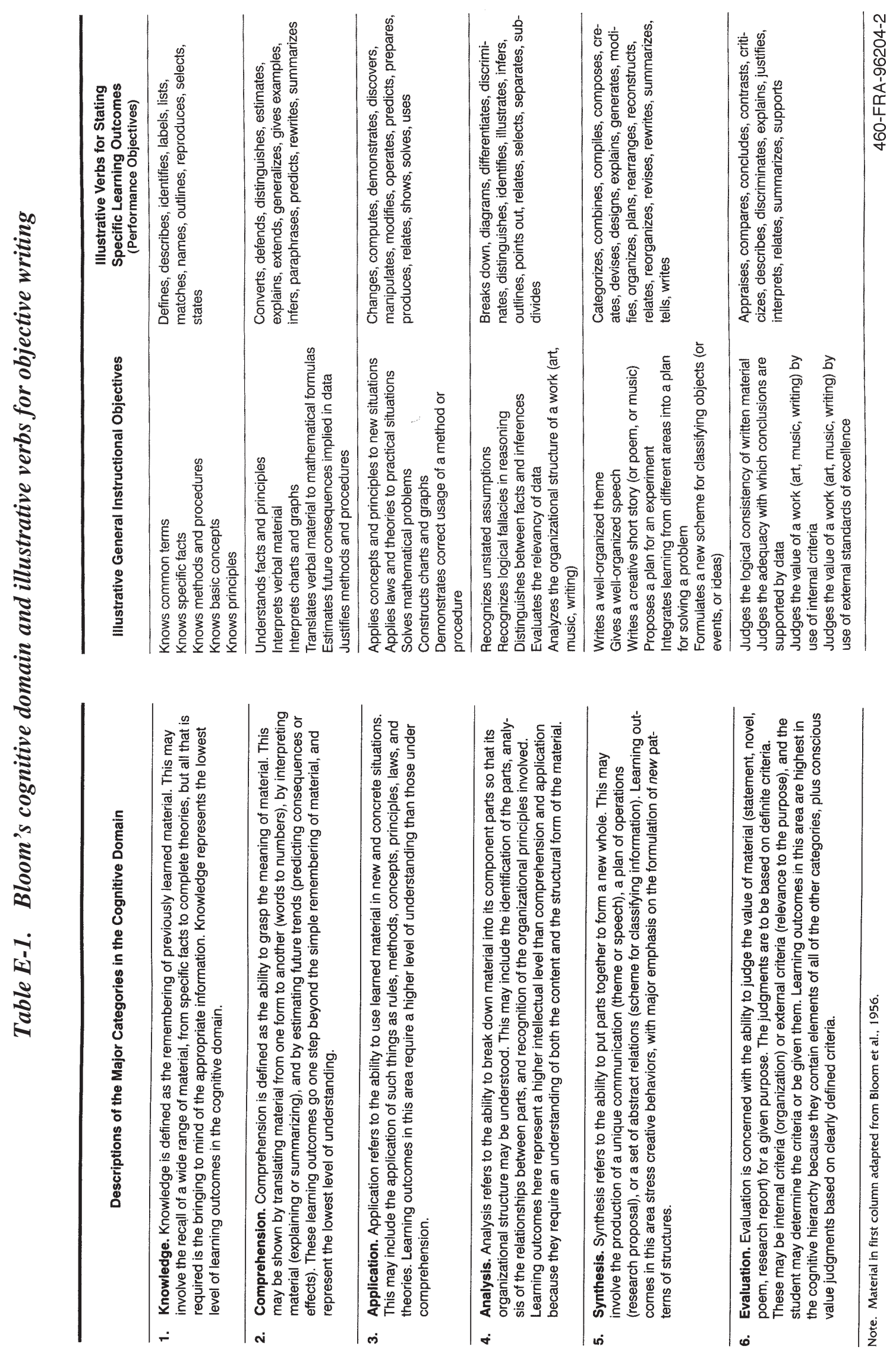


\section{APPENDIX F}

\section{TRAINING RESOURCES}

Appendix F provides a list of training resources to help railroads begin to explore the benefits and uses of CBT and train-the-trainer programs. The list was compiled from a simple search on the internet, and represents only a very small sample of the businesses that provide training services.

\section{Table F-1. Computer-based training (CBT) programs}

\begin{tabular}{llc}
\hline \multicolumn{1}{c}{ Company } & \multicolumn{1}{c}{ Location } & \multicolumn{1}{c}{ Phone No. } \\
\hline First Class Systems Corporation & White Rock, BC & $1-800-567-7766$ \\
3 Dog Multimedia, Inc. & Santa Cruz, CA & $1-408-477-9103$ \\
Sage Interactive & Mill Valley, CA & $1-415-381-4622$ \\
HR Press & Fredonia, NY & $1-800-444-7139$ \\
Training Design Associates & Port Arthur, TX & $1-800-982-0072$ \\
Yanni International Trade, LLC & Colorado Springs, CO & $1-719-593-0877$ \\
\hline
\end{tabular}

Table F-2. Train-the-trainer programs

\begin{tabular}{lll}
\hline \multicolumn{1}{c}{ Company } & \multicolumn{1}{c}{ Location } & \multicolumn{1}{c}{ Phone No. } \\
\hline The Training Clinic & Seal Beach, CA & $1-800-937-4698$ \\
Quality Resources International & Hudson, OH & $1-330-963-4345$ \\
Butler Learning Systems & Dayton, OH & $1-888-298-7462$ \\
The Training Registry & Raleigh, NC & $1-919-847-0331$ \\
\hline
\end{tabular}

